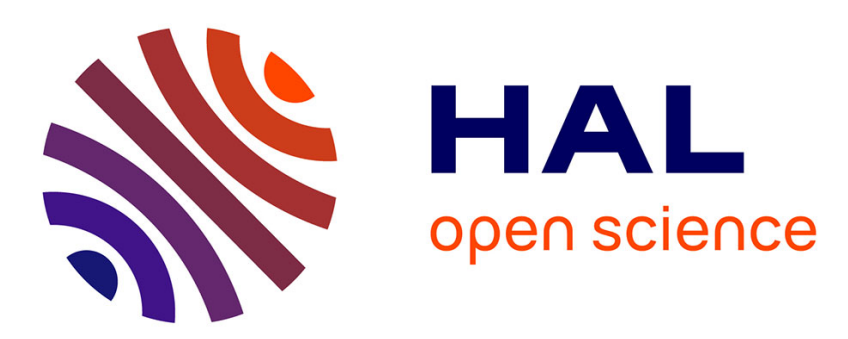

\title{
A comprehensive molecular dynamics simulation study of hydrous magmatic liquids
}

\author{
Thomas Dufils, Nicolas Sator, Bertrand Guillot
}

\section{To cite this version:}

Thomas Dufils, Nicolas Sator, Bertrand Guillot. A comprehensive molecular dynamics simulation study of hydrous magmatic liquids. Chemical Geology, 2020, 533, pp.119300. 10.1016/j.chemgeo.2019.119300 . hal-02985906

\section{HAL Id: hal-02985906 \\ https://hal.sorbonne-universite.fr/hal-02985906}

Submitted on 2 Nov 2020

HAL is a multi-disciplinary open access archive for the deposit and dissemination of scientific research documents, whether they are published or not. The documents may come from teaching and research institutions in France or abroad, or from public or private research centers.
L'archive ouverte pluridisciplinaire HAL, est destinée au dépôt et à la diffusion de documents scientifiques de niveau recherche, publiés ou non, émanant des établissements d'enseignement et de recherche français ou étrangers, des laboratoires publics ou privés. 


\title{
A comprehensive molecular dynamics simulation study of hydrous
}

\section{magmatic liquids}

\author{
Thomas Dufils ${ }^{1}$, Nicolas Sator ${ }^{1}$ and Bertrand Guillot ${ }^{1}$ \\ ${ }^{1}$ Sorbonne Université, CNRS, Laboratoire de Physique Théorique de la Matière Condensée, LPTMC, F75005, \\ Paris, France
}

ABSTRACT

ABSTRACT

Despite its low abundance, water has a great influence on the geodynamics of the Earth's upper mantle. Indeed, water has the ability to modify the phase relations and to affect in a significant way the rheological properties of minerals and melts. However the mechanisms of water incorporation in silicate melts and the impact on the melt properties is still not fully understood. To improve our understanding of hydrous silicate melts, we have performed a series of molecular dynamics simulations to evaluate the $\mathrm{H}_{2} \mathrm{O}$ solubility, the liquid-vapour coexistence, the surface tension, the water speciation, the equation of state, the viscosity, the electrical conductivity, the diffusion of silicate elements and protonated species, as well as the melt structure of various magmatic liquids representative of the Earth's upper mantle (rhyolite, andesite, MORB, peridotite, and kimberlite). For that, we introduce a new force field for water, which is compatible with an accurate force field for silicates recently developed (Dufils et al., 2018). A comparison between MD calculations and experimental data (when they exist) shows that the MD simulations are reliable. Among all the results obtained in this study, the following points may be emphasized. (1) The solubility of water changes very little when the melt composition evolves from rhyolitic to andesitic and basaltic, but it is strongly enhanced in ultramafic melts. (2) When hydrous melt and aqueous fluid are coexisting with each other, the oxide content of the aqueous fluid increases rapidly with the pressure. (3) A consequence of point (2) is that water has a large influence on the surface tension, as the latter one drops by a factor of $2 \sim 4$ when the water pressure increases from 1 bar to a few kbar. (4) Concerning the water speciation, an important point is that the MD simulation probes the liquid phase, when most of the experimental studies are dealing with glasses. Thus at magmatic temperatures the concentration in hydroxyl groups and the one in molecular water are crossing for a water content of about $15 \mathrm{wt} \%$, a value much higher than 
the one observed in glasses $(\sim 3-4 \mathrm{wt} \%)$. (5) MD calculations show that the molar volume of the melt is a linear function of the water content, and so for all the chemical compositions investigated. Therefore the water partial molar volume $\left(V_{\mathrm{H}_{2} \mathrm{O}}\right)$ is virtually independent of total water content and of water speciation. A by-product of this result is that an ideal mixing rule between water and the silicate component leads to an accurate estimate of the melt molar volume. (6) At fixed $\mathrm{T}$ and $\mathrm{P}$, the melt viscosity decreases with water content, more depolymerized the melt the smaller the influence of water on the viscosity. However, at the high temperatures investigated in this study ( $\mathrm{T} \geq 1673 \mathrm{~K}$ ), the decrease in viscosity induced by water does not exceed one or two orders of magnitude, as compared with many orders of magnitude near the glass transition temperature. (7) The diffusivity of ions increases exponentially with water content. As for the protonated species, it is found that, $D_{O^{2-}}<$ $D_{\mathrm{OH}^{-}}<D_{\mathrm{H}_{2} \mathrm{O}} \leq D_{\mathrm{H}_{3} \mathrm{O}^{+}}$, the lower the $\mathrm{NBO} / \mathrm{T}$ ratio the smaller the ratio $D_{\mathrm{OH}^{-}} / D_{\mathrm{H}_{2} \mathrm{O}}$. (8) A structural analysis shows that hydroxyl groups are more preferentially linked to metal cations than to structure makers. In contrast, $\mathrm{H}_{2} \mathrm{O}$ molecules (and $\mathrm{H}_{3} \mathrm{O}^{+}$as well) are almost exclusively linked to metal cations. As for the melt polymerization, it decreases gradually with the water content in andesitic and basaltic melts, whereas it remains almost invariant in peridotitic melt. (9) O-H...O bonds (hydrogen bonding) taking place between the hydroxyl groups, the water molecules, and the oxygens of the silicate are characterized by $\mathrm{O} \ldots \mathrm{O}$ distances in the range $2.5 \sim 3.2 \mathrm{~A}$, and by $\mathrm{O} . . \mathrm{H}-\mathrm{O}$ distances in the range $1.5 \sim 2.2 \mathrm{~A}$. But, because of the high temperature of investigation, these H-bonds are generally weak (weaker than in liquid water at ambient).

Keywords: Classical molecular dynamics simulations, water, silicate melts, EOS, solubility, surface tension, viscosity, self-diffusion coefficients, electrical conductivity, liquid structure. 


\section{INTRODUCTION}

It is well established that, despite its low abundance, water has greatly influenced the Earth's evolution in keeping it as a habitable planet. Earth's interior is the most important reservoir of water, storing a water amount estimated at 3-100 times the equivalent mass of the oceans according to the estimates (Peslier et al., 2017). This water likely was incorporated during the accretion period of the planet and later by asteroidal and cometary impacts (Hallis et al., 2015; O'Brien et al., 2018). Water is thought to be the key agent at the origin of plate tectonics on Earth and may be on other terrestrial exo-planets (Korenaga, 2010; Tikoo and Elkins-Tanton, 2017). When plate subduction takes place, the entrainment of surface water hosted in hydrous minerals and nominally anhydrous minerals (NAMs) leads to a partial melting and dehydration of the subducted plate with production of hydrous melts and aqueous solutions (Poli and Schmidt, 2002). These highly buoyant liquids, in turn, spark off arc volcanism, which at the end is returning water to the hydrosphere. There is also growing evidence that water has played a role in the generation of large igneous provinces (Xia et al., 2016). In fact the influence of water on geodynamics comes from its ability to modify the phase relations and to affect in a significant way the rheological properties of minerals and melts. Thus water lowers the solidus temperature of NAMs by several hundreds of degrees (Goranson, 1938; Green, 1973; Kawamoto and Holloway, 1997; Parman and Grove, 2004; Tenner et al., 2012; Medard and Grove, 2008; Novella et al., 2017), decreases the density of the resulting melts (Ochs and Lange, 1999; Richet et al., 2000; Matsukage et al., 2005; Sakamaki et al., 2006, 2009; Agee, 2008; Seifert et al., 2013; Malfait et al., 2014a, 2014b), and renders the latter ones much less viscous than the corresponding water-free melts (Shaw, 1963; Khitarov et al., 1978; Persikov et al., 1990, 2017; Schulze et al., 1996; Richet et al., 1996; Romano et al., 2003; Vetere et al., 2007, 2008; Misiti et al., 2011; Robert et al., 2013; Di Genova et al., 2014). All these features may have a great impact on the magma mobility at depth and on the eruptive style. Moreover, at conditions prevailing in subduction zones, hydrous melts and aqueous fluids (possibly as supercritical fluids) generated by slab melting and dehydration in subducting lithosphere are the main metamorphic agents leading to huge mass transfer and prolific volcanism (Manning, 2004; Hermann et al., 2006; Kawamoto, 2006; Kawamoto et al., 2012; Ni et al., 2017).

Despite many studies, the mechanisms of water incorporation in silicate melts and their impact on melt properties are still not fully understood. For instance the water solubility in melts of natural composition (from silicic to mafic) is found to be weakly composition 
105 dependent on the T-P range (963-1673K, 0-0.6 GPa) commonly investigated (Khitarov et al., 106 1959; Hamilton et al., 1964; Silver et al., 1990; Dixon et al., 1995; Carroll and Blank, 1997; Moore et al., 1998; Benne and Behrens, 2003; Di Matteo et al., 2004; Schmidt and Behrens, 2008; Lesne et al., 2011; Shishkina et al., 2014; Vetere et al., 2014, and for a data compilation see Table 4 in Iacono-Marziano et al. (2012) and Table 1 in Duan (2014)), though the alkali content seems to play a role (higher the alkali content higher the water solubility). Nevertheless, the $\mathrm{H}_{2} \mathrm{O}$ solubility in ultramafic melts is almost unknown (however see Moussallam et al. (2016) for a kimberlitic melt) and the one in basaltic melt at upper mantle conditions has been recently reevaluated at a much higher value than predicted by solubility models based on low-pressure data (Mitchell et al., 2017). Astonishingly a more complex situation occurs with alkali silicates, alumino silicates, and haplogranitic melts (McMillan and Holloway, 1987; Dingwell et al, 1997; Mysen and Acton, 1999; Mysen and Wheeler, 2000; Holtz et al., 2000; Mysen and Cody, 2004; Simakin et al., 2010) for which a wider variation in water solubility is observed. Thus an increase of the $N B O / T$ ratio (where $N B O$ is the number of nonbridging oxygens and $\mathrm{T}$ that of tetrahedrally coordinated cations $\mathrm{Si}$ and $\mathrm{Al}$ ) driven either by a change in $\mathrm{Al}$ or in alkali contents (or both), generally leads to an increase of the $\mathrm{H}_{2} \mathrm{O}$ solubility.

More problematic is the fact that the water speciation (the ratio between hydroxyl groups and molecular water) is highly temperature dependent and varies with the $\mathrm{H}_{2} \mathrm{O}$ content

124 (Stolper, 1989; Silver et al., 1990; Shen and Keppler, 1995; Nowak and Behrens, 1995, 2001; 125 Zhang et al., 1997; Sowerby and Keppler, 1999; Ihinger et al., 1999; Kohn, 2000; Behrens and Nowak, 2003; Liu et al., 2004; Behrens and Yamashita, 2008; Chertkova and Yamashita, 2015). Thus the water speciation at magmatic temperatures is not preserved on quenching. So the speciation observed in silicate glasses at room temperature does not correspond to that in the equilibrated liquid, and is a picture of the speciation frozen in at (or near) the glass transition temperature $\left(\mathrm{T}_{\mathrm{g}}\right)$. The amount of $\mathrm{OH}$ groups measured at magmatic temperatures is higher and that of molecular water is lower than those measured below $\mathrm{T}_{\mathrm{g}}$, even if the progressive increase of the $\mathrm{H}_{2} \mathrm{O}_{\text {mol }} / \mathrm{OH}$ ratio with increasing $\mathrm{H}_{2} \mathrm{O}$ content observed in the glass is still valid in the liquid. In fact it is the crossing point between the convex upward trend of $\mathrm{OH}$ concentration and the concave upward trend of $\mathrm{H}_{2} \mathrm{O}_{\text {mol }}$ concentration with total water content that is shifting toward higher water contents when the temperature is increased.

136 Hence, the structural information obtained from spectroscopic studies (NMR, IR, and Raman) on hydrous silicate glasses and suggesting that water acts as a structure modifier agent tending to depolymerize silicate melts (Bartholomew et al., 1980; Mysen et al., 1980; Stolper, 1982; 
139 Mysen and Virgo, 1986; McMillan and Remmelé, 1986; Kohn et al., 1989; Zotov and

140 Keppler, 1998; Zeng et al., 2000; Xue and Kanzaki, 2004, 2006, 2008; Malfait, 2014; Malfait

141 and Xue, 2014; Le Losq et al., 2015a), has to be reevaluated for describing hydrous melts at

142 upper mantle conditions. More relevant clues on the way $\mathrm{OH}$ groups and molecular water

143 incorporate into the melt structure can be inferred from in situ Raman studies (Mysen, 2010;

144 Le Losq et al., 2013, 2017). However, a clear interpretation of the evolution of the water band

145 shape with melt composition and temperature in terms of water $\left(\mathrm{OH}, \mathrm{H}_{2} \mathrm{O}\right)$ - silicate

146 interactions is difficult due to a lack of a robust theoretical basis relating O-H vibration band 147 data and melt structure.

148 In order to improve our understanding of hydrous melts we have investigated by classical 149 molecular dynamics simulations (MD) the incorporation of water into silicate melts of various 150 composition mimicking naturally occurring liquids (rhyolitic, andesitic, basaltic, peridotitic 151 and kimberlitic). Although first principle molecular dynamics calculations (FPMD) seem to 152 be a better choice in terms of theoretical background and accuracy, as they have been 153 successfully used to investigate some hydrous silicate melts from molten silica to basaltic 154 liquids (Pöhlmann et al., 2004; Mookherjee et al., 2008; Karki and Stixrude, 2010; Karki et al., 2010; Bouyer et al., 2010; Bajgain et al., 2015, 2019), their high computational cost limits drastically system size and simulation time $\left(\mathrm{N} \sim 100-300\right.$ atoms, and $\left.\mathrm{t}_{\mathrm{run}} \sim 10-150 \mathrm{ps}\right)$. In contrast, large system size $\left(\mathrm{N} \sim 10^{3}-10^{6}\right.$ atoms) and long simulation time (10-100 ns) are now routinely used in classical MD simulations, so that, the transport properties and the solubility of volatiles in melts at mantle conditions can be evaluated with a good accuracy (e.g. Guillot and Sator, 2011, 2012; Aubry et al., 2013; Dufils et al., 2017, 2018). But the price to pay is to implement in the MD simulation code an accurate force field describing realistically the interactions between the elements of the hydrous melt under investigation. The development of such a force field is detailed in section 2. The water solubility in silicate melts of silicic to ultramafic composition, the fluid-melt phase coexistence, the surface tension, the water speciation, the equation of state, the transport properties (viscosity, electrical conductivity and diffusion coefficients), and the liquid structure are evaluated and discussed in section 3 . The main results of the study are summarized in section 4 .

\section{The Force Field}

Water is certainly the most investigated liquid by classical MD simulations in the last three decades due to its importance in physics, chemistry, and biology (Robinson et al., 1996). A 
173

174

175

176

177

178

179

180

181

182

183

184

185

186

187

188

189

190

191

192

193

194

195

196

197

198

199

200

201

202

203

204

205

majority of these studies are based on models where the water molecule is described as rigid or flexible (i.e. vibrating), polarizable or not (i.e. the electronic clouds can be distorted or not), and undissociable (for reviews see Guillot, 2002; Vega and Abascal, 2011; Cisneros et al., 2016). In the present study where it is question to simulate as realistically as possible hydrous silicate melts, it is crucial that the water force field implemented in the MD code accounts for the self-ionization (or auto protolysis) reaction (Stolper, 1982),

$$
\mathrm{H}_{2} \mathrm{O} \leftrightarrow \mathrm{H}^{+}+\mathrm{OH}^{-}
$$

In the simulation literature, only a few models are describing the water molecule as dissociable (e.g. Lemberg and Stillinger, 1975; Stillinger and Rahman, 1978; Stillinger and David, 1978; Kumagai et al., 1994; David, 1996; Corrales, 1998; Mahadevan and Garofalini, 2007; Pinilla et al., 2012; Koziol et al., 2016, Zhang and van Duin, 2017). Of particular interest are the central-force models initiated by Lemberg and Stillinger (1975) and for which water is considered as an electrolyte where hydrogen and oxygen are individual entities that can be eventually associate to form molecules (according to the thermodynamic conditions). In this framework we have developed a new central-force model of water that is compatible with the force field for silicate melts that we have recently introduced (Dufils et al., 2017, 2018), and which is leading to an accurate description of the thermodynamic, structure, and transport properties of magmatic liquids covering a large range of chemical composition (from felsic to ultramafic). However, the use of our force field for silicates imposes some constraints on the parameterization of the water model.

\subsection{A dissociable model for water.}

A requisite for the development of the water force field (FF) is that the water molecule can dissociate into protons $\mathrm{H}^{+}$and hydroxide ions $\mathrm{OH}^{-}\left(\mathrm{H}_{2} \mathrm{O} \leftrightarrow \mathrm{H}^{+}+\mathrm{OH}^{-}\right)$. Moreover, the proton $\mathrm{H}^{+}$may form a hydronium ion $\left(\mathrm{H}^{+}+\mathrm{H}_{2} \mathrm{O} \leftrightarrow \mathrm{H}_{3} \mathrm{O}^{+}\right)$or leads to a hydroxide ion when interacting with oxygen of the silicate $\left(\mathrm{H}^{+}+\mathrm{O}_{\text {sil }}^{2-} \rightarrow \mathrm{OH}^{-}\right)$. The two first reactions are mostly observed in pure water and in aqueous solutions whereas the last reaction takes place in silicate melt. Consequently the hydroxide ions issued from the above reactions have to be identical with each other whatever is the proton donor or proton acceptor oxygen. So, the following constraints have to be fulfilled.

(1) The oxygen atoms of the water molecules and those of the silicate melt have to be undistinguishable to each other, that constraints the charge of the oxygen to be fixed (i.e. $\mathrm{q}_{\mathrm{O}}=-0.945 \mathrm{e}$ ) and the van der Waals oxygen-oxygen interaction to be the same. 
(2) A consequence of (1) is that the hydroxyl groups are all identical, the charge of the hydrogen atom being constrained by the electroneutrality of the water molecule (i.e. $\left.\mathrm{q}_{\mathrm{H}}=-\mathrm{q}_{\mathrm{O}} / 2=+0.4725 \mathrm{e}\right)$.

Notice that, in our model, the electronegativity of the oxygen atom is assumed to be, on average, the same in liquid water and in the silicate melt. In fact, FPMD calculations show that the electronegativity of the oxygen is mostly the same in liquid water and in molten silicates (e.g. Badyal et al., 2000; Vuilleumier, 2014; Liu et al., 2015; Willow et al., 2015) and is close to the value used in the present study $\left(\mathrm{q}_{\mathrm{O}}=-0.945 \mathrm{e}\right)$. However the latter one is an effective charge (time independent), which implicitly takes into account at once the internal charge transfer along the $\mathrm{O}-\mathrm{H}$ bond and the electronic polarization of the water molecule induced by its environment in the liquid. Therefore, the water dipole moment of our model in the liquid at ambient is high $(\langle\mu\rangle=2.57 \mathrm{D}$ instead of $1.86 \mathrm{D}$ in the gas phase $)$ and is comparable to the value estimated by FPMD calculations where the electronic polarization is explicitly accounted for ( 2.5-2.7 D in Silvestrelli and Parrinello, 1999; Zhang et al., 2011; Pan et al., 2013; Liu et al., 2015; Willow et al., 2015; Chen et al., 2017).

In this framework we have developed a water FF in which the water molecule is represented by three force centers merged into the $\mathrm{O}$ and $\mathrm{H}$ nuclei, can dissociate, and is not electronically polarizable. The interaction energy between oxygen and hydrogen atoms and that between hydrogen atoms are composed of 2- and 3- body terms, whereas the oxygenoxygen interaction energy is composed of only 2-body terms. The functional forms that we impose are the following.

For oxygen-hydrogen interactions,

$v_{O H}(r)=$

$\frac{q_{O} q_{H}}{r}+B_{O H} e^{-r / \rho_{O H}}+\frac{E_{w}}{2}\left(\tanh \left(\frac{r-l_{w}}{\sigma_{w}}\right)-1\right)+E_{b} e^{-\left(r-l_{b}\right)^{2} / 2 \sigma_{b}^{2}}-E_{h b} e^{-\left(r-l_{h b}\right)^{2} / 2 \sigma_{h b}^{2}}$

230 and

$v_{\mathrm{HOH}}\left(r_{\mathrm{OH}_{1}}, r_{\mathrm{OH}_{2}}, \theta_{\mathrm{HOH}}\right)=\frac{k_{\mathrm{HOH}}}{2}\left(\theta-\theta_{0}^{\mathrm{HOH}}\right)^{2} e^{-r_{O H_{1}}^{8} / \rho_{\mathrm{HOH}}^{8}} \times e^{-r_{\mathrm{OH}_{2}}^{8} / \rho_{\mathrm{HOH}}^{8}}$.

232 For hydrogen-hydrogen interactions,

$v_{H H}(r)=\frac{q_{H} q_{H}}{r}-E_{H H} e^{-\left(r-l_{H H}\right)^{2} / 2 \sigma_{H H}^{2}}$

234 and

$v_{H H H}\left(r_{H_{1} H_{2}}, r_{H_{1} H_{3}}, \theta_{H H H}\right)=\frac{k_{H H H}}{2}\left(\theta-\theta_{0}^{H H H}\right)^{2} e^{-r_{H_{1} H_{2}}^{8} / \rho_{H O H}^{8}} \times e^{-r_{H_{1} H_{3}}^{8} / \rho_{H O H}^{8}}$.

236 For oxygen-oxygen interactions,

$$
v_{O O}(r)=\frac{q_{O} q_{O}}{r}+B_{O O} e^{-r / \rho_{O O}}-\frac{C_{O O}}{r^{6}} .
$$


With regard to the 2-body potential energy between oxygen and hydrogen atoms (see Eq.2), the first term corresponds to the electrostatic energy, the second term is a core repulsion energy, the third term is a potential well contributing to the intramolecular $\mathrm{O}-\mathrm{H}$ bond, the fourth term generates a potential barrier preventing the formation of long lasting $\mathrm{O}$ $\mathrm{H}-\mathrm{O}$ bonds, and the fifth term contributes to the formation of hydrogen bonds. As for the 3body interaction term (Eq.3) it insures that the water molecule exhibits the right geometry $\left(\theta_{\mathrm{HOH}} \sim 104-109^{\circ}\right)$. The damping function $\left(e^{-\left(\frac{r}{\rho}\right)^{8}}\right.$ in Eq.3) prevents the formation of H-O$\mathrm{H}$ triplets when one of the $\mathrm{OH}$ distances is greater than the $\mathrm{O}-\mathrm{H}$ bond length $(\sim 1.0 \mathrm{~A})$ in the water molecule. Concerning the interaction energy between hydrogen atoms, the 2-body contribution (Eq.4) is composed of a repulsive electrostatic term and an attractive potential well at the equilibrium $\mathrm{H}-\mathrm{H}$ distance equal to about 1.63 A. However, the latter potential well tends to favor the formation of $\mathrm{H}_{3} \mathrm{O}^{+}$with respect to $\mathrm{H}_{2} \mathrm{O}$, and to remedy this drawback an energy penalty is added via the 3-body term given by Eq.5. After optimization the cumulative effect of the 2- and 3-body contributions leads to the correct geometry of the hydronium ion $\left(\theta_{\mathrm{HOH}} \sim 120^{\circ}\right)$. As for the oxygen-oxygen interaction energy (Eq.6), it is composed of a repulsive electrostatic term, a repulsive core term, and an attractive dispersive term, these terms being the same than those describing the oxygen-oxygen interaction energy in silicates (Dufils et al., 2017, 2018).

The last step consists in adjusting the potential parameters not yet fixed (the final potential parameters are listed in Table 1). Those involving the geometry and the vibration modes of the water molecule (i.e. $\mathrm{B}_{\mathrm{OH}}, \rho_{\mathrm{OH}}, \mathrm{E}_{\mathrm{b}}, 1_{\mathrm{B}}, \sigma_{\mathrm{B}}, \mathrm{E}_{\mathrm{w}}, 1_{\mathrm{w}}, \sigma_{\mathrm{w}}, \mathrm{k}_{\mathrm{HOH}}, \theta_{0}^{H O H}, \mathrm{E}_{\mathrm{HH}}, 1_{\mathrm{HH}}$, and $\sigma_{\mathrm{HH}}$ in Eqs.2-4) have been fitted on the flexible simple point charge model of water (Wu et al., 2006), an accurate and popular model for water. As for the parameters involving the hydrogen bonds (i.e. $\mathrm{E}_{\mathrm{hb}}, 1_{\mathrm{hb}}$, and $\sigma_{\mathrm{hb}}$ in Eq.2), they have been adjusted so that the density and the structure of liquid water at ambient are reproduced at best (for the simulation methodology see Methods). For illustration, the molecular parameters of the water molecule in the liquid phase are shown in Fig.S1 of the Supplementary Data (SD), and a comparison between the MD-generated pair distribution functions $\left(\mathrm{g}_{\mathrm{OO}}(\mathrm{r}), \mathrm{g}_{\mathrm{OH}}(\mathrm{r})\right.$ and $\left.\mathrm{g}_{\mathrm{HH}}(\mathrm{r})\right)$ and those obtained by neutrons and X-ray diffraction experiments (Soper and Benmore, 2008; Skinner et al., 2013) is presented in Fig.1. With regard to the structure data, the agreement between simulation and experiment is excellent and even is better than the one generally reached with popular water models of the literature. In order to test the ability of our model to reproduce other water properties near ambient, we have evaluated the temperature of maximum density, the 
viscosity, the water self-diffusion coefficient, and the surface tension. Those properties are satisfactorily reproduced, and our results compare well with simulation data obtained with other models (see Table S1 of the SD).

To evaluate the validity of our model at crustal and mantle conditions we have first calculated the equation of state (EOS) along several isotherms (373, 673, and 1000K). The results are presented in Fig.2 and are compared with density data of the literature. The calculated isotherms at $373 \mathrm{~K}$ and $673 \mathrm{~K}$ are very close to those deduced by Abramson and Brown (2004) and by Sanchez-Valle et al. (2013) from acoustic velocity measurements, although our model tends to slightly underestimate the density in the high-pressure range (e.g. $\Delta \mathrm{n} \sim-3.2 \%$ at $673 \mathrm{~K}$ and $6 \mathrm{GPa})$. At higher temperature (e.g. $1000 \mathrm{~K}$ ) the agreement with the density measurements of Withers et al. (2000) in the pressure range 1.4-2.5 GPa is excellent, and the calculated isotherm is also in accordance with the FPMD results (French et al., 2009; Pan et al., 2013) over a large pressure range (0.9-11.4 GPa). By comparison the SPCE model of water (the most accurate model to reproduce PVT data among the commonly used models of the simulation literature, see Zhang and Duan (2005), and Stubbs (2016)) does better at 373 and $673 \mathrm{~K}$ (see Fig.1) but fails to reproduce the FPMD results at higher temperature. Likely this is due to the fact that the SPCE model is too simplistic (the water molecule is described as non vibrating and non dissociative) to reproduce in every details the local structure in supercritical water at these HT-HP conditions. As a matter of fact, the evolution of the water structure with T and P as it is observed by in situ X-ray diffraction (Goncharov et al., 2009, Ikeda et al., 2010) and neutron diffraction experiments (Strässle et al., 2006) is well reproduced by our MD simulations. In particular, the collapse of the hydrogen bond peak (at about $\mathrm{r}_{\mathrm{OH}}=1.8 \mathrm{~A}$ ) in the $\mathrm{g}_{\mathrm{OH}}(\mathrm{r})$ pair distribution function upon heating (see Fig.1), expresses the weakening of the hydrogen bond with the temperature. This weakening of hydrogen bonding at elevated temperatures facilitates the densification of the local structure with the pressure. The signature of this structural evolution with increasing $\mathrm{T}$ and $\mathrm{P}$ is the expansion of the first shell of neighbors (see in Fig.1 how broadens the first peak of $\mathrm{gOO}(\mathrm{r})$ with $\mathrm{T}$ and $\mathrm{P}$ and the correlated shift toward a greater distance of the second shell of neighbours, from 4.4 $\mathrm{A}$ at ambient to 5.5-6 $\mathrm{A}$ at supercritical conditions). Correspondingly, the oxygen coordination number increases from $\sim 4.6$ at ambient conditions to $\sim 10$ at $1673 \mathrm{~K}$ and $1 \mathrm{GPa}$, and $\sim 13.4$ at $1300 \mathrm{~K}$ and $10 \mathrm{GPa}$.

Concerning the transport properties of water at HT-HP, one notices that the calculated selfdiffusion coefficient compares well with FPMD calculations (e.g. D $=8010^{-9} \mathrm{~m}^{2} / \mathrm{s}$ at $1673 \mathrm{~K}$ and $1 \mathrm{GPa}$ as compared with $\sim 6010^{-9} \mathrm{~m}^{2} / \mathrm{s}$ after French et al., 2010). Moreover, at $1673 \mathrm{~K}$ 
and $1 \mathrm{GPa}$ our simulations leads to a viscosity value of about $0.1 \mathrm{mPas}(\sim 1 \mathrm{mPa} . \mathrm{s}$ at ambient), an order of magnitude compatible with the viscosity data available at lower temperature (at about $573 \mathrm{~K}$, see Abramson (2007) and Liebsher (2010)) and notwithstanding the considerable difficulty to measure the water viscosity at these thermodynamic conditions (Abramson, 2015). Our model also leads to the correct order of magnitude for the electrical conductivity (see Fig.3). The rapid increase of the electrical conductivity with temperature is caused by the concomitant effect of two mechanisms, the proton hopping which dominates at low temperature and the dissociation which increases drastically upon heating (in our simulations about $10 \%$ of the water molecules are dissociated at $1673 \mathrm{~K}$ and $1.5 \mathrm{~g} / \mathrm{cm}^{3}$ ). However, it is noteworthy that the evaluation of the electrical conductivity is depending on the electric charge of the charge carriers (formal charges versus effective charges), and then different results can be reached, this point remaining controversial (see French et al., 2011).

\subsection{Silicate-water interactions.}

As emphasized previously, we have chosen to describe the silicate-silicate interactions with the force field recently developed by us (Dufils et al., 2017, 2018). In this model the atomatom interaction energy of any melt composition in the KNCMFATS system is given by a sum of pairwise contributions,

$v\left(r_{i j}\right)=\frac{q_{i} q_{j}}{r_{i j}}-A_{i j} e^{-\left(\frac{r_{i j}-l_{i j}}{\lambda}\right)^{2}}+B_{i j} e^{-\left(\frac{r_{i j}}{\rho_{i j}}\right)}-\frac{C_{i j}}{r_{i j}^{6}}$

where $r_{i j}$ is the distance between atoms $i$ and $j, q_{i}$ is the effective charge associated with the atom i, and where $A_{i j}, l_{i j}, \lambda, B_{i j}, \rho_{i j}$ and $C_{i j}$ are parameters describing covalent, repulsive and dispersive forces, respectively. To ensure the transferability of the interaction potential with the melt composition, the electroneutrality of the oxide components (e.g. $\mathrm{SiO}_{2}, \mathrm{Al}_{2} \mathrm{O}_{3} .$. ) is assumed, that is the valence of the oxygen is kept fixed irrespective of its environment, and its value is set equal to -0.945 e. The potential parameters are reported in Dufils et al. (2017, 2018) and in Table S2 of the SD. Thus in this approach, when a water molecule (or a hydroxyl) is incorporated into the silicate melt, its oxygen atom interacts with the elements of the silicate in the same way as an oxygen of the silicate. Nevertheless, we will see in the following, that the environment around an oxygen atom belonging to a hydroxyl or a water molecule is quite different from that of an oxygen of the silicate (this is due to the presence of the $\mathrm{OH}$ bond in the protonated species). As a matter of fact, in our model the hydrogen atoms interact with the oxygens of the silicate through the $\mathrm{OH}$ interaction terms of the water force 
337

338

339

340

341

342

343

344

345

346

347

field (see Eqs.2-3), whereas their interactions with the cations of the melt are described by the following potential,

$v_{H X}(r)=\frac{q_{H} q_{X}}{r}+\alpha_{H X} A_{O X} e^{-\left(r-l_{H X}\right) / \lambda}$

where $H$ is a hydrogen atom and $X$ a cation of the silicate. The first term in Eq. 8 corresponds to the repulsive coulombic energy between the hydrogen $H$ and the cation $X$, and the second term (repulsive) reduces the stabilizing effect of the covalent term acting between the oxygen linked to $H$ and the cation $X$ (second term in Eq.7). The parameters $A_{O X}$ and $\lambda$ are those associated with the Gaussian covalent term in Eq.7, and $\alpha_{\mathrm{HX}}$ and $l_{H X}$ are coefficients specific to the pair HX. The reason for the presence of the second term in Eq.8 is that the hydrogen atoms never evolve freely in the hydrous silicate melt, they are always attached to an oxygen atom to form a hydroxide ion, a water molecule, or a hydronium ion. Consequently, the $\mathrm{X} \ldots \mathrm{O}-\mathrm{H}$ bond is less stable that the $\mathrm{X}$... O bond because the repulsive coulombic interaction between $\mathrm{X}$ and $\mathrm{H}$ tends to increase the $\mathrm{X}$... O bond length, and also because the formation of the $\mathrm{O}-\mathrm{H}$ bond relocalizes the electronic cloud of the oxygen towards the $\mathrm{H}$ atom and weakens the $\mathrm{X} . . . \mathrm{O}-\mathrm{H}$ covalency. Furthermore, this effect is thought to be more effective with structure maker cations than with structure modifiers for which the covalent character of the $\mathrm{X}$...O bond is less pronounced. To parameterize this energetic contribution we have, in a first attempt, evaluated the solubility of water in a basaltic melt (because the $\mathrm{H}_{2} \mathrm{O}$ solubility is well documented, see Dixon et al. (1995), Lesne et al. (2011), and Shishkina et al. (2014)) without using this term, and found a water solubility 2-3 times higher than the experimental value $(\sim 3$ wt $\% \mathrm{H}_{2} \mathrm{O}$ at $1 \mathrm{kbar}$ and $1473 \mathrm{~K}$ ). By increasing progressively the value of $\alpha_{H X}$ up to 0.25 (the $\mathrm{H}_{2} \mathrm{O}$ solubility decreases when $\alpha_{H X}$ increases), and so only for structure maker cations (i.e. for $\mathrm{X}=\mathrm{Si}, \mathrm{Ti}, \mathrm{Al}$, and $\mathrm{Fe}^{3+}$ ), the aimed value of the $\mathrm{H}_{2} \mathrm{O}$ solubility in basalt is recovered. The final set of potential parameters is given in Table 2 .

\section{Simulation results and discussion.}

In order to cover a large range of melt composition and degree of polymerization, we have evaluated the effect of water on five compositions: a rhyolitic composition (with $83 \mathrm{wt} \%$ $\mathrm{SiO}_{2}$ ) investigated by Shen and Keppler (1995) in their study of water speciation, an andesitic composition from Unzen volcano (Chen et al., 1993), a tholeiitic composition of the MidAtlantic Ridge (MORB sample TK21B in Reynolds and Langmuir (1997)), a garnet lherzolite (PHN1611) representative of the Earth's upper mantle (Nixon and Boyd, 1973), and a Ca-rich 
kimberlitic composition $\left(\sim 25 \mathrm{wt} \% \mathrm{SiO}_{2}\right)$ investigated by Moussallam et al. $(2015,2016)$ to estimate $\mathrm{CO}_{2}$ and $\mathrm{H}_{2} \mathrm{O}$ solubilities in kimberlitic melt. The chemical compositions are detailed in Table 3. Notice that in our MD simulations the silicate samples were composed of 1,000 or 2,000 atoms according to the property under investigation (1,000 atoms to evaluate the $\mathrm{H}_{2} \mathrm{O}$ solubility, and 2,000 atoms to evaluate the thermophysical properties of hydrous melts), at which a certain amount of water is added. For instance, in adding 25, 101, or 211 water molecules to a basaltic melt composed of 2,000 atoms, the water content in the corresponding hydrous melt is approximately equal to 1,4 , or $8 \mathrm{wt} \%$, respectively. Furthermore, the simulations were run at high enough temperatures $(T \geq 1673 \mathrm{~K})$ to be sure that the thermochemical equilibrium is reached in a reasonable computer time (of the order of $10 \mathrm{~ns}$ or less).

\subsection{Solubility of $\mathrm{H}_{2} \mathrm{O}$ in melts.}

Before to investigate the properties of hydrous melts, it is important to know what is the amount of water that a melt composition is able to accommodate at fixed T and P. A wellestablished basic method to evaluate the solubility of a volatile (e.g. water) in a solvent (e.g. silicate melt) by MD simulation consists to come into contact the two phases (phase coexistence), the fluid and the melt. The water molecules being free to move across the interface separating the supercritical $\mathrm{H}_{2} \mathrm{O}$ phase and the liquid silicate, the solubility of $\mathrm{H}_{2} \mathrm{O}$ is obtained by evaluating, at equilibrium, the average number of protonated species $\left(\mathrm{H}_{2} \mathrm{O}, \mathrm{OH}^{-}\right.$, and $\mathrm{H}_{3} \mathrm{O}^{+}$) present in the silicate melt. In practice, we have followed the simulation protocol developed by two of us for evaluating the solubility of $\mathrm{CO}_{2}$ in a silicate melt (for further details see Guillot and Sator (2011), and Methods). In brief, at the beginning of a simulation run the two phases (pure water and dry silicate melt) are in contact with each other at given $\mathrm{T}$ and P. Gradually in the course of the MD run, some water molecules enter into the silicate melt, diffuse and eventually react with the oxide anions of the melt to form $\mathrm{OH}^{-}$. A stationary state is reached after several ns (depending on temperature and melt composition) when $\mathrm{H}_{2} \mathrm{O}$ molecules are exchanged continuously between the two phases, the reaction $\mathrm{H}_{2} \mathrm{O}+\left(\mathrm{O}^{2-}\right)_{\text {sil }} \leftrightarrow$ $2 \mathrm{OH}^{-}$taking place in the silicate and at the aqueous fluid - silicate melt interface, whereas the reaction $2 \mathrm{H}_{2} \mathrm{O} \leftrightarrow \mathrm{H}_{3} \mathrm{O}^{+}+\mathrm{OH}^{-}$occurring in the aqueous fluid or at the interface. For illustration the mean concentration profile of water in the simulation cell is presented in Fig.4 for a hydrous MORB melt coexisting with its aqueous phase. The $\mathrm{H}_{2} \mathrm{O}$ solubility then is given by the amount of water (in mol/l, or in $\mathrm{g}$ of water/ $\mathrm{g}$ of melt) in the bulk of the $\mathrm{H}_{2} \mathrm{O}$-bearing 
403

404

405

406

407

408

409

410

411

412

413

414

415

416

417

418

419

420

421

422

423

424

425

426

427

428

429

430

431

432

433

434

435

436

melt. Interestingly enough, the simulation shows that an excess of hydroxyl groups are located at the interface between the hydrous melt and the aqueous phase, the water molecules of the latter one stabilizing the hydroxyl groups of the melt. In fact, the amount of water in the bulk of the $\mathrm{H}_{2} \mathrm{O}$-saturated melt (i.e. that corresponding to the flat region located between the two interfaces in Fig.4) is defined with a good accuracy (a few percent) if the simulation time is long enough ( $\left.\mathrm{t}_{\mathrm{run}} \sim 10-30 \mathrm{~ns}\right)$. For instance, the time evolution of the number of $\mathrm{H}_{2} \mathrm{O}, \mathrm{OH}^{-}$, and $\mathrm{H}_{3} \mathrm{O}^{+}$molecules in the bulk region of a saturated MORB melt at $1673 \mathrm{~K}$ and $1.0 \mathrm{GPa}$ is shown in Fig.5. Although each population of protonated species is fluctuating with time, the total number (i.e. the sum of all species) fluctuates smoothly around a stationary value, indicating that a chemical equilibrium is reached, and the water solubility well defined.

In applying the above methodology, we have evaluated the $\mathrm{H}_{2} \mathrm{O}$ solubility in the five melts compositions detailed in Table 3. The results are presented in Fig.6 as a function of pressure at fixed $\mathrm{T}(\mathrm{T}=1673 \mathrm{~K}$ for andesite, MORB, peridotite, and kimberlite, and $2073 \mathrm{~K}$ for rhyolite because its high viscosity at lower temperature precludes a good achievement of the equilibrium in a reasonable simulation time). The pressure dependence of the $\mathrm{H}_{2} \mathrm{O}$ solubility in rhyolitic, andesitic, and basaltic melts is different from that in the two ultramafic melts (peridotitic and kimberlitic), since the solubility is higher and increases much more rapidly with the pressure in the latter two compositions. From the experimental viewpoint, it is well documented that the $\mathrm{H}_{2} \mathrm{O}$ solubility varies little with composition along the line rhyolite andesite - basalt, only a slight trend is evidenced (rhyo>and $>$ bas, see among others, Tamic et al. (2001), Botcharnikov et al. (2006), Shishkina et al. (2010, 2014)), a feature well reproduced by our simulations. But the experimental data show a steeper increase of the solubility with the pressure than predicted by the simulations (for instance some of the solubility data are greater by a factor of $\sim 2$ at $0.5 \mathrm{GPa}$, see Fig.6). At this stage we don't know if this discrepancy is due to a defect of our model or is generated by some simulation inaccuracies (the solubility can be system size dependent, and the achievement of the water/silicate melt coexistence equilibrium can be rather long). However, our results are much closer to the solubility data obtained by Mysen et al. (1999, 2000, 2002, 2004) in alkali silicates and in metal oxide alumino silicate melts between 0.8 and $2.0 \mathrm{GPa}$ (e.g. in Fig.6). Contrarily to other solubility studies using FIR spectroscopy and titration methods (for a compilation of solubility data, see Table 1 in Duan, 2014), these authors evaluate the solubility by locating the univariant phase boundary, melt $\leftrightarrow$ melt + vapor, and by examining the run products in a petrographic microscope. Is it the differences in composition (even for similar $N B O / T$ ratio) between the different studies (binary or ternary oxide mixtures versus 
437

438

439

440

441

442

443

444

445

446

447

448

449

450

451

452

453

454

455

456

457

458

459

460

461

462

463

464

465

466

467

468

469

more complex or natural compositions), which could explain the differences in $\mathrm{H}_{2} \mathrm{O}$ solubility, or is it due to the experimental protocol used? With regard to the $\mathrm{H}_{2} \mathrm{O}$ solubility in ultramafic melts, we are aware of only one study (Moussallam et al., 2016) measuring the solubility of a two-component fluid $\left(\mathrm{H}_{2} \mathrm{O}+\mathrm{CO}_{2}\right)$ in a molten Ca-rich kimberlite (e.g. TA6). These authors conclude that the $\mathrm{H}_{2} \mathrm{O}$ solubility in kimberlitic melt (in the P-range $0.1-0.35$ $\mathrm{GPa}$ ) is close to that found in other natural silicate melts. But in considering the large experimental uncertainties leading to the solubility value $(\sim \pm 50 \%)$, we think that the last conclusion is uncertain.

\subsection{Coexisting fluids.}

In our simulation method the coexistence between the hydrous silicate melt and the aqueous fluid is directly observed. In Fig.7 is reported the phase diagram in a $\left(\mathrm{P}, X_{\mathrm{H}_{2} \mathrm{O}}\right)$ representation along the isotherm $\mathrm{T}=1673 \mathrm{~K}$ for andesite, MORB, peridotite, and kimberlite, and along the isotherm $\mathrm{T}=2073 \mathrm{~K}$ for rhyolite. A critical point can be surmised at about (1. $\left.\sim 1.1 \mathrm{GPa} ; \sim 40 \mathrm{wt} \% \mathrm{H}_{2} \mathrm{O}\right)$ for kimberlite and at about $\left(1 . \sim 1.1 \mathrm{GPa} ; \sim 45 \mathrm{wt} \% \mathrm{H}_{2} \mathrm{O}\right)$ for peridotite, whereas the critical point for rhyolite, andesite, and MORB is likely located well above $2.0 \mathrm{GPa}$ (with $X_{\mathrm{H}_{2} \mathrm{O}}>50 \mathrm{wt} \%$ ). Above the critical point (i.e. at a higher pressure) a complete miscibility between hydrous melt and aqueous fluid is expected. Complete phase miscibility has been observed in the systems $\mathrm{H}_{2} \mathrm{O}-\mathrm{SiO}_{2}$ (Kennedy et al., 1962; Newton and Manning, 2008), $\mathrm{H}_{2} \mathrm{O}$ - albite (Paillat et al., 1992; Shen and Keppler, 1997), and also in a large range of melt composition including nepheline, jadeite, dacite, haplogranite, Ca-bearing granite (see Bureau and Keppler, 1999), basalt (Mibe et al., 2011) and peridotite (Mibe et al., 2007).

Concerning the $\mathrm{H}_{2} \mathrm{O}$ - basalt system, Mibe et al. (2011) predict a phase coexistence at $\mathrm{T}=$ $1623 \mathrm{~K}$ and $\mathrm{P}=2.8 \mathrm{GPa}$, and a critical point at about $\mathrm{P}=3-3.3 \mathrm{GPa}$ and $X_{\mathrm{H}_{2} \mathrm{O}}=62-68$ wt $\%$ along the isotherm $\mathrm{T}=1673 \mathrm{~K}$, findings which are compatible with the phase envelope obtained by simulation (see Fig.7). The composition of the aqueous fluid coexisting with the hydrous MORB melt is shown in Fig. 8 as function of $\mathrm{P}$ along the isotherm $\mathrm{T}=1673 \mathrm{~K}$. The oxide content increases steadily with pressure although a decrease of the slope is observed above $0.5 \mathrm{GPa}$. Thus the alkali content remains virtually constant above $0.5 \mathrm{GPa}$ whereas that of the metal oxides ( $\mathrm{Ca}, \mathrm{Mg}, \mathrm{Fe}$ : $\mathrm{O}$ ) increases with $\mathrm{P}$ at a smaller rate (especially for $\mathrm{Mg}$ ). At high pressure $\mathrm{Si}$ is the dominant element, followed by $\mathrm{Ca}, \mathrm{Mg}, \mathrm{Fe}, \mathrm{Na}, \mathrm{Al}, \mathrm{K}$, and $\mathrm{Ti}$. A similar hierarchy between the elements of the silicate is observed by Mibe et al. (2011) in the 
470

471

472

473

474

475

476

477

478

479

480

481

482

483

484

485

486

487

488

489

490

491

492

493

494

495

496

497

498

499

500

501

502

aqueous fluid, except that the concentrations in $\mathrm{Si}$ and $\mathrm{Al}$ are higher $\left(\sim 18 \mathrm{wt} \% \mathrm{SiO}_{2}\right.$ at 2.8 GPa instead of $\sim 8 \mathrm{wt} \%$ by MD at $2.0 \mathrm{GPa}$, and $\sim 4.5 \mathrm{wt} \% \mathrm{Al}_{2} \mathrm{O}_{3}$ instead of $\sim 1.5 \mathrm{wt} \%$ ) and those in metal oxides are lower $(\sim 1.8 \mathrm{wt} \%$ for $\mathrm{CaO}, \mathrm{MgO}$, and $\mathrm{FeO}$, instead of $4.2-5.5 \mathrm{wt} \%$ by $\mathrm{MD})$.

For andesite, even if our phase envelope at $\mathrm{T}=1673 \mathrm{~K}$ is restricted in pressure $\left(\mathrm{P}_{\max }=1\right.$ GPa), its similarity with the MORB phase envelop leads us to the conclusion that a critical point located at about $2.5 \mathrm{GPa}$, as extrapolated from the critical line obtained by Kawamoto et al. (2012) for a Mg-rich andesite, is quite possible (see Fig.7). For peridotite, our calculations predict a critical point at a much lower pressure ( $\sim \mathrm{GPa}$ at $1673 \mathrm{~K}$ with $\left.X_{\mathrm{H}_{2} \mathrm{O}} \sim 45 \mathrm{wt} \%\right)$ than the second critical end point ( $3.8 \mathrm{GPa}$ at $1273 \mathrm{~K}$, after Mibe et al. (2007)). However, it is noteworthy that the critical line (the locus of the critical points depending on $\mathrm{P}$ and $\mathrm{T}$ ) terminating at the second critical end point is surmised to show a strong decrease of the critical pressure when the temperature is increasing (for a discussion, see Ni et al., 2017). So it is not unreasonable to assume that our estimation of the critical point at $1673 \mathrm{~K}$ and $\sim 1$ $\mathrm{GPa}$, could be in agreement with the data of Mibe et al. (2007) at $1273 \mathrm{~K}$. Only the evaluation by MD of the critical line could answer this question but this is a long task that we have not pursued.

\subsection{Surface tension.}

The surface tension is an important parameter for magma degassing as it has a direct influence on the bubble nucleation rate (Sparks, 1978). This quantity can be directly evaluated from the integration of the stress tensor along an axis perpendicular to the water-silicate interface in the simulation box (see Methods). The calculated surface tension for the five hydrous melts is reported in Fig.9 as function of (water) pressure. The effect of water is remarkable as the surface tension drops very rapidly with the pressure (or the water content), and so for any melt composition. As a matter of fact, the surface tension of a dry MORB melt at $2273 \mathrm{~K}$ amounts to $\sim 365 \mathrm{~N} / \mathrm{m}$ by $\mathrm{MD}$, a value in excellent agreement with the one obtained by Walker and Mullins (1981) for a tholeiitic basalt at $1773 \mathrm{~K}(\sim 365 \mathrm{~N} / \mathrm{m})$. Furthermore, dry melts ranging from Fe-rich basalt to andesite and rhyolite have a surface tension very close to $\sim 350 \mathrm{~N} / \mathrm{m}$ at $1473 \mathrm{~K}$, with no systematic variations with composition (Walker and Mullins, 1981; Bagdassarov et al., 2000) and a weak temperature dependence (on average the surface tension is positively correlated with the temperature). Coming back to 
hydrous melts, a number of studies have evaluated the surface tension of various

504 compositions (haplogranitic, rhyolitic, dacitic, phonolitic, trachytic, and basaltic) as function 505 of water pressure (Khitarov, 1979; Bagdassarov et al., 2000; Mangan and Sisson, 2005; 506 Iacono-Marziano, 2007; Gardner and Ketcham, 2011; Gardner, 2012; Gardner et al., 2013). 507 Despite a relative dispersion in the data, these experiments show a drastic decrease of the 508 surface tension with water content. Furthermore, it has been shown (Gardner et al., 2013) that 509 for melt composition ranging from basaltic andesite to trachyte and rhyolite, the surface 510 tension falls within a relatively narrow range of 65 to $85 \mathrm{~N} / \mathrm{m}$ for a water content about $4.4-$ $5115 \mathrm{wt} \%$ and a temperature around $1423-1473 \mathrm{~K}$. Our simulation data, though at a higher 512 temperature, are in agreement with these findings (see Fig.9). With regard to ultramafic melts, 513 we find that the decrease of the surface tension with the pressure is even stronger because of 514 the high $\mathrm{H}_{2} \mathrm{O}$ solubility in these melts (see Fig.7). Consequently, at about $\mathrm{P}=1 \mathrm{GPa}$ 515 (corresponding to a $\mathrm{H}_{2} \mathrm{O}$ solubility equal to $\sim 35 \mathrm{wt} \%$ ) the surface tension of ultramafic melts 516 is nearly zero, because of the vicinity of the critical point. Indeed the structural differences 517 between the two coexisting fluids vanish at the critical point.

518 A last remark concerns the role played by the nature of the volatile in contact with the melt. 519 For comparison sake, we have evaluated the pressure evolution of the surface tension of a 520 MORB melt equilibrated with a $\mathrm{CO}_{2}$ phase (Guillot and Sator, 2011). It is found that the 521 decrease of the surface tension with $P_{\mathrm{CO}_{2}}$ is much weaker than with water (not shown). This is 522 due to a much weaker solubility of $\mathrm{CO}_{2}$ with respect to that of water (roughly by one order of 523 magnitude), the melt structure being also much less affected by $\mathrm{CO}_{2}$ than by $\mathrm{H}_{2} \mathrm{O}$. Nevertheless, if the surface tension is reported as function of the $\mathrm{CO}_{2}$ content (in wt\%), its decrease is similar to the one observed with water.

\subsection{Water speciation.}

A number of experimental studies (Stolper, 1989; Shen and Keppler, 1995; Romano et al., 1995; Nowak and Behrens, 1995, 2001; Sowerby and Keppler, 1999) have shown that the water speciation $\left(\mathrm{H}_{2} \mathrm{O}+\mathrm{O}^{2-}\right.$ sil $\left.\leftrightarrow 2 \mathrm{OH}^{-}\right)$is temperature dependent with some of the molecular water that is present in glasses at room temperature being converted to hydroxyl at magmatic temperatures (for a review see Kohn, 2000). A consequence is that the crossing point at which hydroxyl and molecular water concentrations are equal is shifted at much higher total water content when the temperature is increased from room temperature to superliquidus temperatures. So we have evaluated the evolution of hydroxyl and molecular water 
concentrations with the total water content at a fixed superliquidus temperature (e.g. $\mathrm{T}=2073$ $\mathrm{K}$ in Fig.10). As it is shown in Fig.10, at low water content $\left(X_{\mathrm{H}_{2} \mathrm{O}} \leq 3 \mathrm{wt} \%\right)$ the concentration in hydroxyl is preponderant whereas at higher water content the two concentrations become close to each other and eventually are crossing. For a MORB melt the crossing point at 2073 $\mathrm{K}$ is at about $15 \mathrm{wt} \% \mathrm{H}_{2} \mathrm{O}$ as compared with $\sim 3.5 \mathrm{wt} \%$ in a MORB glass at room temperature (Dixon et al., 1995), and 3-4 wt\% for most of silicate glasses (e.g. Silver et al., 1990). Notice that the influence of the melt composition on the partitioning between molecular water and hydroxyl groups is relatively weak even if a trend can be identified at high water content (at low water content the statistical fluctuations in the MD calculations tend to blur the results). Thus the concentration in molecular water is slightly lower in ultramafic melts than in basaltic, andesitic, and rhyolitic melts, the water speciation being similar in the latter three melts. A weak composition dependence is also observed in going from rhyolitic to basaltic glasses (Olhorst et al., 2001). From a more quantitative point of view our results are in accordance (see Fig.10) with the observed evolution of the $\mathrm{H}_{2} \mathrm{O}$ and $\mathrm{OH}^{-}$concentrations in a sodium disilicate melt at $1173 \mathrm{~K}$ (Chertkova and Yamashita, 2015).

The distribution between hydroxyl groups and molecular water is given by the equilibrium constant,

$$
K=\frac{X_{O H}^{2}}{X_{H_{2} O} X_{O}}
$$

where $X_{i}$ is the mole fraction of species $i$ in the melt. $K$ is temperature dependent according to the thermodynamic relation,

$\ln K=-\frac{\Delta H}{R T}+\frac{\Delta S}{R}$

where $\Delta H$ and $\Delta S$ are the reaction enthalpy and reaction entropy, respectively. In evaluating $K$ from Eq.9 we have found (not shown) that its value at a given temperature is virtually independent of the total water concentration and of the pressure (on the pressure range investigated). For illustration, its temperature dependence is shown in Fig.11 for water content equal to $8 \mathrm{wt} \%$ at $\mathrm{P}=0.5 \mathrm{GPa}$. In the investigated range of temperature $(1673-2273$ $\mathrm{K}), K$ varies between 0.8 and 3 according to the melt composition. The value of $K$ is roughly the same $(\sim 0.8-1.2)$ in rhyolitic, andesitic, and basaltic melts, whereas it is higher in peridotitic $(\sim 1.5)$ and kimberlitic melts $(\sim 3)$. Notice that Karki et al. (2010), in their FPMD calculations, found a similar value $(K=1.74$ at $2000 \mathrm{~K})$ for hydrous enstatite. The reaction enthalpy and reaction entropy (graphically deduced from Fig.11) evolve with the melt composition, the enthalpy decreasing continuously with the NBO/T ratio (from $\Delta H \sim 16$ 
$\mathrm{kJ} / \mathrm{mol}$ in rhyolite to $\sim 5 \mathrm{~kJ} / \mathrm{mol}$ in kimberlite), while the reaction entropy varying non monotically with it $(\Delta S=9.2 \mathrm{~J} / \mathrm{mol} . \mathrm{K}$ in rhyolite, 4.6 in andesite, 3.7 in MORB, 7.2 in peridotite, and 11.7 in kimberlite). Experimentally, $K$ was evaluated in rhyolitic (Sowerby and Keppler, 1999; Ihinger et al., 1999; Nowak and Behrens, 2001; Hui et al., 2008) and dacitic melts (Liu et al., 2004) on a lower temperature range close to the glass transition temperature. The reaction enthalpy and entropy deduced from the latter data are generally higher than those evaluated by simulation ( $\Delta H \sim 32-35 \mathrm{~kJ} / \mathrm{mol}$ and $\Delta S \sim 13-28 \mathrm{~J} / \mathrm{mol} . \mathrm{K}$ ). However, the right order of magnitude of the equilibrium constant, $K$, is recovered by extrapolating our hightemperature MD values with a simple low-temperature linear fitting (see the full curves in Fig.11 and compare with the high-temperature extrapolation of the experimental data). Last but not least, in their study, Chertkova and Yamashita (2015) in dealing with a sodium disilicate melt have shown that the decrease of the degree of polymerization of the melt is associated with an increase of the $\mathrm{K}$ value and a decrease of the reaction enthalpy, findings which are in agreement with our calculations.

\subsection{Equation of state of hydrous melts.}

We have evaluated the pressure evolution of the density of our simulated melts as function of the water content (e.g. 1, 4, and $8 \mathrm{wt} \%$ ) along several isotherms (1673, 1873, 2073 and $2273 \mathrm{~K})$. As it is expected, at fixed (T, P) conditions, the density of hydrous melts decreases when the water content is increased. A fitting of our simulation data by a $3^{\text {rd }}$ order BirchMurnaghan equation of state (BMEOS) indicates that the hydrous melts become more compressible when increasing the water content (the BMEOS parameters for the investigated hydrous melts are collected in Table 4). For instance, the bulk modulus of a MORB melt at $1673 \mathrm{~K}$ decreases from $\sim 20.5 \mathrm{GPa}$ to $\sim 18 \mathrm{GPa}$ when adding $1 \mathrm{wt} \% \mathrm{H}_{2} \mathrm{O}$, and $\sim 15 \mathrm{GPa}$ with $8 \mathrm{wt} \% \mathrm{H}_{2} \mathrm{O}$. In fact, when the water content is increased, the melt becomes more compressible due to an increasing abundance of highly compressible molecular water. To compare at best our simulation results with literature data, we have evaluated the density of the hydrous melts at the same T-P conditions as those investigated in the corresponding experimental studies. Thus Sakamaki et al. (2001) in investigating the density of a molten peridotite with $5 \mathrm{wt} \% \mathrm{H}_{2} \mathrm{O}$ by X-ray absorption method found a value of $2.87 \pm 0.04 \mathrm{~g} / \mathrm{cm}^{3}$ at $3.22 \mathrm{GPa}$ and $1773 \mathrm{~K}\left(2.86 \pm 0.03 \mathrm{~g} / \mathrm{cm}^{3}\right.$ by MD), $2.73 \pm 0.08 \mathrm{~g} / \mathrm{cm}^{3}$ at $2.35 \mathrm{GPa}$ and $1873 \mathrm{~K}$ $\left(2.75 \pm 0.03\right.$ by MD), $2.76 \pm 0.05 \mathrm{~g} / \mathrm{cm}^{3}$ at $3.01 \mathrm{GPa}$ and $1973 \mathrm{~K}(2.79 \pm 0.03$ by MD), and 
$6012.81 \pm 0.05 \mathrm{~g} / \mathrm{cm}^{3}$ at $2073 \mathrm{~K}(2.84 \pm 0.03$ by MD). Malfait et al. (2014b) have evaluated by $602 \mathrm{X}$-ray the density of a haplo-andesitic melt with $5.5 \mathrm{wt} \% \mathrm{H}_{2} \mathrm{O}$ : a value of $2.34 \pm 0.03 \mathrm{~g} / \mathrm{cm}^{3}$ 603 was found at $0.85 \mathrm{GPa}$ and $1735 \mathrm{~K}(2.38 \pm 0.03$ by MD for a Fe-bearing andesite, see Table $6041), 2.50 \pm 0.03 \mathrm{~g} / \mathrm{cm}^{3}$ at $2.34 \mathrm{GPa}$ and $1805 \mathrm{~K}(2.54 \pm 0.03$ by MD), whereas for a water 605 content of $9 \mathrm{wt} \%$ they found a density of $2.30 \pm 0.03 \mathrm{~g} / \mathrm{cm}^{3}$ at $1.43 \mathrm{GPa}$ and $1600 \mathrm{~K}(2.32 \pm$ 6060.02 by MD), and $2.58 \pm 0.04 \mathrm{~g} / \mathrm{cm}^{3}$ at $4.01 \mathrm{GPa}$ and $1770 \mathrm{~K}(2.56 \pm 0.03$ by MD). At last, 607 Sakamaki et al. (2006) have investigated a MORB composition by the sink-float method. 608 They evaluated the density of the hydrous melt at about $3.55 \pm 0.05 \mathrm{~g} / \mathrm{cm}^{3}$ at $16.8 \mathrm{GPa}$ and $6092573 \mathrm{~K}$ with $2 \mathrm{wt} \% \mathrm{H}_{2} \mathrm{O}\left(3.48 \pm 0.04\right.$ by MD), and about $3.58 \pm 0.02 \mathrm{~g} / \mathrm{cm}^{3}$ at $20 \mathrm{GPa}$ and $6102473 \mathrm{~K}$ with $8 \mathrm{wt} \% \mathrm{H}_{2} \mathrm{O}(3.53 \pm 0.04$ by $\mathrm{MD})$. In considering the various sources of 611 uncertainties, the agreement between simulation results and experimental data is quite 612 satisfactory.

613 By definition, the partial molar volume of water $\left(V_{\mathrm{H}_{2} \mathrm{O}}\right)$ is given by the derivative of the 614 melt molar volume with respect to the water content (at fixed T and P). So, we have evaluated 615 by MD the evolution of the melt molar volume $\left(V_{m}\right)$ as function of the water content, and 616 found that $V_{m}$ is a linear function of the water content for the five melts under investigation 617 (see Fig.S2 in Supplementary Data). This result has been observed experimentally with 618 silicate glasses (Richet et al., 2000), and means that $V_{\mathrm{H}_{2} \mathrm{O}}$ is independent of the total water 619 concentration and of the water speciation (the concentration ratio between molecular water 620 and hydroxyl groups varying strongly with water content, as shown in Fig.10, the volume 621 change for the reaction, $\mathrm{H}_{2} \mathrm{O}+\mathrm{O}^{2-}$ sil $\leftrightarrow 2 \mathrm{OH}^{-}$, therefore is nearly zero). Moreover, a quick 622 look at Fig.12 shows that the partial molar volume of water, $V_{\mathrm{H}_{2} \mathrm{O}}$, is weakly dependent on 623 composition at low pressure $\left(\sim 21-23 \mathrm{~cm}^{3} / \mathrm{mol}\right.$ at $1673 \mathrm{~K}$ and $\left.0.5 \mathrm{GPa}\right)$, confirming the 624 observations made in the literature (Ochs and Lange, 1999; Malfait et al., 2014 a,b; Bouhifd 625 et al., 2015). Furthermore, it is found that the partial molar volume of water is much more 626 compressible than that of the silicate melt (for an evaluation of the water compressibility see 627 the legend of Fig.12), a conclusion also reached by Sakamaki (2017) from a data analysis of 628 the literature. A comparison between values of $V_{\mathrm{H}_{2} \mathrm{O}}$ obtained by MD (from the derivative of $629 V_{m}$ with respect to the water concentration) and those given in the experimental literature (e.g. 630 in Fig.12) shows a satisfying agreement in considering all sources of uncertainties. For 631 information, FPMD calculations on hydrous enstatite (Mookherjee et al., 2008) and on a 
632

633

634

635

636

637

638

639

640

641

642

643

644

645

646

647

648

649

650

651

652

653

654

655

656

657

658

659

660

661

662

663

664

hydrous basaltic liquid (Bajgain et al., 2015) exhibit slightly lower values of $V_{\mathrm{H}_{2} \mathrm{O}}$ (i.e. $V_{\mathrm{H}_{2} \mathrm{O}} \sim$ $18-21 \mathrm{~cm}^{3} / \mathrm{mol}$ at $2200 \mathrm{~K}$ ). Moreover, in using our calculated values for $V_{m}, V_{\text {sil }}$ (for dry melts, see Dufils et al., 2018) and $V_{\mathrm{H}_{2} \mathrm{O}}$, we have checked that, at least at low pressure $(\mathrm{P}=0$ $2 \mathrm{GPa}$ ), the ideal mixing hypothesis holds (i.e. $V_{m}=x V_{H_{2} O}+(1-x) V_{\text {sil }}$, where $x$ is the water mole fraction). This ideal mixing rule doesn't mean that the hydrous melt is an ideal solution $\left(V_{\mathrm{H}_{2} \mathrm{O}}\right.$ is different from the molar volume of pure water, at least at pressures under investigation).

\subsection{Viscosity.}

The viscosity of hydrous melts was evaluated from the integral of the stress tensor time correlation function (see Methods). The evolution of the viscosity with water content is reported in Fig.13 for the five compositions under investigation $(\mathrm{P}=0.5 \mathrm{GPa})$. At a given temperature, the melt viscosity decreases with water content, the higher the degree of depolymerization of the melt the smaller the viscosity decrease. For instance at $1673 \mathrm{~K}$ and $\mathrm{P}$ $=0.5 \mathrm{GPa}$, the viscosity of the andesitic melt drops by a factor of $\sim 26$ when adding $8 \mathrm{wt} \%$ $\mathrm{H}_{2} \mathrm{O}$, whereas that of a MORB melt decreases by a factor of $\sim 8.5$ and that of molten peridotite by a factor of $\sim 6$ (all the viscosity values are given in Table S3 of the SD). This trend, experimentally observed (e.g. Persikov et al., 2017), can be correlated to the increase of the degree of depolymerization of the melt with the water content (see section 3.9). Moreover, the lower the temperature the stronger the effect of water on the melt viscosity, a feature well documented near the glass transition temperature (e.g. Richet et al., 1996). Concerning the high temperature range investigated here $(\mathrm{T} \geq 1673 \mathrm{~K})$, our results are compared with the viscosity data of Vetere et al. (2008) for Unzen andesite (their data obtained below $1523 \mathrm{~K}$ are extrapolated up to $1673 \mathrm{~K}$ for the present comparison), with the phenomenological model of Whittington et al. (2009) for haplogranite, and with the data of Giordano and Dingwell (2003) for Etna basalt. When the agreement is satisfactory for Unzen andesite and haplogranite (in considering the high-temperature extrapolations made), the one for the basaltic composition is not (except for the dry melt where the measured viscosity is identical to that of the simulated MORB melt). However the viscosity data for hydrous Etna basalt were obtained near the glass transition temperature and the high-temperature extrapolation made by Giordano and Dingwell (2003) could generate significant uncertainties in the results (see the discussion therein). So we believe that the strong viscosity decrease with water content proposed by these authors is unrealistic, the true values should be closer to our MD results. Interestingly, 
665 the first $1 \mathrm{wt} \%$ of water added has a greater effect on the viscosity than the subsequent ones, a 666 feature well documented in the experimental literature (Shaw, 1963; Schulze et al., 1995; 667 Richet et al., 1996; Romano et al., 2003; Robert et al., 2013), and is all the more important than the melt is more polymerized and the temperature low.

669

670

671

672

673

674

675

676

\subsection{Electrical conductivity.}

The electrical conductivity of hydrous melts was evaluated from the mean square displacement of the ionic charges in the melt (see Methods). We have mentioned elsewhere (Dufils et al., 2018) that the magnitude of the electrical conductivity depends on the choice made for the electric charges assigned to the ionic species. This choice is not yet settled from a theoretical standpoint (formal charges versus effective charges, see French et al., 2011), and for the sake of consistency we prefer to use the effective charges of the implemented force field (i.e. $z_{O}=-0.945 e$ instead of $-2 e$ for the charge of the oxygen). Therefore, the comparison of the simulation results with conductivity data of the literature has to be done with caution knowing that the electrical conductivity scales with $\mathrm{z}^{2}$ (for a comparison with conductivity data on dry silicate melts, see Dufils et al. (2018)). Moreover, $\mathrm{H}_{2} \mathrm{O}$ molecules being neutral, they do not contribute directly to the conductivity (but indirectly through the molar volume of the melt and the action of molecular water as polar solvent), on the contrary to the hydroxyl groups and hydronium ions, although the latter ones are contributing very little due to a very low abundance.

The evolution of the electrical conductivity with the $\mathrm{H}_{2} \mathrm{O}$ content is illustrated in Fig.14. The presence of water tends to increase the conductivity of the melt, and this effect both depends on the melt composition (the lower the degree of polymerization of the melt the weaker the effect of water), and on the temperature (the higher the temperature the weaker the influence of water, not shown). These findings are in agreement with conductivity data on rhyolitic, dacitic, andesitic, and basaltic melts (Ni et al., 2011; Dai et al., 2015; Laumonier et al., 2015, 2017; Guo et al., 2016a, 2016b, 2017; Gaillard, 2004; Pommier et al., 2008). For instance, the conductivity of the simulated andesitic melt increases steadily with the $\mathrm{H}_{2} \mathrm{O}$ content at $1873 \mathrm{~K}$, whereas the conductivity of the simulated hydrous basalt seems to saturate above 4 wt $\% \mathrm{H}_{2} \mathrm{O}$. A further scrutiny shows that at high temperature ( $\mathrm{T}>1873 \mathrm{~K}$ ) the conductivity of mafic and ultramafic melts tends to level off or to exhibit a maximum with the $\mathrm{H}_{2} \mathrm{O}$ content, whereas in a more polymerized melt as andesite the conductivity is always positively correlated with the $\mathrm{H}_{2} \mathrm{O}$ content (all the conductivity data are collected in Table S4 
698 of the SD). This complex behavior cannot be rationalized in a simple manner because it is driven both by the evolution with temperature and $\mathrm{H}_{2} \mathrm{O}$ content of the ionic diffusivities (see section 3.8), by the increasing number of hydroxyl groups which enhance the conductivity at high water content (for the evolution of water speciation see Fig.10), and by the presence of molecular water which acts as a polar solvent. Thus the evolution of the electrical conductivity with water content is at variance with the one exhibited by the viscosity, which is always negatively correlated with the water content (see Fig.13). In fact, the viscosity is mainly governed by the low mobility of the structure former ions (mediated by water) whereas the electrical conductivity is driven by the most mobile ions as also as by the ion-ion correlations (see Dufils et al., 2018). So, the search of a simple relationship between viscosity and electrical conductivity in hydrous silicate melts is uncertain.

\subsection{Diffusion of silicate elements and protonated species.}

The self-diffusion coefficients of ions and protonated species $\left(\mathrm{H}_{2} \mathrm{O}, \mathrm{OH}^{-}\right.$, and $\left.\mathrm{H}_{3} \mathrm{O}^{+}\right)$have been evaluated from the mean square displacements in the melt (see Methods). For any silicate element $\log D$ increases almost linearly with water content (see in Fig. 15 the example of the oxygen, all the self-diffusion coefficients are collected in Table S5 of the SD). Thus, according to the melt composition, the $D$ 's increase by a factor of $2 \sim 3$ for a water content increasing from 1 to $8 \mathrm{wt} \%$. Furthermore, the hierarchy between the $D$ 's is maintained with increasing water content (i.e. $\mathrm{Si}<\mathrm{O}<\mathrm{Ti}<\mathrm{Al}<\mathrm{Fe}^{3+}<\mathrm{Fe}^{2+}<\mathrm{Mg} \sim \mathrm{Ca}<\mathrm{K}<\mathrm{Na}$ ), except that in Si-poor kimberlite, Ti has the smallest value of the $D$ 's for any water content.

The self-diffusion coefficients of $\mathrm{H}_{2} \mathrm{O}, \mathrm{OH}^{-}$, and $\mathrm{H}_{3} \mathrm{O}^{+}$also increase exponentially with water content (see Fig.15), but the increase is more pronounced for $\mathrm{H}_{2} \mathrm{O}$ and $\mathrm{H}_{3} \mathrm{O}^{+}$than for $\mathrm{OH}^{-}$. Moreover, it is found that $D_{\mathrm{OH}^{-}}<D_{\mathrm{H}_{2} \mathrm{O}} \leq D_{\mathrm{H}_{3} \mathrm{O}^{+}}$, the deviation between $D_{\mathrm{OH}^{-}}$and $D_{\mathrm{H}_{2} \mathrm{O}}$ being positively correlated with the degree of polymerization of the melt (e.g. at $2073 \mathrm{~K}$ and for $8 \mathrm{wt} \% \mathrm{H}_{2} \mathrm{O}$, the ratio $D_{\mathrm{H}_{2} \mathrm{O}} / D_{\mathrm{OH}^{-}}$is equal to $\sim 1.6$ in a kimberlitic melt, $\sim 4.8$ in a MORB melt, and $\sim 66$ in a rhyolitic melt). Furthermore, the diffusion of $\mathrm{OH}^{-}$is always larger than the one of the oxygen of the silicate (by a factor about 2 to 5 according to the melt composition and in the T-P range of investigation), whereas the diffusion coefficient associated with $\mathrm{H}$ (named $\mathrm{H}_{2} \mathrm{O}_{\text {tot }}$ in Fig.15), regardless the protonated species at which the proton is linked, is intermediate between those associated with $\mathrm{H}_{2} \mathrm{O}$ and $\mathrm{OH}^{-}$(as expected). Thus at high water content, as investigated here $\left(X_{\mathrm{H}_{2} \mathrm{O}} \geq 1 \mathrm{wt} \%\right)$, the protonated species are the main carriers for oxygen (and hydrogen) in hydrous silicate melts. 
A number of the above findings are supported by water diffusion data in hydrous silicate melts (for a review see Zhang and Ni, 2010). For instance, Nowak and Behrens (1997) have shown that the diffusivity of water, regardless of its speciation, increases exponentially with water content in haplogranitic melts. This behavior was also observed in dacitic, haplo andesitic, and haplobasaltic melts (Liu et al., 2004; Persikov et al., 2010). With regard to rhyolitic hydrous melts, Behrens et al. (2007) have found that the diffusivity of oxygen is 1-2 orders of magnitude slower than bulk water diffusivity, a finding in agreement with our results obtained at much higher temperature (see Fig.15). Furthermore, the MD results indicate that the proton diffusion (given by $\mathrm{H}_{2} \mathrm{O}_{\text {tot }}$ ) is weakly dependent on the melt composition, a conclusion reached in a recent study of hydrous silicate melts investigated by quasielastic neutron scattering experiments (Yang et al., 2017).

From a more quantitative viewpoint, several studies (Persikov et al., 2010; Ni et al., 2013; Zhang et al., 2017; Ni and Zhang, 2018) have estimated, from a diffusion model, the diffusivity of total water, hydroxyl groups and molecular water in rhyolitic, haploandesitic and haplobasaltic melts. The overall comparison with our MD results is rather satisfying. Thus, Ni et al. $(2013,2018)$ and Zhang et al. (2017) report a ratio $D_{\mathrm{OH}^{-}} / D_{\mathrm{H}_{2} \mathrm{O}}$ around $0.10-$ 0.17 in a haplobasaltic melt at $1 \mathrm{GPa}$ and $2 \mathrm{wt} \% \mathrm{H}_{2} \mathrm{O}$ in the T-range $1700-1850 \mathrm{~K}$ when we obtain a similar value of about $0.12-0.44$ in a MORB melt at $0.5 \mathrm{GPa}$ and for a water content evolving between 1 and $8 \mathrm{wt} \%$. However, the reported values for the diffusivity of total water (i.e. $\mathrm{H}_{2} \mathrm{O}_{\text {tot }}$ ) in (haplo) basaltic melt seems to be higher than those obtained in the present study whereas those published for a rhyolitic melt present an important curvature with water content (see Fig.15). At this stage, we don't know if these disagreements are real or come from the diffusion model used in these studies (Persikov et al., 2010; Ni and Zhang, 2018) to extract from the diffusion profiles the intrinsic diffusivities of the protonated species. More work is needed to clarify this point.

\subsection{Structure.}

Many studies dealing with infrared, Raman, and NMR spectroscopies have been devoted to the elucidation of the speciation and environment of water in hydrous silicate glasses and melts (e.g. Mysen et al., 1980; Stolper, 1982; Mysen and Virgo, 1986; Kohn et al., 1989; Zotov and Keppler, 1998; Xue and Kanzaki, 2004, 2006, 2007, 2008; Mysen and Cody, 2005; Malfait and Xue, 2010, 2014, Le Losq et al., 2015a, 2015b, 2017). It was evidenced at once the formation of $\mathrm{Si}-\mathrm{OH}$ and $\mathrm{Al}-\mathrm{OH}$ groups leading to a melt depolymerization, and the 
764 formation of $\mathrm{M}-\mathrm{OH}$ species (with $\mathrm{M}=\mathrm{Mg}, \mathrm{Ca}$ or $\mathrm{Na}$ ) which tend to increase the melt polymerization (and to compensate the depolymerizing effect of Si-OH and Al-OH bonds). In this context the MD simulations can be useful as they lead to a direct access to the melt microstructure (see also the FPMD calculations on hydrous enstatite by Karki et al. (2010) and those on a hydrous basaltic liquid by Bajgain et al. (2015)).

Thus we have evaluated the occurrence $\mathrm{P}$ (in \%) that a protonated species $\left(\mathrm{H}_{2} \mathrm{O}, \mathrm{OH}^{-}\right.$, or $\mathrm{H}_{3} \mathrm{O}^{+}$) is bonded to a cation of species $X$ in the melt. In practice, a protonated species is considered as bonded to a cation $X$ if the distance $R\left(O_{P}-X\right)$, where $O_{P}$ is the oxygen of the protonated species under consideration, is smaller or equal to the position of the first maximum of the corresponding pair distribution function $g_{O_{P} X}(R)$. In Fig.16 is reported the occurrence that a protonated species is bonded to a cation $\mathrm{X}$, this occurrence being compared with the one that an oxygen of the silicate is bonded to a cation $\mathrm{X}$ of the same species (this occurrence is simply given by the fraction of oxygens which are bonded to a cation $\mathrm{X}$ in the melt). A rapid look at Fig.16 shows that the solvation structure around water depends strongly on the protonated species under investigation, and only marginally on the melt composition (except for a compositional effect). Thus the near surrounding of molecular $\mathrm{H}_{2} \mathrm{O}$ is deeply depleted in structure former ions $\left(\mathrm{T}=\mathrm{Si}, \mathrm{Ti}, \mathrm{Al}\right.$ and $\left.\mathrm{Fe}^{3+}\right)$, and is composed almost exclusively of structure modifiers $\left(\mathrm{M}=\mathrm{Mg}, \mathrm{Fe}^{2+}, \mathrm{Ca}, \mathrm{Na}\right.$, and $\left.\mathrm{K}\right)$. A further scrutiny shows that the depletion in structure formers around $\mathrm{H}_{2} \mathrm{O}$ is almost complete in mafic and ultramafic melts, whereas it is not the case in andesitic and rhyolitic melts. In contrast, the proportion of bonds between the hydroxyl groups and the structure former cations is only slightly lower than that of the oxygens of the silicate, when the proportion of $\mathrm{OH}^{-}$linked to the structure modifiers is enhanced (a factor of $\sim 2$ with respect to $\mathrm{O}_{\text {sil }}$ ). All these features are found to be weakly dependent on water concentration and temperature (not shown). As for the hydronium ions, $\mathrm{H}_{3} \mathrm{O}^{+}$, they are exclusively linked to alkali and alkaline earth cations. At last, it is notable that the length of the $\mathrm{T}-\mathrm{OH}$ bonds are found to be barely greater (by $\sim 0.02 \mathrm{~A}$ ) than the one of the $\mathrm{T}-\mathrm{O}_{\text {sil }}$ bonds, whereas the length of the $\mathrm{M}-\mathrm{OH}$ and $\mathrm{M}-\mathrm{OH}_{2}$ bonds are virtually identical to those of the $\mathrm{M}-\mathrm{O}_{\text {sil }}$ bonds (for information, $\mathrm{T}-\mathrm{O}$ and $\mathrm{M}-\mathrm{O}$ bonds are the following: 1.625 (Si-O), 1.925 (Ti-O), 1.775 (Al-O), $1.875\left(\mathrm{Fe}^{3+}-\mathrm{O}\right), 2.025\left(\mathrm{Fe}^{2+}-\mathrm{O}\right), 2.025$ (Mg-O), $2.375(\mathrm{Ca}-\mathrm{O}), 2.425(\mathrm{Na}-\mathrm{O})$, and $2.85 \mathrm{~A}(\mathrm{~K}-\mathrm{O}))$. At variance, in rhyolitic and andesitic melts the small population of $\mathrm{T}-\mathrm{OH}_{2}$ bonds exhibits a $\mathrm{T}-\mathrm{O}$ bond length increased by $\sim 0.2 \mathrm{~A}$ with respect to that of $\mathrm{T}-\mathrm{O}_{\text {sil }}$ bonds. 
The observation of $\mathrm{MOH}$ groups, in addition to $\mathrm{TOH}$ ones, is quite in accordance with NMR spectroscopic studies of depolymerized silicate glasses (Xue and Kanzaki, 2004, 2006, 2007, 2008; Cody et al., 2005; Mysen and Cody, 2005). Nevertheless we have to be aware that the environment of hydroxyl groups in quenched glasses is not necessarily representative of that in the liquid phase, so the comparison with spectroscopic studies dealing with quenched glasses must be made with some caution (Le Losq et al., 2017). With regard to the environment of molecular water, our results are new and point out that $\mathrm{H}_{2} \mathrm{O}$ is preferentially solvated in the depolymerized region of the melt (the same rationale holds for $\mathrm{H}_{3} \mathrm{O}^{+}$).

An important point concerns the role played by water on the degree of depolymerization of the melt. For that, we have evaluated the proportion $\left(X_{B O}\right)$ of $(\mathrm{Si}, \mathrm{Al})-\mathrm{O}$ and $(\mathrm{Si}, \mathrm{Al})-\mathrm{OH}$ bonds involved into $\mathrm{T}-\mathrm{O}-\mathrm{T}$ bonds (bridging oxygen). Thus we have analyzed the evolution of $X_{B O}$ with water content for a MORB melt $(1673 \mathrm{~K}$; $0.5 \mathrm{GPa})$, an andesitic melt (1673 K; $0.5 \mathrm{GPa})$ and a peridotitic melt $(2273 \mathrm{~K} ; 0.5 \mathrm{GPa})$. For andesitic and basaltic melts, $X_{B O}$ decreases gradually with water content (from 0.42 for a dry basalt to 0.37 with $8 \mathrm{wt} \% \mathrm{H}_{2} \mathrm{O}$, and for an andesite from 0.44 to 0.40 ), indicating a decrease of the melt polymerization, while for the peridotitic melt $X_{B O}$ remains virtually constant (around 0.23 ) in spite of a very slight maximum $(\sim 0.235)$ at about $4 \mathrm{wt} \% \mathrm{H}_{2} \mathrm{O}$. Thus, an andesitic melt with a water content of 4 wt $\%$ shows a $X_{B O}$ value $(\sim 0.42)$ equivalent to the one of a dry MORB melt, a result meaning that water induced a significant depolymerization of the andesitic melt. In contrast, water has virtually no effect on the degree of depolymerization of a peridotitic melt, a result that can be explained by a compensation between a low abundance of $\mathrm{T}-\mathrm{OH}$ bonds (promoting a melt depolymerization via the reaction, TOT $\left.+\mathrm{H}_{2} \mathrm{O} \leftrightarrow 2 \mathrm{TOH}\right)$ and a high abundance of $\mathrm{M}-\mathrm{OH}$ bonds (especially $\mathrm{Mg}-\mathrm{OH}$ ) which may lead to an increase of the melt polymerization (2TOM $+\mathrm{H}_{2} \mathrm{O} \leftrightarrow \mathrm{TOT}+2 \mathrm{MOH}$, see Le Losq et al., 2015b).

The above results give information on the cationic environment around protonated species, but say very little on the hydrogen bond formation $(\mathrm{O} \ldots \mathrm{H}-\mathrm{O})$ between water and the oxygens of the silicate. So, we have evaluated the O...O distances between the oxygen atoms of the silicate $\left(\mathrm{O}_{\text {sil }}\right)$, the hydroxyl groups, and the $\mathrm{H}_{2} \mathrm{O}$ molecules in calculating the corresponding pair distribution functions $\left(g_{O_{s i l}, O H}^{O O}(r), g_{O_{s i l} H_{2} O}^{O O}(r), g_{O H, O H}^{O O}(r), g_{O H, H_{2} O}^{O O}(r)\right.$, and $g_{\mathrm{H}_{2} \mathrm{O}, \mathrm{H}_{2} \mathrm{O}}^{\mathrm{O}}(r)$, see Fig.S3 for the example of an hydrous MORB melt). The average O...O distances, evaluated from the position of the first maximum of the corresponding PDF, are the following:

$$
d_{O_{s i l}, O H}^{O O}=2.71 \mathrm{~A}<d_{O H, O H}^{O O}=2.84 A<d_{O H, H_{2} O}^{O O} \sim d_{H_{2} O, H_{2} O}^{O O}=3.0 A<d_{O_{s i l}, H_{2} O}^{O O}=3.13 A .
$$


829

830

831

832

833

834

835

836

837

838

839

840

841

842

843

844

845

846

847

848

849

850

851

852

853

854

855

856

857

858

859

860

This hierarchy is virtually independent of composition and water content. Therefore, hydroxyl groups are located in an environment where $\mathrm{O}$... O distances evolve between $2.7 \sim 2.84 \mathrm{~A}$, whereas $\mathrm{H}_{2} \mathrm{O}$ molecules are located in regions where $\mathrm{O} \ldots \mathrm{O}$ distances are in the range $3.0-$ 3.13 A. These results corroborate those obtained from NMR studies (Xue and Kanzaki, 2004; Le Losq et al., 2015a). In fact, the above O...O distances are compatible with the range spanned by the hydrogen bond, namely $2.5-3.2 \mathrm{~A}$, where distances close to $\sim 2.5 \mathrm{~A}$ correspond to strong hydrogen bond and those close to $2.8-3.2$ A correspond to weak hydrogen bond (for instance, in liquid water at ambient the $\mathrm{O} \ldots \mathrm{H}-\mathrm{O}$ distance is about $2.8 \mathrm{~A}$, when it is about 3.0 A in supercritical water at $1673 \mathrm{~K}$ and $0.5 \mathrm{GPa}$ ).

More informative is the analysis of the O...H distances in hydrous melts which shows the presence of hydrogen bonds between the oxygens of the silicate and the protonated species, and between the protonated species themselves. In Fig.17 is shown (e.g. for a MORB melt) the oxygen-hydrogen PDF between $\mathrm{O}_{\text {sil }} \ldots \mathrm{H}\left(g_{O H}\left(O_{s i l}, H\right)(r)\right), \mathrm{HO} \ldots \mathrm{H} \quad\left(g_{O H}(O H, H)(r)\right)$, and $\mathrm{H}_{2} \mathrm{O} \ldots \mathrm{H}\left(g_{\mathrm{OH}}\left(\mathrm{H}_{2} \mathrm{O}, \mathrm{H}\right)(r)\right)$. These PDFs are characterized by three features: a first peak corresponding to the intramolecular $\mathrm{O}-\mathrm{H}$ bond $(\sim 1 \mathrm{~A})$ in $\mathrm{OH}$ groups and $\mathrm{H}_{2} \mathrm{O}$ molecules, a second peak located between 3.2 and 3.5 A, which represents the distribution of hydrogens that are not directly connected (by hydrogen bond) to the reference oxygen, and in between a shouldering associated with $\mathrm{O} \ldots \mathrm{H}-\mathrm{O}$ bonds. The latter shouldering is centered on $\mathrm{r}_{\mathrm{O}} \ldots \mathrm{H} \sim 2.0$ A, which is a distance typical of weak hydrogen bond (the various hydrogen bonded complexes leading to the shouldering and to the second peak of the PDF's are detailed in Fig.17). Moreover, one notices on the $\left(\mathrm{O}_{\text {sil }} \ldots \mathrm{H}\right) \mathrm{PDF}$ a population of strong hydrogen bonds $(\mathrm{O} . . \mathrm{H}-\mathrm{O})$ between $\mathrm{O}_{\text {sil }}$ and hydroxyl groups (see in Fig.17 the small bump at about $1.5 \mathrm{~A}$ on $g_{O H}\left(O_{s i l}, H\right)(r)$ ), a finding also reported in NMR studies (Kohn et al., 1989; Xue and Kanzaki, 2007). At variance, the shouldering at $2.0 \mathrm{~A}$ is less visible on $g_{\mathrm{OH}}\left(\mathrm{H}_{2} \mathrm{O}, \mathrm{H}\right)(r)$ than on $g_{O H}\left(O_{s i l}, H\right)(r)$, and the second peak around 3.3 $\mathrm{A}$ is broader on the former PDF. These features suggest that water molecules and hydroxyl groups are loosely connected (by hydrogen bond) with each other, leading to an important protonic disorder. As for the little peak located near $r=2.6 \mathrm{~A}$ on $g_{O H}(O H, H)(r)$, it corresponds to a small population of hydroxyl groups set out face to face $(\mathrm{O}-\mathrm{H}$...H-O), configurations which are generated by the compact structure of the silicate melt (the same kind of configuration is also observed in FPMD calculations of hydrous enstatite (Karki et al., 2010). 


\section{Conclusion.}

Thanks to the introduction of a new interaction potential for water compatible with a force field describing silicate melts (Dufils et al., 2017, 2018), we have been able to evaluate by MD simulation a number of thermo physical and transport properties, and to point out some structural features of a series of hydrous magmatic melts. The main conclusions reached in this study are the following.

(1) The solubility of water and its pressure dependence calculated by MD change very little when the melt composition evolves from rhyolitic to andesitic and basaltic. At variance, the solubility of water is found to be strongly enhanced in ultramafic melts (molten peridotite and molten kimberlite). The comparison with water solubility data of the literature is somewhat disappointing in part because the latter ones exhibit large data dispersion, and clearly more work is needed. However it is noteworthy that classical $\mathrm{FF}$, as used here, are not able to capture certain aspects of the electronic structure in the melt (charge transfer, ionic polarizability..), and these shortcomings may have some consequences on the evaluated properties.

(2) The analysis of the phase coexistence between the hydrous melt and the aqueous fluid shows that the oxide content of the coexisting aqueous fluid increases rapidly with the pressure. This allows one to locate approximately the critical point of the melt under investigation (e. g. for a peridotitic melt at $1673 \mathrm{~K}, \mathrm{P}_{\text {crit }}=1-1.1 \mathrm{GPa}$ and $\mathrm{X}_{\text {crit }} \sim 45 \mathrm{wt} \%$ $\mathrm{H}_{2} \mathrm{O}$ ). Our predictions for the critical parameters are in a qualitative agreement with the rare experimental studies (e.g. for the phase envelop of a hydrous basalt melt, see Mibe et al., 2011).

(3) When the aqueous fluid and the hydrous melt are in coexistence with each other in the simulation cell, it is possible to evaluate the surface tension and its evolution with the pressure. Water has a large influence on the surface tension as the latter one drops by a factor of 2-4 when the water pressure increases from 1 bar to a few kbars, a finding in agreement with experimental data (e.g. Gardner et al., 2013). Above this pressure range, the calculated surface tension of felsic to basaltic compositions continues to decrease with pressure but at a lower rate, whereas with ultramafic melts the surface tension goes to zero at about $1 \mathrm{GPa}$ because of the proximity of the critical point.

(4) Concerning the water speciation, an important point is that the MD simulation probes the liquid phase, when most of the experimental studies are dealing with glasses. Thus 
at magmatic temperatures and at low and moderate water content, the concentration in hydroxyl groups is found to be greater than the one in molecular water, both concentrations increasing with the total water content (with a convex upward trend for $\mathrm{OH}^{-}$concentration, and a concave upward trend for $\mathrm{H}_{2} \mathrm{O}$ concentration). However, the two concentrations are crossing for a water content of about $15 \mathrm{wt} \%$, a value much higher than the one observed in glasses $(\sim 3.5 \mathrm{wt} \%$ in a MORB glass at ambient, Dixon et al. (1995)). Although the water speciation depends on the melt composition, the effect is weak for felsic to basaltic compositions and is more pronounced with ultramafic melts (the ratio $\mathrm{OH} / \mathrm{H}_{2} \mathrm{O}$ is higher in these compositions).

(5) We have shown that the molar volume of the melt is a linear function of the water content, and so for all the chemical compositions investigated. Therefore the water partial molar volume $\left(V_{\mathrm{H}_{2} \mathrm{O}}\right)$ is virtually independent of total water content and of water speciation. A by-product of this result is that an ideal mixing rule between water and the silicate component leads to an accurate evaluation of the melt molar volume. Moreover, $V_{\mathrm{H}_{2} \mathrm{O}}$ is found to be weakly dependent on the melt composition and decreases drastically with the pressure, features which are supported by the experimental data (e.g. Sakamaki, 2017). Moreover, the effect of water is to decrease the melt density, the melt becoming more compressible with water content. A consequence is that the density deviation between dry and hydrous melt is more important at low pressures than at high pressures.

(6) At fixed $\mathrm{T}$ and $\mathrm{P}$, the melt viscosity decreases with water content, the more depolymerized the melt the smaller the influence of water on the viscosity. Furthermore, the lower the temperature the stronger the effect of water on the viscosity decrease. Thus at the high temperatures investigated in this study ( $\mathrm{T} \geq 1673 \mathrm{~K}$ ), the decrease in viscosity induced by water does not exceed one or two orders of magnitude (according to the melt composition and water content), as compared with many orders of magnitude near the glass transition temperature (e.g. Richet et al., 1996).

(7) The evolution of the electrical conductivity with water content depends on the melt composition. Whereas the conductivity of the andesitic melt increases steadily with increasing water content, it tends to level off in the basaltic melt (above $\sim 4 \mathrm{wt} \% \mathrm{H}_{2} \mathrm{O}$ ), and remains almost invariant in the peridotitic melt. This complex behavior cannot be rationalized in a simple way because it is driven both by the evolution with temperature and $\mathrm{H}_{2} \mathrm{O}$ content of the ionic diffusivities, by the increasing number of hydroxyl groups 
which enhance the conductivity at high water content, and by the presence of molecular water which acts as a polar solvent. A consequence is that electrical conductivity and viscosity of hydrous silicate melts are not simply related with each other.

(8) Concerning the diffusivity of ionic species, $\log D$ increases almost linearly with water content. So the hierarchy between the $D$ 's observed in the dry melt is maintained with increasing water content. With regard to the protonated species, the following hierarchy is found: $D_{\mathrm{OH}^{-}}<D_{\mathrm{H}_{2} \mathrm{O}} \leq D_{\mathrm{H}_{3} \mathrm{O}^{+}}$, the ratio $D_{\mathrm{OH}^{-}} / D_{\mathrm{H}_{2} \mathrm{O}}$ being positively correlated with the $\mathrm{NBO} / \mathrm{T}$ ratio. Moreover, the diffusion of hydroxyl groups being greater than the one of the oxygens of the silicate, at high water content, $\mathrm{H}_{2} \mathrm{O}$ and $\mathrm{OH}^{-}$are the main oxygen carriers in the hydrous melt.

(9) From a structural point of view, it is found that hydroxyl groups are linked to structure maker cations and to metal cations, as well. However, with respect to the oxygens of the silicate, they are more preferentially linked to metal cations than to structure makers, this trend increasing with the $\mathrm{NBO} / \mathrm{T}$ ratio of the melt. In contrast, $\mathrm{H}_{2} \mathrm{O}$ molecules (and $\mathrm{H}_{3} \mathrm{O}^{+}$as well) are almost exclusively linked to metal cations. Therefore, knowing that only hydroxyl groups may have an influence on the degree of polymerization of the silicate network, the evaluation of the proportion of ( $\mathrm{Si}, \mathrm{Al})-\mathrm{O}$ and $(\mathrm{Si}, \mathrm{Al})-\mathrm{OH}$ bonds involved into $\mathrm{T}-\mathrm{O}-\mathrm{T}$ bonds (with $\mathrm{T}=\mathrm{Si}, \mathrm{Al}$ ) have shown that the polymerization decreases gradually with the water content in andesitic and basaltic melts, and remains almost invariant in peridotitic melt. The latter result seems to be in conflict with the fact that the viscosity of a hydrous peridotitic melt decreases when its water content is increased. Actually, the viscosity, a dynamical quantity, is sensitive to the evolution of the diffusion of ionic species with water content (all the ionic diffusivities increase with water content), whereas the degree of polymerization (as defined, for instance, by the $\mathrm{NBO} / \mathrm{T}$ ratio) is a static parameter, originally defined for glasses, and for which the notion of lifetime is absent.

An important point addressed in this study is the presence of O-H...O bonds (hydrogen bonding) in the hydrous melts. These hydrogen bonds taking place between the hydroxyl groups, the water molecules, and the oxygens of the silicate are characterized by $\mathrm{O} \ldots \mathrm{O}$ distances in the range $2.5 \sim 3.2 \mathrm{~A}$, and by $\mathrm{O} \ldots \mathrm{H}-\mathrm{O}$ distances in the range $1.5 \sim 2.2$. But, because of the high temperature of investigation, these H-bonds are generally weak (weaker than in liquid water at ambient, for instance) which leads to a high protonic disorder with large amplitude of angular reorientation. Correlatively, even if these H-bonds tend to 
960 strengthen the silicate network, they are much too weak to play a role in the degree of 961 polymerization or to affect the melt viscosity.

962

963 Acknowledgements

964 The research leading to these results has received funding from the European Community's Seventh 965 Framework Program (FP7/2007-2013) under Grant agreement (ERC, N²79790).

\section{Methods.}

972 Simulation parameters. The MD simulations were performed with the DL-Poly 2.0 code (Smith and 973 Forrester, 1996). The silicate component of the simulated system is composed of 2,000 atoms, at 974 which is added a number of water molecules in order to reach the aimed water content (e.g. $25 \mathrm{H}_{2} \mathrm{O}$ 975 molecules to simulate a hydrous melt with $\sim 1$ wt $\% \mathrm{H}_{2} \mathrm{O}$ ) and some checks have been performed with 976 different system sizes showing that no significant size dependence is found on the results, except the 977 shrinking of the statistical fluctuations with the system size $(\sim 1 / \sqrt{N})$. The simulation box is cubic with 978 periodic boundary conditions and the equations of motion are solved with the Verlet's algorithm with 979 a time step of $1 \mathrm{fs}\left(10^{-15} \mathrm{~s}\right)$. The long-range Coulomb interactions are accounted for by an Ewald sum. 980 The calculations are carried out in the isothermal-isobaric ensemble (NPT) when evaluating 981 thermodynamic properties, whereas the transport properties (viscosity, electrical conductivity, and 982 self-diffusion coefficients) are evaluated in the microcanonical ensemble (NVE). MD trajectories are 983 long enough (10-30 ns) to ensure a good convergence of the average values and especially of the 984 transport coefficients that are more demanding. The statistical uncertainty is of the order of $1 \%$ for 985 the density (at given $T$ and $P$ ), a few percent for the self-diffusion coefficients (except for elements in 986 low concentration, < 2 wt\%, for which the uncertainty may reach 10\% or much more) and of the order 987 of $10-20 \%$ for the surface tension, the viscosity and the electrical conductivity that are slowly 988 converging collective properties.

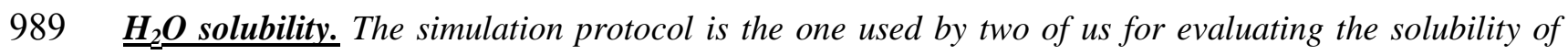
$990 \mathrm{CO}_{2}$ in a silicate melt (Guillot and Sator, 2011). An aqueous phase composed of $300 \sim 900 \mathrm{H}_{2} \mathrm{O}$ 991 molecules (according to the expected solubility), is put in contact with a silicate phase composed of 992 1,000 atoms at given (T, P) conditions. The water molecules being free to move through the interface 993 (the same is true with the silicate elements), a stationary state (equilibrium) is reached after a few $n s$ 994 where a number of water molecules and hydroxyl groups are present in the silicate melt. An averaging 995 of these numbers over a long simulation time (10-30 ns) leads to a precise evaluation ( 10\%) of the 
996

water solubility. This method is accurate as long as the solubility is not too low. In the present case, an estimation of the lowest solubility that can be measured corresponds approximately to one water molecule dissolved in the silicate melt, i.e. a solubility value equal to $\sim 0.1 \mathrm{wt} \% \mathrm{H}_{2} \mathrm{O}$ for a silicate sample composed of $\sim 1,000$ atoms.

Surface tension. In the case where the interface between the aqueous phase and the coexisting hydrous melt is planar, the surface tension is given by (Kirkwood and Buff, 1949), $\gamma=\frac{L_{z}}{2}\left(P_{z z}-\frac{1}{2}\left(P_{x x}+P_{y y}\right)\right)$ where $L_{z}$ is the length of the simulation box perpendicular to the interface and $P_{x x}, P_{y y}$ and $P_{z z}$ are the diagonal components of the stress tensor given by,

$P_{\alpha \alpha}=\frac{1}{V}\left(<\sum_{i=1}^{N} m_{i} v_{i \alpha} v_{i \alpha}>+<\sum_{i=1}^{N} \sum_{j>i}^{N} F_{i j}^{\alpha} r_{i j}^{\alpha}>\right)$, where $\alpha=x, y, z, \rho$ is the numeral density, $k_{B}$ the Boltzmann constant, $T$ the temperature, $V$ the volume of the simulation cell, $m_{i}$ the mass of atom $i$, $v_{i \alpha}$ the $\alpha$ component of the velocity of atom $i$, $F_{i j}^{\alpha}$ the $\alpha$ component of the force acting between atoms $i$ and $j$ separated by the distance $r_{i j}$, and where the brackets express an average over a long simulation run. The use of this method in MD simulation is well documented.

Viscosity. The viscosity of the hydrous melts under investigation has been evaluated from the GreenKubo relation (Zwanzig, 1965; Allen and Tildesley, 1987) relating the viscosity to the time correlation function of the stress tensor (many MD studies have used this relation, see for instance Hess (2002), Bauchy et al. (2013)). In this framework, the viscosity evaluation is accurate as long as $t_{\text {run }}>\tau_{\text {relax, }}$ where $t_{\text {run }}$ is the simulation time and $\tau_{\text {relax }}$ is the viscous relaxation time. An estimate of $\tau_{\text {relax }}$ is given by the Maxwell relation, $\tau_{\text {relax }}=\eta / G_{\infty}$, where the shear modulus at infinite frequency $G_{\infty}$ is equal to $\sim 3-$ 30 GPa for silicate melts (Dingwell and Webb, 1989). Consequently, to evaluate by MD a viscosity of the order of $\sim 100$ Pa.s, one needs to run a MD calculation over a simulation time longer than $\sim 30 \mathrm{~ns}$. So, with our limited computational resources, we have restricted our evaluation of the viscosity to temperatures higher than $\sim 1673 \mathrm{~K}$, a temperature range corresponding to viscosity values smaller than 100 Pa.s with the melt compositions investigated here.

The viscosity calculation consists in integrating over the time the correlation function of the stress tensor. This integral exhibits a S-shaped curve as function of running time (not shown, see e.g. in Dufils et al., 2017), a curve which can be accurately fitted by a stretched exponential,

$\eta=\eta_{\infty}\left(1-e^{-\left(\frac{t}{\tau_{\text {relax }}}\right)^{\alpha}}\right)$ where $\eta_{\infty}$ is the MD-estimated value of the viscosity corresponding to the plateau value at long time, $\tau_{\text {relax }}$ is the viscous relaxation time and $\alpha$, a coefficient $\leq 1$. For the melts under investigation $\alpha$ varies between 0.30 and 1.0 according to temperature and composition (lower the viscosity smaller the value of $\alpha$ ). Interestingly, the use of the above equation in conjunction with the Maxwell relation leads to the evaluation of the shear modulus at infinite frequency, $G_{\infty}=\eta_{\infty} / \tau_{\text {relax. }}$. A quick look at Table $S 2$ (in 
1031 Supplementary Data), shows that $G_{\infty}$ is in the range $3-16 \mathrm{GPa}$, a finding in agreement with the

1032 experimental observation for dry silicate melts (Dingwell and Webb, 1989; Richet et al., ...).

1033 Electrical conductivity. The electrical conductivity was calculated from the Green-Kubo relation

1034 (Hansen and McDonald, 1986),

$1035 \sigma=\frac{1}{k_{B} T V} \lim _{t \rightarrow \infty} \frac{1}{6 t}<\left|\sum_{i=1}^{N} z_{i}\left(\vec{r}_{i}(t)-\vec{r}_{i}(0)\right)\right|^{2}>$,

1036 where $k_{B}$ is the Boltzmann constant, $T$ the temperature, $V$ the volume of the sample, $z_{i}$ the electric 1037 charge of ion $i, \vec{r}_{i}(t)$ its position at time $t$, and where the angular brackets express an average taken 1038 over many time origins. Here the ionic transport is considered as the only responsible mechanism of 1039 the conductivity, the electronic conduction being assumed to be negligible at high temperatures in 1040 silicate melts (Yoshino et al., 2009). Values assigned to the charges $z_{i}$ are equal to the effective 1041 charges implemented in our force field (i.e. $\left.z_{0}=-0.945 e, z_{S i}=+1.89 e ..\right)$. However we have to keep in 1042 mind that the electric charges involved in the melt conductivity could be not strictly equal to those of 1043 the force field (which take into account polarization effects in an effective way, for a discussion see 1044 Dufils et al, 2017). Note that $\mathrm{H}_{2} \mathrm{O}$ molecules do not contribute to the conductivity, on the contrary to 1045 hydroxide ions, which contribute significantly to it. In fact the Green-Kubo equation rigorously takes 1046 into account the contribution of the water speciation to the conductivity. However, the evaluation of 1047 the conductivity is reliable as long as the diffusive regime is reached, that is when the mean square 1048 displacement of the charges as function of time follows a straight line of slope equal to one in a log1049 log representation. In practice the MD runs have to be long enough (up to $40 \mathrm{~ns}$ ) to reach accuracy 1050 better than $20 \%$ on the conductivity value.

1051 Diffusion coefficient. The self-diffusion coefficients of ions and protonated species have been 1052 evaluated from the time evolution of their mean square displacements (MSD), $D_{S}=\lim _{t \rightarrow \infty} \frac{1}{N_{S}} \sum_{i=1}^{N_{S}} \frac{\left\langle\left(\vec{r}_{i}(t)-\vec{r}_{i}(0)\right)^{2}>\right.}{6 t}$,

1054 where $N_{s}$ is the number of atoms of species $s, \vec{r}_{i}(t)$ the position at time $t$ of ion $i$, and where the 1055 angular brackets express an average taken over many time origins. With regard to the protonated 1056 species $\left(\mathrm{H}_{2} \mathrm{O}, \mathrm{OH}\right.$, and $\left.\mathrm{H}_{3} \mathrm{O}^{+}\right)$, we remove from the statistics those species that are reacting during the 1057 simulation run used to evaluate the diffusion coefficient. The diffusive regime is reached when the time 1058 evolution of the MSD described a straight line of slope equal to one in a log-log representation. The accuracy on $D_{s}$ is generally better than $10 \%$, except for Ti, $K$, and $\mathrm{H}_{3} \mathrm{O}+$ for which their low concentration leads to a poorer statistics ( $30-50 \%)$. 
1066 Supplementary data associated with this article can be found, in the online version, at

1067 http://dx.doi.org/xxx

1068

1069

1070

1071

1072

1073

1074

1075

1076

1077

1078

\section{Bibliography}

1079

1080

1081

Abramson E.H., 2007. Viscosity of water measured to pressures of $6 \mathrm{GPa}$ and temperatures of $300{ }^{\circ} \mathrm{C}$.

1082

Phys. Rev. E 76, 051203-1-6.

1083

1084

Abramson E.H. and Brown J.M., 2004. Equation of state of water based on speeds of sound measured

1085 in the diamond-anvil cell. Geochim. Cosmochim. Acta 68, 1827-1835.

1086

1087

Abramson E.H., 2015. Speculation on measurements of the viscosity of shocked fluid water. Shock

1088 waves 25, 103-106.

1089

1090

Agee C.B., 2008. Static compression of hydrous silicate melt and the effect of water on planetary

1091 differentiation. Earth Planet. Sci. Lett. 265, 641-654.

1092

1093

Aubry G.J., Sator N. and Guillot B., 2013. Vesicularity, bubble formation and noble gas fractionation

1094 during MORB degassing. Chem. Geol. 343, 85-98.

1095

1096 Badyal Y.S., Saboungi M.-L., Price D.L., Shastri S.D. and Haeffner D.R., 2000. Electron distribution 1097 in water. J. Chem. Phys. 112, 9206-9208.

1099 Bagdassarov N., Dorfman A. and Dingwell D.B., 2000. Effect of alkalis, phosphorus, and water on the 1100 surface tension of haplogranite melt. Am. Mineral. 85, 33-40. 
1102 Bajgain S., Ghosh D.B. and Karki B.B., 2015. Structure and density of basaltic melts at mantle

1103 conditions from first-principles simulations. Nature Communications 6, 8578-1-7.

1105 Bajgain S., Peng Y., Mookherjee M., Jing Z. and Solomon M., 2019. Properties of hydrous 1106 aluminosilicate melt at high pressures. ACS Earth Space Chem., DOI: 1107 10.1021/acsearthspacechem.8b00157.

1109 Bartholomew R.F., Butler B.L., Hoover H.L. and Wu C.K., 1980. Infrared spectra of a water1110 containing glass. J. Am. Ceram. Soc. 63, 481-485.

Benne D. and Behrens H., 2003. Water solubility in haplobasaltic melts. Eur. J. Mineral. 15, 803-814.

Behrens H. and Nowak M., 2003. Quantification of H2O speciation in silicate glasses and melts by IR spectroscopy - in situ versus quench techniques. Phase Transit. 76, 45-61.

Behrens H., Zhang Y., Leschik M., Wiedenbeck M., Heide G. and Frischat G.H., 2007. Molecular $\mathrm{H}_{2} \mathrm{O}$ as carrier for oxygen diffusion in hydrous silicate melts. Earth Planet. Sci. Lett. 254, 69-76.

Behrens H. and Yamashita S., 2008. Water speciation in hydrous sodium tetrasilicate and hexasilicate melts: Constraint from high temperature NIR spectroscopy. Chem. Geol. 256, 306-315.

Botcharnikov R.E., Behrens and Holtz F., 2006. Solubility and speciation of C-O-H fluids in andesitic melt at $\mathrm{T}=1100-1300^{\circ} \mathrm{C}$ and $\mathrm{P}=200$ and $500 \mathrm{MPa}$. Chem. Geol. 229, 125-143.

Bouhifd M.A., Whittington A.G. and Richet P., 2015. Densities and volumes of hydrous silicate melts: New measurements and predictions. Chem. Geol. 418, 40-50. aluminosilicate glasses investigated by first principles techniques. J. Sol. State Chem. 183, 2786-2796. upper mantle: experimental evidence and geochemical implications. Earth Planet. Sci. Lett. 165, 187196. 556. 
1139 Chen H.C., De Paolo D.J., Nakada S., Shieh Y.M., 1993. Relationship between eruption volume and

1140 neodymic isotopic composition at Unzen volcano. Nature 362, 831-834.

1141

1142 Chen M., Ko H.-Y., Remsing R.C., Calegari Andrade M.F., Santra B., Sun Z., Selloni A., Car R.,

1143 Klein M.L., Perdew J.P. and Wu X., 2017. Ab initio theory and modeling of water. P.N.A.S. 114, 1144 10846-10851.

1145

1146 Chertkova N. and Yamashita S., 2015. In situ spectroscopic study of water speciation in the 1147 depolymerized $\mathrm{Na}_{2} \mathrm{Si}_{2} \mathrm{O}_{5}$ melt. Chem. Geol. 409, 149-156.

1148

1149 Cisneros G.A., Wikfeldt KT, Ojamäe L., Lu J., Xu Y., Torabifard H., Bartok A.P., Csanyi G., 1150 Molinero V. and Paesani F., 2016. Modeling molecular interactions in water: From pairwise to many1151 body potential energy functions. Chem. Rev. 116, 7501-7528.

1152

Cody G.D., Mysen B.O. and Lee S.K., 2005. Structure versus composition: a solid state ${ }^{1} \mathrm{H}$ and ${ }^{29} \mathrm{Si}$ NMR study of quenched glasses along the $\mathrm{Na}_{2} \mathrm{O}-\mathrm{SiO}_{2}-\mathrm{H}_{2} \mathrm{O}$ join. Geochim Cosmochim. Acta 69, 23732384.

1156

Corrales L.R., 1999. Dissociative model of water clusters. J. Chem. Phys. 110, 9071-9080.

Mahadevan T.S. and Garofalini S.H., 2007. Dissociative water potential for molecular dynamics simulations. J. Phys. Chem. B 111, 8919-8927.

Dai L., Jiang J., Li H., Hu H. and Hui K., 2015. Electrical conductivity of hydrous natural basalts at high temperatures and pressures. J. Appl. Geophys. 112, 290-297.

David C.W., 1996. A variable charge central force model for water and its ionic dissociation products. J. Chem. Phys. 104, 7255-7260. Etna and Fondo Riccio (Phlegrean Fields) liquid viscosity, glass transition temperature and heat capacity. Chem. Geol. 377, 72-86. granitic melts. Am. Mineral. 82, 434-437. 
1175 Di Matteo V., Carroll M.R., Behrens H., Vetere F. and Brooker R.A., 2004. Water solubility in

1176 trachytic melts. Chem. Geol. 213, 187-196.

1178 Dixon J.E., Stolper E.M. and Holloway J.R., 1995. An experimental study of water and carbon dioxide 1179 solubilities in mid-ocean ridge basaltic liquids. Part I: Calibration and solubility models. J. Petrol. 36, $1180 \quad 1607-1631$.

1182 Duan X., 2014. A general model for predicting the solubility behavior of $\mathrm{H}_{2} \mathrm{O}-\mathrm{CO}_{2}$ fluids in silicate 1183 melts over a wide range of pressure, temperature and compositions. Geochim. Cosmochim. Acta 125, $1184 \quad 582-609$.

1186 Dufils Th., Folliet N., Mantisi B., Sator N. and Guillot B., 2017. Properties of magmatic liquids by 1187 molecular dynamics simulation: The example of a MORB melt. Geochim. Cosmochim. Acta 461, 34118846.

Dufils Th., Sator N. and Guillot B., 2018. Properties of planetary silicate melts by molecular dynamics simulation. Chem. Geol. 493, 298-315.

French M., Mattsson T.R., Nettelmann N. and Redmer R., 2009. Equation of state and phase diagram of water at ultrahigh pressures as in planetary interiors. Phys. Rev. B 79, 054107-1-11.

French M., Mattsson T.R. and Redmer R., 2010. Diffusion and electrical conductivity in water at ultrahigh pressures. Phys. Rev. B 82, 174108-1-9.

French M., Hamel S. and Redmer R., 2011. Dynamical screening and ionic conductivity in water from Ab Initio simulations. Phys. Rev. Lett. 107, 185901-1-4.

Gaillard F., 2004. Laboratory measurements of electrical conductivity of hydrous and dry silicic melts under pressure. Earth Planet. Sci. Lett. 218, 215-228.

Gardner J.E. and Ketcham R.A., 2011. Bubble nucleation in rhyolite and dacite melts: temperature dependence of surface tension. Contrib. Mineral. Petrol. 162, 929-943.

1208 Gardner J.E., 2012. Surface tension and bubble nucleation in phonolite magmas. Geochim. 1209 Cosmochim. Acta 76, 93-102. 
1211 Gardner J.E., Ketcham R.A. and Moore G., 2013. Surface tension of hydrous silicate melts:

1212 Constraints on the impact of melt composition. J. Volcanol. Geotherm. Res. 267, 68-74.

1213

1214 Giordano D. and Dingwell D.B., 2003. Viscosity of hydrous Etna basalt: implications for Plinian-style 1215 basaltic eruptions. Bull. Volcanol. 65, 8-14.

Goncharov A.F., Sanloup C., Goldman N., Crowhurst J.C., Bastea S., Howard W.M., Fried L.E., Guignot N., Mezouar M. and Meng Y., 2009. Dissociative melting of ice VII at high pressure. J. Chem. Phys. 130, 124514-1-9.

1220

Goranson R.W., 1938. Silicate-water systems: Phase equilibria in the NaAlSi3O8 and KAlSi3O8 systems at high temperatures and pressures. Am. J. Sci. 5A, 71-91.

Green D.H., 1973. Experimental melting studies on a model upper mantle composition at high pressure under water-saturated and water-undersaturated conditions. Earth Planet. Sci. Lett. 19, 37-53.

Guillot B., 2002. A reappraisal of what we have learnt during three decades of computer simulations on water. J. Mol. Liq. 101, 219-260.

1229

Guillot B. and Sator N., 2011. Carbon dioxide in silicate melts: A molecular dynamics simulation study. Geochim. Cosmochim. Acta 75, 1829-1857.

Guillot B. and Sator N., 2012. Noble gases in high-pressure silicate liquids: A computer simulation study. Geochim. Cosmochim. Acta 80, 51-69.

Guo X., Zhang L., Behrens H. and Ni H., 2016a. Probing the status of felsic magma reservoirs: Constraints from the P-T-H2O dependences of electrical conductivity of rhyolitic melt. Earth Planet. Sci. Lett. 433, 54-62.

Guo X., Chen Q. and Ni H., 2016b. Electrical conductivity of hydrous silicate melts and aqueous fluids: Measurement and applications. Sci. China Earth Sci. 59, 889-900.

Guo X., Bin L., Ni H. and Mao Z., 2017. Electrical conductivity of hydrous andesitic melts pertinent to subduction zones. J. Geophys. Res. Solid Earth 122, 1777-1788. 
1249 Hamilton D.L., Burnham C.W. and Osborn E.F., 1964. The solubility of water and effects of oxygen

1250 fugacity and water content on crystallization in mafic magmas. J. Petrol. 5, 21-39.

Hamann S.D. and Linton M. (1966). Electrical conductivity of water in shock compression. Trans. Faraday Soc. 62, 2234-2241.

Hermann J., Spandler C., Hack A. and Korsakov A.V., 2006. Aqueous fluids and hydrous melts in high-pressure and ultra-high pressure rocks: Implications for element transfer in subduction zones. Lithos 92, 399-417.

Holtz F., Roux J., Behrens H. and Pichavant M., 2000. Water solubility in silica and quartzofeldspathic melts. Am. Mineral. 85, 682-686.

Hui H., Zhang Y., Xu Z., and Behrens H., 2008. Pressure dependence of the speciation of dissolved water in rhyolitic melts. Geochim. Cosmochim. Acta 72, 3229-3240.

Iacono-Marziano G., Schmidt B.C. and Dolfi D., 2007. Equilibrium and disequilibrium degassing of a phonolitic melt (Vesuvius AD 79 "white pumice") simulated by decompression experiments. J. Volcanol. GeotherM. Res. 161, 151-164.

Iacono-Marziano G., Morizet Y., Trong E.L. and Gaillard F., 2012. New experimental data and semiempirical parametrization of $\mathrm{H}_{2} \mathrm{O}-\mathrm{CO}_{2}$ solubility in mafic melts. Geochim. Cosmochim. Acta 97, 1-23.

Ihinger Ph. D., Zhang Y. and Stolper E.M., 1999. The speciation of dissolved water in rhyolitic melt. Geochim. Cosmochim. Acta 63, 3567-3578. Chem. Phys. 132, 121102-1-4.

Karki B.B. and Stixrude L., 2010. First-principles study of enhancement of transport properties of silica melt by water. Phys. Rev. Lett. 104, 215901-1-4. structural and dynamical properties of simulated hydrous silicate melt. Phys. Chem. Minerals 37, 103117. 
1285 Kawamoto T. and Holloway J.R., 1997. Melting temperature and partial melt chemistry of $\mathrm{H}_{2} \mathrm{O}-$

1286 saturated mantle peridotite to 11 gigapascals. Science 276, 240-243.

1287

1288 Kawamoto T., 2006. Hydrous phases and water transport in the subducting slab. Rev. Mineral.

1289 Geochem. 62, 273-289.

Kawamoto T., Kanzaki M., Mibe K., Matsukage and Ono S., 2012. Separation of supercritical slabfluids to form aqueous fluid and melt components in subduction zone magmatism. P.N.A.S. 109, 18695-18700.

1294

1295

Kennedy G.C., Wasserberg G.J., Heard H.C. and Newton R.C., 1962. The upper three-phase region in the system $\mathrm{SiO}_{2}-\mathrm{H}_{2} \mathrm{O}$. Am. J. Sci. 260, 501-521.

Keppler H., 2003. Water solubility in carbonatite melts. Am. Mineral. 88, 1822-1824.

Khitarov N.I., Lebedev E.B., Rengarten E.V and Arsenieva R.V., 1959. Comparative characteristics of the solubility of water in basaltic and granitic melts. Geokhimiya 5, 479-492.

Khitarov N.I., Lebedev Y.B., Dorfman A.M. and Slutsky A.B., 1978. Viscosity of dry and waterbearing basalt melts under pressure. Geokhimya, 900-905.

Khitarov N.I., Lebedev Y.B., Dorfman A.M. and Bagdassarov N.S., 1979. Effects of temperature, pressure, and volatiles on the surface tension of molten basalt. Geochem. Int. 16, 78-86.

Kohn S.C., Dupree R. and Smith M.E., 1989. Proton environments and hydrogen-bonding in hydrous silicate glasses from proton NMR. Nature 337, 539-541.

Kohn S.C., 2000. The dissolution mechanisms of water in silicate melts; a synthesis of recent data. Mineral. Mag. 64, 389-408.

Korenaga J., 2010. On the likelihood of plate tectonics on Super-Earths:does size matter? Astrophys. for water under extreme thermodynamic conditions. J. Chem. Theory Comp. 13, 135-146. 
1321 Kumagai N., Kawamura K. and Yokokawa T., 1994. An interatomic potential model for $\mathrm{H}_{2} \mathrm{O}$ :

1322 Applications to water and ice polymorphs. Mol. Sim. 12, 177-186.

1323

1324 Laumonier M., Gaillard F. and Sifré D., 2015. The effect of pressure and water concentration on the 1325 electrical conductivity of dacitic melts: Implication for magnetotelluric imaging in subduction areas. Chem. Geol. 418, 66-76.

Laumonier M., Gaillard F., Muir D., Blundy J. and Unsworth M., 2017. Giant magmatic water reservoirs at mid-crustal depth inferred from electrical conductivity and the growth of the continental crust. Earth Planet. Sci. Lett. 457, 173-180.

Le Losq C., Moretti R. and Neuville D.R., 2013. Speciation and amphoteric behavior of water in aluminosilicate melts and glasses: high-temperature Raman spectroscopy and reaction equilibria. Eur. J. Mineral. 25, 777-790.

Le Losq C., Cody G.D. and Mysen B.O., 2015a. Alkali influence on the water speciation and the environment of protons in silicate glasses revealed by ${ }^{1} \mathrm{H}$ MAS NMR spectroscopy. Am. Mineral. 100, 466-473.

Le Losq C., Mysen B.O. and Cody G.D., 2015b. Water and Magmas: insights about the water solution mechanisms in alkali silicate melts from infrared, Raman, and 29Si solid-state NMR spectroscopies. Prog. in Earth and Planet. Sci. 2, 22-1-16.

Le Losq C., Dalou C. and Mysen B.O., 2017. In situ study at high pressure and temperature of the environment of water in hydrous $\mathrm{Na}$ and $\mathrm{Ca}$ aluminosilicate melts and coexisting fluids. J. Geophys. Res. Solid Earth 122, 4888-4899.

Lemberg H.L. and Stillinger F.H., 1975. Central-force model for liquid water. J. Chem. Phys. 62, 1677-1690.

Lesne P., Scaillet B., Pichavant M., Iacono-Marziano G. and Beny J.-M., 2011. The $\mathrm{H}_{2} \mathrm{O}$ solubility of alkali basaltic melt: an experimental study. Contrib. Mineral. Petrol. 162, 133-151.

Liebsher A., 2010. Aqueous fluids at elevated pressure and temperature. Geofluids 10, 3-19. 
Liu Y., Zhang Y. and Behrens H., 2004. $\mathrm{H}_{2} \mathrm{O}$ diffusion in dacitic melts. Chem. Geol. 209, 327-340.

McMillan P.F. and Remmelé R.L., 1986. Hydroxyl sites in $\mathrm{SiO}_{2}$ glass: A note on infrared and Raman spectra. Am. Mineral. 71, 772-778.

McMillan P.F. and Holloway J.R., 1987. Water solubility in aluminosilicate melts. Contrib. Mineral. Petrol. 97, 320-332.

Malfait W.J. and Xue X., 2010. The nature of hydroxyl groups in aluminosilicate glasses: Quantifying

$\mathrm{Si}-\mathrm{OH}$ and $\mathrm{Al}-\mathrm{OH}$ abundances along the $\mathrm{SiO}_{2}-\mathrm{NaAlSiO}_{4}$ join by ${ }^{1} \mathrm{H},{ }^{27} \mathrm{Al}-{ }^{1} \mathrm{H}$ and ${ }^{29} \mathrm{Si}-{ }^{1} \mathrm{H} \mathrm{NMR}$ spectroscopy. Geochim. Cosmochim. Acta 74, 719-737.

Malfait W.J., 2014. The nearly complete dissociation of water in glasses with strong aluminum avoidance. Am. Mineral. 99, 1648-1652.

Malfait W.J. and Xue X., 2014. Hydroxyl speciation in felsic magmas. Geochim. Cosmochim. Acta $140,606-620$.

Malfait W.J., Seifert R., Petitgirard S., Perrillat J.-Ph., Mezouar M., Ota T., Nakamura E., Lerch Ph. And Sanchez-Valle C., 2014a. Supervolcano eruptions driven by melt buoyancy in large silicic magma chambers. Nature Geoscience 7, 122-125.

Malfait W.J., Seifert R., Petitgirard S., Mezouar M. and Sanchez-Valle C., 2014b. The density of andesitic melts and the compressibility of dissolved water in silicate melts at crustal and upper mantle conditions. Earth Planet. Sci. Lett. 393, 31-38.

Mangan M. and Sisson Th., 2005. Evolution of melt-vapor surface tension in silicic volcanic systems: Experiments with hydrous melts. J. Geophys. Res. 110, B01202-1-9.

Manning C.E., 2004. The chemistry of subduction-zone fluids. Earth Planet. Sci. Lett. 223, 1-16.

Matsukage K.N., Jing Z. and Karato S.-I., 2005. Density of hydrous silicate melt at the conditions of Earth's deep upper mantle. Nature 438, 488-491. 
Mibe K., Kanzaki M., Kawamoto T., Matsukage K.N., Fei Y. and Ono S., 2007. Second critical endpoint in the peridotite- $\mathrm{H}_{2} \mathrm{O}$ system. J. Geophys. Res. 112, B03201-1-8.

Mibe K., Kawamoto T., Matsukage K.N., Fei Y. and Ono S., 2011. Slab melting versus slab dehydration in subduction-zone magmatism. P.N.A.S. 108, 8177-8182.

Misiti V., Vetere F., Freda C., Scarlato P., Behrens H., Mangiacapra A. and Dingwell D.B., 2011. A general viscosity model of Campi Flegrei (Italy) melts. Chem. Geol. 290, 50-59.

1404

Mitchell A.L., Gaetani G.A., O'Leary J.A. and Hauri E.H., 2017. $\mathrm{H}_{2} \mathrm{O}$ solubility in basalt at upper mantle conditions. Contrib. Mineral. Petrol. 172, 85-1-16.

Mookherjee M., Stixrude L. and Karki B., 2008. Hydrous silicate melt at high pressure. Nature 452, 983-986.

Moore G., Vennemann T. and Carmichael I., 1998. An empirical model for the solubility of H2O in magmas to 3 kilobars. Am. Mineral. 83, 36-42. kimberlite melts. Chem. Geol. 418, 198-205.

Moussallam Y., Morizet Y. and Gaillard F., 2016. $\mathrm{H}_{2} \mathrm{O}-\mathrm{CO}_{2}$ solubility in low $\mathrm{SiO}_{2}$-melts and the unique mode of kimberlite degassing and emplacement. Earth Planet. Sci. Lett. 447, 151-160. silicate melts at high pressures and temperatures: a Raman spectroscopic study. Am. Mineral. 65, 690710.

Mysen B.O. and Virgo D., 1986. Volatiles in silicate melts at high pressure and temperature 1. In teraction between $\mathrm{OH}$ groups and $\mathrm{Si}^{4+}, \mathrm{Al}^{3+}, \mathrm{Ca}^{2+}, \mathrm{Na}^{+}$and $\mathrm{H}^{+}$. Chem. Geol. 57, 303-331.

Mysen B.O. and Acton M., 1999. Water in H2O-saturated magma-fluid systems: Solubility behavior in $\mathrm{K}_{2} \mathrm{O}-\mathrm{Al}_{2} \mathrm{O}_{3}-\mathrm{SiO}_{2}-\mathrm{H}_{2} \mathrm{O}$ to $2.0 \mathrm{GPa}$ and $1300^{\circ} \mathrm{C}$. Geochim. Cosmochim. Acta 63, 3799-3815. 
1433 Mysen B., 2002. Water in peralkaline aluminosilicate melts to $2 \mathrm{GPa}$ and $1400^{\circ} \mathrm{C}$. Geochim.

1434 Cosmochim. Acta 66, 2915-2928.

1436 Mysen B.O. and Cody G.D., 2004. Solubility and solution mechanism of $\mathrm{H}_{2} \mathrm{O}$ in alkali silicate melts and glasses at high pressure and temperature. Geochim. Cosmochim. Acta 68, 5113-5126.

Mysen B.O. and Cody G., 2005. Solution mechanisms of $\mathrm{H}_{2} \mathrm{O}$ in depolymerized peralkaline melts. Geochim. Cosmochim. Acta 69, 5557-5566.

Mysen B., 2010. Structure of $\mathrm{H}_{2} \mathrm{O}$-saturated peralkaline aluminosilicate melt and coexisting 1443 aluminosilicate-saturated aqueous fluid determined in-situ to $800{ }^{\circ} \mathrm{C}$ and $\sim 800 \mathrm{MPa}$. Geochim. 1444 Cosmochim. Acta 74, 4123-4139.

Newton R.C. and Manning C.E., 2008. Thermodynamics of $\mathrm{SiO}_{2}-\mathrm{H}_{2} \mathrm{O}$ fluid near the upper critical end point from quartz solubility measurements at 10 kbar. Earth Planet. Sci. Lett. 274, 241-249.

Ni H., Keppler H. and Behrens H., 2011. Electrical conductivity of hydrous basaltic melts: implications for partial melting in the upper mantle. Contrib. Mineral. Petrol. 162, 637-650.

Ni H., Xu Z. and Zhang Y., 2013. Hydroxyl and molecular $\mathrm{H}_{2} \mathrm{O}$ diffusivity in a haploandesitic melt. Geochim. Cosmochim. Acta 103, 36-48.

Ni H., Zhang L., Xiong X., Mao Z. and Wang J., 2017. Supercritical fluids at subduction zones: Evidence, formation condition, and physicochemical properties. Earth-Science Rev. 167, 62-71.

Ni H. and Zhang L., 2018. A general model of water diffusivity in calc-alkaline silicate melts and glasses. Chem. Geol. 478, 60-68.

1461 Nixon P.H., Boyd F.R., 1973. Petrogenesis of the granular and sheared ultramafic nodule suite. In: Kimberlites, Nixon P.H. (Ed.). Lesotho National Development. Maseru, 48-56. 
1468 Nowak M. and Behrens H., 1995. The speciation of water in haplogranitic glasses and melts

1469 determined by in situ near-infrared spectroscopy. Geochim. Cosmochim. Acta 59, 3445-3550.

1470

1471 Nowak M. and Behrens H., 1997. An experimental investigation on diffusion of water in haplogranitic melts. Contrib. Mineral. Petrol. 126, 365-376.

Nowak M. and Behrens H., 2001. Water in rhyolitic magmas: getting a grip on a slippery problem. Earth Planet. Sci. Lett. 184, 515-522.

1476

O’Brien D.P., Izidoro A., Jacobson S.A., Raymond S.N. and Rubie D.C., 2018. The delivery of water during terrestrial planet formation. Space Sci. Rev. 214, 47-1-24.

Ochs A. and Lange R.A., 1999. The density of hydrous magmatic liquids. Science 283, 1314-1317.

Olhorst S., Behrens H. and Holtz F., 2001. Compositional dependence of molar absorptivities of nearinfrared $\mathrm{OH}^{-}$and $\mathrm{H}_{2} \mathrm{O}$ bands in rhyolitic to basaltic glasses. Chem. Geol. 174, 5-20.

Paillat O., Elphik S.C. and Brown W.L., 1992. The solubility of water in $\mathrm{NaAlSi}_{3} \mathrm{O}_{8}$ melts: a reexamination of $\mathrm{Ab}-\mathrm{H}_{2} \mathrm{O}$ phase relationships and critical behavior at high pressures. Contrib. Mineral. Petrol. 112, 490-500.

Pan D., Spanu L., Harrison B., Sverjensky D.A. and Galli G., 2013. Dielectric properties of water under extreme conditions and transport of carbonates in the deep Earth. P.N.A.S. 110, 6646-6650.

Parman S.W. and Grove T.L., 2004. Hartzburgite melting with and without $\mathrm{H}_{2} \mathrm{O}$ : Experimental data and predictive modeling. J. Geophys. Res. 109, B02201-1-20.

Persikov E.S., Zharikov V.A. and Bukhtiyarov P.G., 1990. The effect of volatiles on the properties of magmatic melts. Europ. J. Mineral. 2, 621-642.

Persikov E.S., Newman S., Bukhtiyarov, Nekrasov A.N. and Stolper E.M., 2010. Experimental study of water diffusion in haplobasaltic and haploandesitic melts. Chem. Geol. 276, 241-256. melts at high pressures. Russian Geol. and Geophys. 58, 1093-1100. 
1504 Peslier A.H., Schönbächler M., Busemann H. and Karato S.-I., 2017. Water in the Earth's interior:

1505 distribution and origin. Space Sci. Rev. 212, 743-810.

1507 Pinilla C., Irani A.H., Seriani N. and Scandolo S., 2012. Ab initio parametrization of an all-atom polarizable and dissociable force field for water. J. Chem. Phys. 136, 114511

Pöhlmann M., Benoit M. and Kob W., 2004. First-principles molecular-dynamics simulations of a hydrous silica melt: Structural properties and hydrogen diffusion mechanism. Phys. Rev. B 70, 184209-1-14.

1513

Poli S. and Schmidt M.W., 2002. Petrology of subducted plates. Ann. Rev. Earth Planet. Sci. 30, $207-$ 235.

Pommier A., Gaillard F., Pichavant M. and Scaillet B., 2008. Laboratory measurements of electrical conductivities of hydrous and dry Mount Vesuvius melts under pressure. J. Geophys. Res. 113, B05205-1-16.

Reynolds J.R., Langmuir C.H., 1997. Petrological systematics of the Mid-Atlantic Ridge south of Kane: Implications for ocean crust formation. J. Geophys. Res. 102, 14915-14946.

Richet P., Lejeune A.-M., Holtz F. and Roux J., 1996. Water and the viscosity of andesite melts. Chem. Geol. 128, 185-197.

Richet P., Whittington A., Holtz F., Behrens H., Ohlhorst S. and Wilke M., 2000. Water and the density of silicate glasses. Contrib. Mineral. Petrol. 138, 337-347.

Robert G., Whittington A.G., Stechern A. and Behrens H., 2013. The effect of water on the viscosity of a synthetic calc-alkaline basaltic andesite. Chem. Geol. 346, 135-148.

Robinson G.W., Zhu S.-B., Singh S. and Evans M.W., 1996. Water in biology, chemistry and physics: Experimental overviews and computational methodologies. World scientific series in contemporary chemical physics vol.9, World Scientific Pub. (Singapore). water in $\mathrm{NaAlSi}_{3} \mathrm{O}_{8}$ melts: an application of fictive temperatures derived from synthetic fluidinclusions. Contrib. Mineral. Petrol. 122, 1-10. 
1541 Romano C., Giordano D., Papale P., Mincione V., Dingwell D.B. and Rosi M., 2003. The dry and

1542 hydrous viscosities of alkaline melts from Vesuvius and Phlegrean Fields. Chem. Geol. 202, 23-38.

1543

1544 Sakamaki T., Suzuki A. and Ohtani E., 2006. Stability of hydrous melt at the base of the Earth's upper 1545 mantle. Nature 439, 192-194.

Sakamaki T., Ohtani E., Urakawa S., Suzuki A. and Katayama Y., 2009. Measurement of hydrous peridotite magma density at high pressure using the X-ray absorption method. Earth Planet. Sci. Lett. 287, 293-297.

Sakamaki T., 2017. Density of hydrous magma. Chem. Geol. 475, 135-139.

Sanchez-Valle C., Mantegazzi D., Bass J.D. and Reusser E., 2013. Equation of state, refractive index and polarizability of compressed water to $7 \mathrm{GPa}$ and 673K. J. Chem. Phys. 138, 054505-1-9.

Schmidt B.C. and Behrens H., 2008. Water solubility in phonolite melt: influence of melt composition and temperature. Chem. Geol. 256, 259-268. viscosity of a haplogranitic melt. Am. Mineral. 81, 1155-1165.

Seifert R., Malfait W.J., Petitgirard S. and Sanchez-Valle C., 2013. Density of phonolitic magmas and time scales of crystal fractionation in magma chambers. Earth Planet. Sci. Lett. 381, 12-20.

Shaw H.R., 1963. Obsidian $-\mathrm{H}_{2} \mathrm{O}$ viscosities at 1000 and 2000 bars in the temperature range $700^{\circ}$ to $900^{\circ}$ C. J. Geophys. Res. 68, 6337-6343.

Shen A. and Keppler H., 1995. Infrared spectroscopy of hydrous silicate melts to $1000^{\circ} \mathrm{C}$ and $10 \mathrm{kbar}$ : Direct observation of $\mathrm{H}_{2} \mathrm{O}$ speciation in a diamond-anvil cell. Am. Mineral. 80, 1335-1338.

Shen A. H. and Keppler H., 1997. Direct observation of complete miscibility in the albite- $\mathrm{H}_{2} \mathrm{O}$ system. Nature 385, 710-712. and $\mathrm{CO}_{2}$ - bearing fluids in tholeiitic basalts at pressures up to $500 \mathrm{MPa}$. Chem. Geol. 277, 115-125. 
1577 Shishkina T.A., Botcharnikov R.E., Holtz F., Almeev R.R., Jazwa A.M. and Jakubiak A.A., 2014.

1578 Compositional and pressure effects on the solubility of $\mathrm{H}_{2} \mathrm{O}$ and $\mathrm{CO}_{2}$ in mafic melts. Chem. Geol. 388,

$1579 \quad 112-129$.

1580

1581 Silver L.A., Ihinger P.D. and Stolper E., 1990. The influence of bulk composition on the speciation of water in silicate glasses. Contrib. Mineral. Petrol. 104, 142-162.

Silvestrelli P.L. and Parrinello M., 1999. Water molecule dipole in the gas and in the liquid phase. Phys. Rev. Lett. 82, 3308-3311.

1586

Simakin A.G., Salova T.P. and Eremyashev V.E., 2010. Mechanism of water solubility in silicate melts of the albite-nepheline system. Miner. Petrol. 99, 279-285.

Skinner L.B., Huang C., Schlesinger D., Pettersson L.G.M., Nilsson A. and Benmore C., 2013. Benchmark oxygen-oxygen pair-distribution function of ambient water from $\mathrm{x}$-ray diffraction measurements with a wide Q-range. J. Chem. Phys. 138, 074506-1-12.

Soper A. and Benmore C.J. (2008). Quantum differences between heavy and light water. Phys. Rev. Lett. 101, 065502-1-4.

Sowerby J.R. and Keppler H., 1999. Water speciation in rhyolitic melt determined by in-situ infrared spectroscopy. Am. Mineral. 84, 1843-1849.

Sparks R.S.J., 1978. The dynamics of bubble formation and growth in magmas: A review and analysis. J. Volcanol. Geotherm. Res. 3, 1-37.

Stillinger F.H. and David C.W., 1978. Polarization model for water and its ionic dissociation products.

Stillinger F.H. and Rahman A., 1978. Revised central force potentials for water. J. Chem. Phys. 68, 666-670.

Stolper E., 1982. Water in silicate glasses: An infrared spectroscopic study. Contrib. Mineral. Petrol. $81,1-17$.

1612 Stolper E., 1989. Temperature dependence of the speciation of water in rhyolitic melts and glasses. 
1615 Strässle Th., Saitta A.M., Le Godec Y., Hamel G., Klotz S., Loveday J.S. and Nelmes R.J., 2006.

1616 Structure of dense liquid water by neutron scattering to $6.5 \mathrm{GPa}$ and $670 \mathrm{~K}$. Phys. Rev. Lett. 96,

1617 067801-1-4.

1618

1619

1620

Stubbs J.M., 2016. Molecular simulations of supercritical fluid systems. J. of Supercritical Fluids 108, 104-122.

Tamic N., Behrens H. and Holtz F., 2001. The solubility of $\mathrm{H}_{2} \mathrm{O}$ and $\mathrm{CO}_{2}$ in rhyolitic melts in equilibrium with a mixed $\mathrm{CO}_{2}-\mathrm{H}_{2} \mathrm{O}$ fluid phase. Chem. Geol. 174, 333-347.

Tenner T.J., Hirschmann M.M. and Humayun M., 2012. The effect of H2O on partial melting of garnet peridotite at 3.5 GPa. Geochem. Geophys. Geosyst. 13, 1-28.

Tikoo S.M. and Elkins-Tanton L.T., 2017. The fate of water within Earth and super-Earths and implications for plate tectonics. Phil. Trans. R. Soc. A 375, 20150394-1-17.

Vega C. and Abascal J.L., 2011. Simulating water with rigid non-polarizable models: a general perspective. Phys. Chem. Chem. Phys. 13, 19663-19688. viscosity of shoshonitic melts (Vulcanello Peninsula, Aeolian Islands, Italy): Insight on the magma ascent in dikes. Chem. Geol. 245, 89-102.

Vetere F., Behrens H., Schuessler J.A., Holtz F., Misiti V. and Borchers L., 2008. Viscosity of andesite melts and its implication for magma mixing prior to Unzen 1991-1995 eruption. J. Volc. Geoth. Res. 175, 208-217.

Vetere F., Holtz F., Behrens H., Botcharnikov R.E. and Fanara S., 2014. The effect of alkalis and polymerization on the solubility of $\mathrm{H} 2 \mathrm{O}$ and $\mathrm{CO} 2$ in alkali-rich silicate melts. Contrib. Mineral. Petrol. Vuilleumier R., 2014. Atomic partial charges in condensed phase from an exact sum rule for infrared spectroscopy. Mol. Phys. 112, 1457-1462.

1649 Walker D. and Mullins O. Jr., 1981. Surface tension of natural silicate melts from $1,200^{\circ}-1,500^{\circ} \mathrm{C}$ and implications for melt structure. Contrib. Mineral. Petrol. 76, 455-462. 
1652 Whittington A.G., Bouhifd M. Ali and Richet P., 2009. The viscosity of hydrous $\mathrm{NaAlSi}_{3} \mathrm{O}_{8}$ and 1653 granitic melts: Configurational entropy models. Am. Mineral. 94, 1-16.

1654

Willow S.Y., Salim M.A., Kim K.S. and Hirata S., 2015. Ab initio molecular dynamics of liquid water using embedded-fragment second-order many-body perturbation theory towards its accurate property prediction. Scientific Reports 5, 14358-1-14.

Withers A.C., Kohn S.C., Brooker R.A. and Wood B.J., 2000. A new method for determining the P-VT properties of high-density $\mathrm{H}_{2} \mathrm{O}$ using NMR: Results at 1.4-4.0 $\mathrm{GPa}$ and $700-11^{\circ} \mathrm{C}$. Geochim. Cosmochim. Acta 64, 1051-1057.

Wu Y., Tepper H.L. and Voth G.A., 2006. Flexible simple point-charge water model with improved liquid-state properties. J. Chem. Phys. 124, 024503-1-12.

Xia Q.-K., Bi Y., Li P., Tian W. and Chen H.-L., 2016. High water content in primitive continental flood basalts. Sci. Rep. 6, 25416-1-6.

Xue X. and Kanzaki M., 2004. Dissolution mechanisms of water in depolymerized silicate melts: Constraints from ${ }^{1} \mathrm{H}$ and ${ }^{29} \mathrm{Si}$ NMR spectroscopy and ab initio calculations. Geochimica et Cosmochimica Acta 68, 5027-5057.

Xue X. and Kanzaki M., 2006. Depolymerization effect of water in aluminosilicate glasses: Direct evidence from ${ }^{1} \mathrm{H}^{-27} \mathrm{Al}$ heteronuclear correlation NMR. Am. Mineral. 91, 1922-1926.

Xue X. and Kanzaki M., 2007. Al coordination and water speciation in hydrous aluminosilicate Nucl. Magn. Reson. 31, 10-27.

Xue X. and Kanzaki M., 2008. Structure of hydrous of aluminous silicate glasses along the diopsideanorthite join: A comprehensive one- and two-dimensional ${ }^{1} \mathrm{H}$ and ${ }^{27} \mathrm{Al}$ NMR study. Geochim. Cosmochim. Acta 72, 2331-2348. dynamics in hydrous silicate melts as seen by quasielastic neutron scattering at elevated temperature and pressure. Chem. Geol. 461, 152-159. 
1688 Zeng Q., Nekvasil H. and Grey C.P., 1999. In support of a depolymerization model for water in 1689 sodium aluminosilicate glasses: Information from NMR spectroscopy. Geochim. Cosmochim. Acta $1690 \quad 64,883-896$.

1691

Zhang Z. and Duan Z., 2005. Prediction of the PVT properties of water over wide range of temperatures and pressures from molecular dynamics simulation. Phys. Earth Planet. Int. 149, 335354.

Zhang Y., Jenkins J. and Xu Z., 1997. Kinetics of the reaction $\mathrm{H}_{2} \mathrm{O}+\mathrm{O} \leftrightarrow 2 \mathrm{OH}$ in rhyolitic glasses upon cooling: Geospeedometry and comparison with glass transition. Geochim. Cosmochim. Acta 61, 2167-2173.

1699

Zhang C., Spanu L. and Galli G., 2011. Entropy of liquid water from ab initio molecular dynamics. J. Phys. Chem. B 115, 14190-14195.

1702

1703

Zhang Y. and Ni H., 2010. Diffusion of H, C, and O components in silicate melts. Rev. Mineral. Geochem. 72, 171-225.

1705

1706

Zhang W. and van Duin A.C.T., 2017. Second-generation ReaxFF water force field: Improvements in the description of water density and OH-anion diffusion. J. Phys. Chem. B 121, 6021-6032.

1708

Zhang L., Guo X., Wang Q., Ding J. and Ni H., 2017. Diffusion of hydrous species in model basaltic melt. Geochim. Cosmochim. Acta 215, 377-386.

Zotov N. and Keppler H., 1998. The influence of water on the structure of hydrous sodium tetrasilicate glasses. Am. Mineral. 83, 823-834.

1714

1715

1716 
Table 1

1758

Potential parameters for water (see Eqs. 2-6 in the text). Notice that the effective charge of the oxygen 1759 atom is $-0.945 \mathrm{e}$ and the one of the hydrogen atom is $+0.4725 \mathrm{e}$.

\begin{tabular}{|c|c|c|c|c|c|c|c|}
\hline 2-body interaction & $i$ & $E_{i}(\mathrm{~kJ} / \mathrm{mol})$ & $l_{i}(\mathrm{~A})$ & $\sigma_{i}(\mathrm{~A})$ & $\mathrm{B}_{i}(\mathrm{~kJ} / \mathrm{mol})$ & $\rho_{i}(\mathrm{~A})$ & $\mathrm{C}_{i}\left(\mathrm{~A}^{6} \mathrm{~kJ} / \mathrm{mol}\right)$ \\
\hline $\mathrm{O}-\mathrm{O}$ & $O O$ & & & & 153000.0 & 0.325 & 5259.83 \\
\hline $\begin{array}{l}\mathrm{O}-\mathrm{H} \\
\mathrm{O}-\mathrm{H} \\
\mathrm{O}-\mathrm{H} \\
\mathrm{O}-\mathrm{H}\end{array}$ & $\begin{array}{l}O H \\
b \\
w \\
h b\end{array}$ & $\begin{array}{r}100.0 \\
60.0 \\
5.45\end{array}$ & $\begin{array}{l}1.23 \\
1.18 \\
2.0\end{array}$ & $\begin{array}{l}0.07 \\
0.07 \\
0.45168\end{array}$ & 500995.36 & 0.1107 & \\
\hline $\mathrm{H}-\mathrm{H}$ & $H H$ & 30.0 & 1.625 & 0.1 & & & \\
\hline
\end{tabular}


1785

1786

1787

1788

1789

1790

1791

1792

1793

1794

1795

1796

1797

1798

1799

1800

1801

1802

1803

1804

1805

1806

1807

1808

1809

1810

1811

1812

1813

1814

1815

1816

1817

1818

1819

1820

1821

1822

1823

1824

1825

1826

1827

1828

1829

1830

1831

1832

1833

1834

1835

1836

1837

1838

\section{Table 2}

Potential parameters for cation-hydrogen interaction (see Eq.(8) in the text).

\begin{tabular}{ccccc}
\hline $\mathrm{X}$ & $\alpha_{H X}$ & $B_{O X}(\mathrm{~kJ} / \mathrm{mol})$ & $l_{H X}(\mathrm{~A})$ & $\lambda(\mathrm{A})$ \\
\hline $\mathrm{Si}$ & 0.25 & 50.00 & 2.56 & 0.1414 \\
$\mathrm{Ti}$ & 0.25 & 32.20 & 2.81 & 0.1414 \\
$\mathrm{Al}$ & 0.25 & 39.30 & 2.62 & 0.1414 \\
$\mathrm{Fe}^{3+}$ & 0.25 & 40.65 & 2.68 & 0.1414 \\
$\mathrm{Fe}^{2+}$ & 0 & 30.20 & 2.59 & 0.1414 \\
$\mathrm{Mg}$ & 0 & 28.40 & 2.63 & 0.1414 \\
$\mathrm{Ca}$ & 0 & 18.60 & 2.77 & 0.1414 \\
$\mathrm{Na}$ & 0 & 7.80 & 2.70 & 0.1414 \\
$\mathrm{~K}$ & 0 & 5.65 & 2.97 & 0.1414
\end{tabular}


1839

1840

1841

1842

1843

1844

1845 
1846

1847

1848

1849

1850

1851

1852

1853

1854

1855

1856

1857

1858

1859

1860

1861

1862

1863

1864

1865

1866

1867

1868

1869

1870

1871

1872

1873

1874

1875

1876

1877

\section{Table 3}

Chemical composition (in wt \%) of the simulated silicate melts. The number of cations of each species used in the simulation is indicated in parenthesis (for a total number of simulated atoms equal to $\sim 2,000$ ).

\begin{tabular}{|c|c|c|c|c|c|c|c|c|c|}
\hline Silicate & $\mathrm{SiO}_{2}$ & $\mathrm{TiO}_{2}$ & $\mathrm{Al}_{2} \mathrm{O}_{3}$ & $\mathrm{Fe}_{2} \mathrm{O}_{3}$ & $\mathrm{FeO}$ & $\mathrm{MgO}$ & $\mathrm{CaO}$ & $\mathrm{Na}_{2} \mathrm{O}$ & $\mathrm{K}_{2} \mathrm{O}$ \\
\hline Rhyolite & $83.09(556)$ & & 11.67(92) & & & & & $5.24(68)$ & \\
\hline Andesite & $56.91(406)$ & $0.93(5)$ & $17.48(147)$ & $4.66(25)$ & $3.52(21)$ & $4.33(46)$ & $7.46(57)$ & $3.18(44)$ & $1.54(14)$ \\
\hline MORB & $50.80(370)$ & $1.46(8)$ & $15.14(130)$ & $1.09(6)$ & $8.54(52)$ & $7.74(84)$ & $12.04(94)$ & $2.97(42)$ & $0.22(2)$ \\
\hline Peridotite & 44.97(319) & & $2.87(24)$ & & $10.45(62)$ & $38.29(405)$ & $3.42(26)$ & & \\
\hline Kimberlite & $25.07(202)$ & $0.33(2)$ & $5.79(55)$ & & $1.3(9)$ & $10.41(125)$ & $53.28(460)$ & $0.38(6)$ & $3.40(35)$ \\
\hline
\end{tabular}


1878

1879

1880 Parameters of the Birch-Murnhagan equation of state for the hydrous simulated melts.

1881

1882

1883

1884

1885

1886

1887

1888

1889

1890

1891

1892

1893

1894
1895

1896

1897

1898

1899

1900

1901

1902

1903

1904

1905

1906

1907

1908

\begin{tabular}{|c|c|c|c|c|c|}
\hline Melt & $w_{\mathrm{H}_{2} \mathrm{O}}(w t \%)$ & $\mathrm{T}_{0}(\mathrm{~K})$ & $n_{0}\left(\mathrm{~g} / \mathrm{cm}^{-3}\right)$ & $K_{T_{0}}(\mathrm{GPa})$ & $\mathrm{K}^{\prime}$ \\
\hline \multirow{3}{*}{ Rhyolite } & 1 & 2273 & 1.96 & 9.1 & 6.8 \\
\hline & 4 & 2273 & 1.85 & 8.0 & 6.8 \\
\hline & 8 & 2273 & 1.68 & 5.7 & 7.1 \\
\hline \multirow{3}{*}{ Andesite } & 1 & 1673 & 2.45 & 17.4 & 5.8 \\
\hline & 4 & 1673 & 2.31 & 14.3 & 5.8 \\
\hline & 8 & 1673 & 2.12 & 12.0 & 5.8 \\
\hline \multirow{3}{*}{ MORB } & 1 & 1673 & 2.60 & 20.8 & 5.2 \\
\hline & 4 & 1673 & 2.45 & 18.5 & 5.2 \\
\hline & 8 & 1673 & 2.26 & 15.7 & 5.2 \\
\hline \multirow{3}{*}{ Peridotite } & 1 & 2273 & 2.58 & 17.2 & 5.8 \\
\hline & 4 & 2273 & 2.39 & 14.2 & 5.8 \\
\hline & 8 & 2273 & 2.16 & 10.8 & 5.8 \\
\hline \multirow{3}{*}{ Kimberlite } & 1 & 1673 & 3.08 & 32.9 & 4.7 \\
\hline & 4 & 1673 & 2.92 & 28.6 & 5.2 \\
\hline & 8 & 1673 & 2.70 & 21.6 & 5.94 \\
\hline
\end{tabular}

Table 4 


\section{Figures}

Fig.1 Pair distribution functions for water. Black lines correspond to our results at ambient conditions, the blue lines are those at $673 \mathrm{~K}$ and $7 \mathrm{GPa}$, and the red lines are those at $1300 \mathrm{~K}$ and $10 \mathrm{GPa}$. Notice that in going from ambient water to the supercritical states $(\mathrm{T}>647 \mathrm{~K}$ ), the peak of second neighbors in $\mathrm{g}_{\mathrm{OO}}(\mathrm{r})$ shifts from 4.5 to $5.5 \mathrm{~A}$ and the first peak on $\mathrm{g}_{\mathrm{OH}}(\mathrm{r})$ associated with the hydrogen bond collapses, these features meaning that the hydrogen bond network vanishes in supercritical water. For comparison sake are also shown the PDFs obtained at ambient conditions with the SPCE model (dotted lines), the oxygen-oxygen PDF deduced by Skinner at al. (2013) from X-ray data (circles) and the oxygen-hydrogen and hydrogen-hydrogen PDFs deduced by Soper and Benmore (2008) from Xray and neutron scattering experiments (circles).

Fig.2 Pressure-density diagram for the water model of this study. Three isotherms are presented: 373, 673 and 1000 K. For comparison are shown the experimental data of Sanchez-Valle et al. (2013) along the isotherms 373 and $673 \mathrm{~K}$, those of Withers et al. (2000) for the isotherm $983 \mathrm{~K}$, the MD data at 673 and $973 \mathrm{~K}$ obtained by Zhang and Duan (2005) in using the SPCE model for water, and the ab initio results obtained by French et al. (2009) and Pan et al. (2013) at $1000 \mathrm{~K}$.

Fig.3 Ionic conductivity of water. The conductivity of our water model is calculated along the isochore $\mathrm{n}=1.5 \mathrm{~g} / \mathrm{cm} 3$ at 1073,1373 and $1873 \mathrm{~K}$, and is compared with the conductivity data of Hamann and Linton (1966) along a Hugoniot.

Fig.4 Concentration profile of protonated species in the simulation cell containing a hydrous MORB melt in coexistence with an aqueous phase at $1673 \mathrm{~K}$ and $0.5 \mathrm{GPa}$. Notice the excess of hydroxyl groups at the interfaces and the quasi absence of $\mathrm{H}_{3} \mathrm{O}^{+}$in the bulk melt.

Fig.5 Evolution with running time of the numbers of protonated species in the region of the simulation cell corresponding to the bulk of a saturated MORB melt at $1673 \mathrm{~K}$ and $1 \mathrm{GPa}$. Notice how flat is the total number of protonated species (this number leading to the $\mathrm{H}_{2} \mathrm{O}$ solubility), the dashed line indicating the stationary value.

Fig.6 Pressure evolution of the solubility of water in various silicate melts. The solubility is evaluated at $1673 \mathrm{~K}$ in andesitic, basaltic, peridotitic, and kimberlitic melts and at $2073 \mathrm{~K}$ in the rhyolitic melt. References of the experimental data are the following: kimberlite (Moussallam et al., 2016), MORB (Lesne et al., 2011), andesite (Botcharnikov et al., 2006), rhyolite (Yamashita, 1999; Tamic et al., 
2001), Ca-Mg-Na carbonatite (Keppler, 2003), and for NS4, NS4A3 and NS4A6 (Mysen and Wheeler, 2000). Notice that in the latter compositions (NS4, NS4A3 and NS4A6) the NBO/T ratio is about 0.5.

Fig.7 Phase coexistence between hydrous silicate melt and aqueous fluid in the $\left(\mathrm{P}, w_{\mathrm{H}_{2} \mathrm{O}}\right)$ representation. The phase coexistence is investigated along the isotherm $\mathrm{T}=1673 \mathrm{~K}$ for andesite, MORB, peridotite, and kimberlite, and along the isotherm $\mathrm{T}=2073 \mathrm{~K}$ for rhyolite. For comparison it is shown the water content of the two coexisting phases in the MORB- $\mathrm{H}_{2} \mathrm{O}$ system investigated by Mibe et al. (2011) at $1623 \mathrm{~K}$ and $2.8 \mathrm{GPa}$.

Fig.8 Pressure evolution of the concentrations in silicate elements of the aqueous phase in coexistence with a hydrous MORB melt at $1673 \mathrm{~K}$.

Fig.9 Pressure evolution of the surface tension of hydrous silicate melts. The surface tension is evaluated at $1673 \mathrm{~K}$ for the andesitic, basaltic, peridotitic, and kimberlitic melts, and at $2073 \mathrm{~K}$ for the rhyolitic melt. References of the experimental data are the following: for rhyolite (Bagdassarov et al., 2000), for basalt at $\mathrm{P}=0$ (Walker and Mullins, 1981) and at $\mathrm{P}>0$ (Khitarov et al., 1979), for phonotephrite/ basaltic andesite/ trachyte/ dacite/ rhyolite at 0.12 - 0.2 GPa and 1423-1473 K (Gardner et al., 2013).

Fig.10 Evolution of $\mathrm{H}_{2} \mathrm{O}$ and $\mathrm{OH}^{-}$concentrations in hydrous silicate melts as function of the total $\mathrm{H}_{2} \mathrm{O}$ content. Notice that the concentrations in the simulated melts were evaluated at $2073 \mathrm{~K}$ and $1 \mathrm{GPa}$ (2 GPa for MORB), when the data of Chertkova and Yamashita (2015) for $\mathrm{Na}_{2} \mathrm{Si}_{2} \mathrm{O}_{5}$ were obtained at $1173 \mathrm{~K}$ in the pressure range $0.2-1.5 \mathrm{GPa}$.

Fig.11 Effect of the temperature on the reaction constant in the different hydrous melts with 8 wt $\%$ $\mathrm{H}_{2} \mathrm{O}$. The three dashed curves correspond to high-temperature extrapolations of the experimental data obtained near the glass transition temperature.

Fig.12 Partial molar volume of water at $0.5 \mathrm{GPa}$ in hydrous silicate melts as function of temperature.

Data for andesitic melts (green bold line; Malfait et al., 2014) and for silicic melts (black bold line; Ochs and Lange, 1999) are given for comparison. From the simulation data, the thermal expansivity, $\frac{1}{V_{\mathrm{H}_{2} \mathrm{O}}}\left(\frac{\partial V_{\mathrm{H}_{2} \mathrm{O}}}{\partial T}\right)$, is equal to $3.910^{-4} \mathrm{~K}^{-1}$ in rhyolite $\left(4.110^{-4} \mathrm{~K}^{-1}\right.$ after Ochs and Lange, 1999), $2.910^{-4} \mathrm{~K}^{-1}$ in andesite $\left(2.710^{-4} \mathrm{~K}^{-1}\right.$ after Malfait et al., 2014b) and in MORB, and $2.210^{-4} \mathrm{~K}^{-1}$ in peridotite and kimberlite (these values correspond to the slope of the dotted curves). Furthermore, from the evolution of $V_{\mathrm{H}_{2} \mathrm{O}}$ with the pressure between 0.5 and $1 \mathrm{GPa}$ at a given temperature, one is leaded to a rough 
1982 estimate of the bulk modulus of water in the melt. Thus at $2073 \mathrm{~K}$ one obtains $K_{T}=5.1 \mathrm{GPa}$ in

1983 rhyolite, $4.2 \mathrm{GPa}$ in andesite, 8.5 GPa in MORB, 6.0 GPa in peridotite, and 1.9 GPa in kimberlite.

1985 Fig.13 Effect of water on the viscosity. The reported MD data are evaluated at $1673 \mathrm{~K}$ (except for rhyolite where $\mathrm{T}=2073 \mathrm{~K}$ ) and $0.5 \mathrm{GPa}$, whereas the experimental data for andesite and basalt are extrapolated up to $1673 \mathrm{~K}$ (or $2073 \mathrm{~K}$ for haplogranite) according to the equations provided by the corresponding studies (Eqs.(2), (6), (7), and (8) in Whittington et al., 2009; Eq.(4) in Vetere et al., 2008; Eq.(1) in Giordano and Dingwell, 2003). Notice that in the case of hydrous Etna basalt (Giordano and Dingwell, 2003) the experimental uncertainties at $1673 \mathrm{~K}$ are very large because the measurements were made at much lower temperatures, near the glass transition temperature, and hence the results are very uncertain. In the case of haplogranite, the model calculation of Whittington et al. (2009), based on a data compilation, leads to two sets of parameters corresponding to two different predictions (see the black dotted curves): our evaluation lies in between them.

Fig.14 Effect of water on the electrical conductivity. The reported MD data are evaluated at $1873 \mathrm{~K}$ and $0.5 \mathrm{GPa}$, whereas the experimental data for hydrous andesitic and haplobasaltic melts are extrapolated up to $1873 \mathrm{~K}$ according to the equations provided by the corresponding studies (Eqs(1), (2), (3), and (4) in Laumonier et al., 2017; Eq.(3) in Ni et al., 2011).

Fig.15 Self-diffusion coefficients of protonated species in hydrous melts as function of total water content. The self-diffusion coefficient of the silicate oxygen $\left(\mathrm{O}^{2-}\right)$ is also shown for comparison. The temperature of investigation is $1673 \mathrm{~K}$ for MORB, $1873 \mathrm{~K}$ for andesite, peridotite, and kimberlite, and $2273 \mathrm{~K}$ for rhyolite, the pressure being fixed to $0.5 \mathrm{GPa}$. The red curves are diffusion data of the literature for total water: Zhang and $\mathrm{Ni}$ (2010) for rhyolite (see the red dotted curve given by their Eq. (15) extrapolated to $2273 \mathrm{~K}$ ), Persikov et al. (2010) for a haplobasalt and a haploandesite at $1573 \mathrm{~K}$ (full red curves), and Zhang et al. (2017) for a haplobasalt at $1673 \mathrm{~K}$ (red dotted curve).

Fig.16 Distribution of cations around protonated species. The panels show the probability of occurrence (see text) that a protonated species is linked to a cation $\mathrm{X}$ in rhyolite (2073 $\mathrm{K}$ and $8 \mathrm{wt} \%$ $\left.\mathrm{H}_{2} \mathrm{O}\right)$, in andesite $\left(1873 \mathrm{~K}\right.$ and $\left.8 \mathrm{wt} \% \mathrm{H}_{2} \mathrm{O}\right)$, in MORB $\left(1873 \mathrm{~K}\right.$ and $\left.8 \mathrm{wt} \% \mathrm{H}_{2} \mathrm{O}\right)$, in peridotite $(1873 \mathrm{~K}$ and $\left.8 \mathrm{wt} \% \mathrm{H}_{2} \mathrm{O}\right)$, and in kimberlite $\left(1873 \mathrm{~K}\right.$ and $\left.8 \mathrm{wt} \% \mathrm{H}_{2} \mathrm{O}\right)$. The distribution of cations around $\mathrm{O}^{2-}$ is given for comparison. Notice that the $\mathrm{X}-\mathrm{O}_{\mathrm{p}}$ distances used for the above evaluations (see text) are the following: 1.625 (Si-O), 1.925 (Ti-O), 1.775 (Al-O), $1.875\left(\mathrm{Fe}^{3+}-\mathrm{O}\right), 2.025\left(\mathrm{Fe}^{2+}-\mathrm{O}\right), 2.025$ (Mg-O), 2.375 (Ca-O), $2.425(\mathrm{Na}-\mathrm{O})$, and $2.85 \mathrm{~A}(\mathrm{~K}-\mathrm{O})$. 
$2019 \mathrm{OH}^{-}$), panel (b) that between the oxygen of hydroxyl groups and the $\mathrm{H}$ atoms of protonated species,

2020 and panel (c) that between the oxygen of molecular water and the $\mathrm{H}$ atoms of protonated species. In 2021 each panel the main complexes responsible of the shape of the PDF in the range 0-4 A are presented. 2022 Thus in panel (a), $\mathrm{O}_{\text {sil }} \ldots \mathrm{H}^{1}$ hydrogen bond is responsible of the shoulder at about $2 \mathrm{~A}$, whereas the 2023 peak at $3.5 \mathrm{~A}$ is associated with the $\mathrm{O}_{\text {sil }} \ldots \mathrm{H}^{1}$ distance. In panel (b) the $\mathrm{O}^{1} \ldots \mathrm{H}^{2}$ and $\mathrm{H}^{1} \ldots \mathrm{O}^{2}$ hydrogen 2024 bonds produce the shoulder at 1.5-2 A whereas the broad peak at $3.5 \mathrm{~A}$ is induced by the $\mathrm{O}^{2} \ldots \mathrm{H}^{1}$, $2025 \mathrm{O}^{1} \ldots \mathrm{H}^{2}$, and $\mathrm{O}^{1} \ldots \mathrm{H}^{2}$ distances. Notice that the small peak at $2.6 \mathrm{~A}$ comes from the configurations 2026 where two $\mathrm{OH}$ groups are facing to each other (O-H....H-O). In panel (c) the hydrogen bonds between 2027 water molecules and between $\mathrm{OH}$ groups and water molecules are responsible of the shoulder in the 2 2028 A range and the broad peak at about 3-3.5 A is produced by the O---H distances not directly involved 2029 in the hydrogen bonds. Notice that in each panel the intense peak at $1.0 \mathrm{~A}$ is due to the O-H bonds of 2030 the protonated species.

2031

2032

2033

2034

2035

2036

2037

2038

2039

2040

2041

2042

2043

2044

2045

2046

2047

2048

2049

2050

2051

2052

2053

2054

2055 
2056

2057

2058

2059

2060
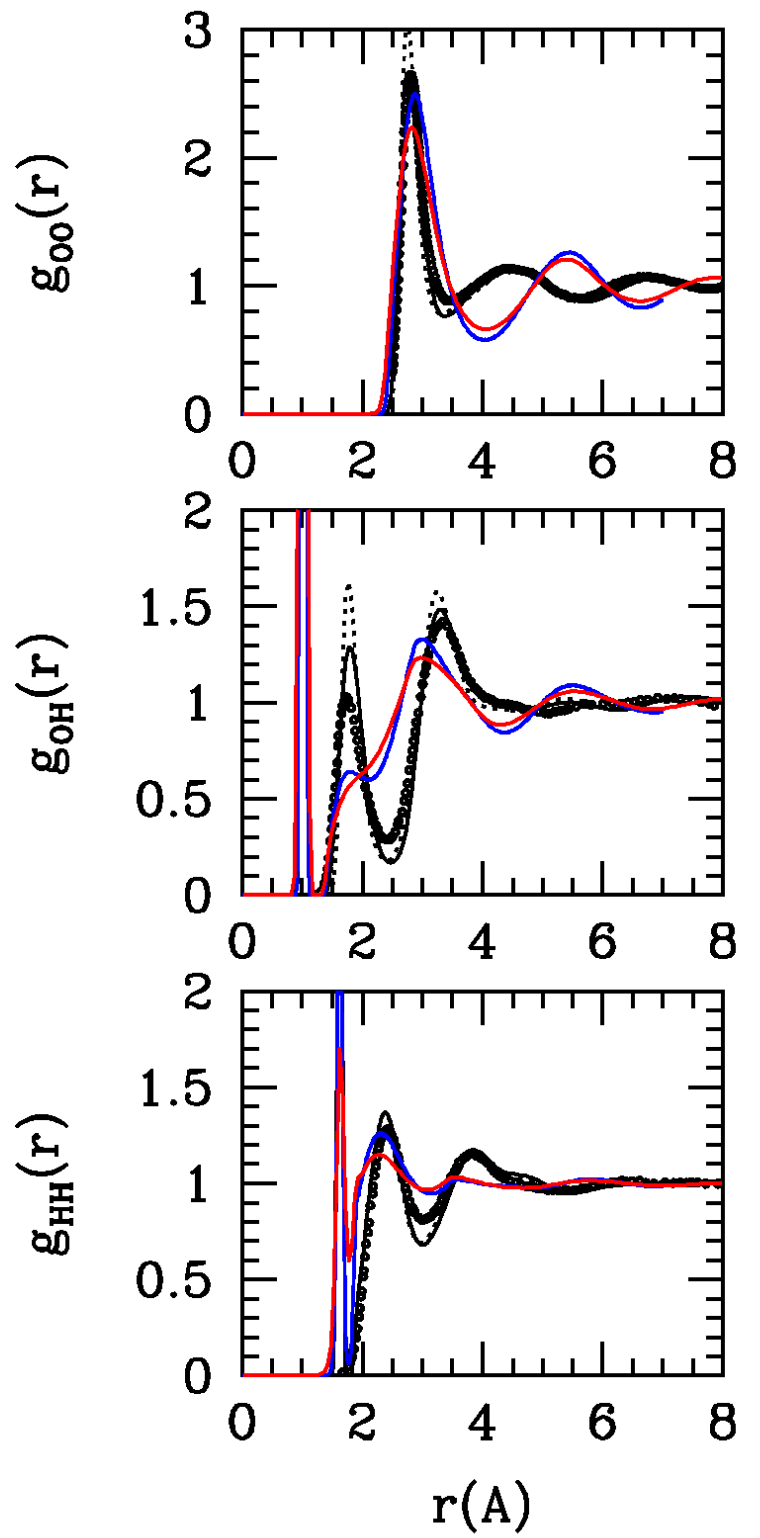

2061

2062

2063

Fig1

2064

2065

2066

2067

2068 
2069

2070

2071

2072

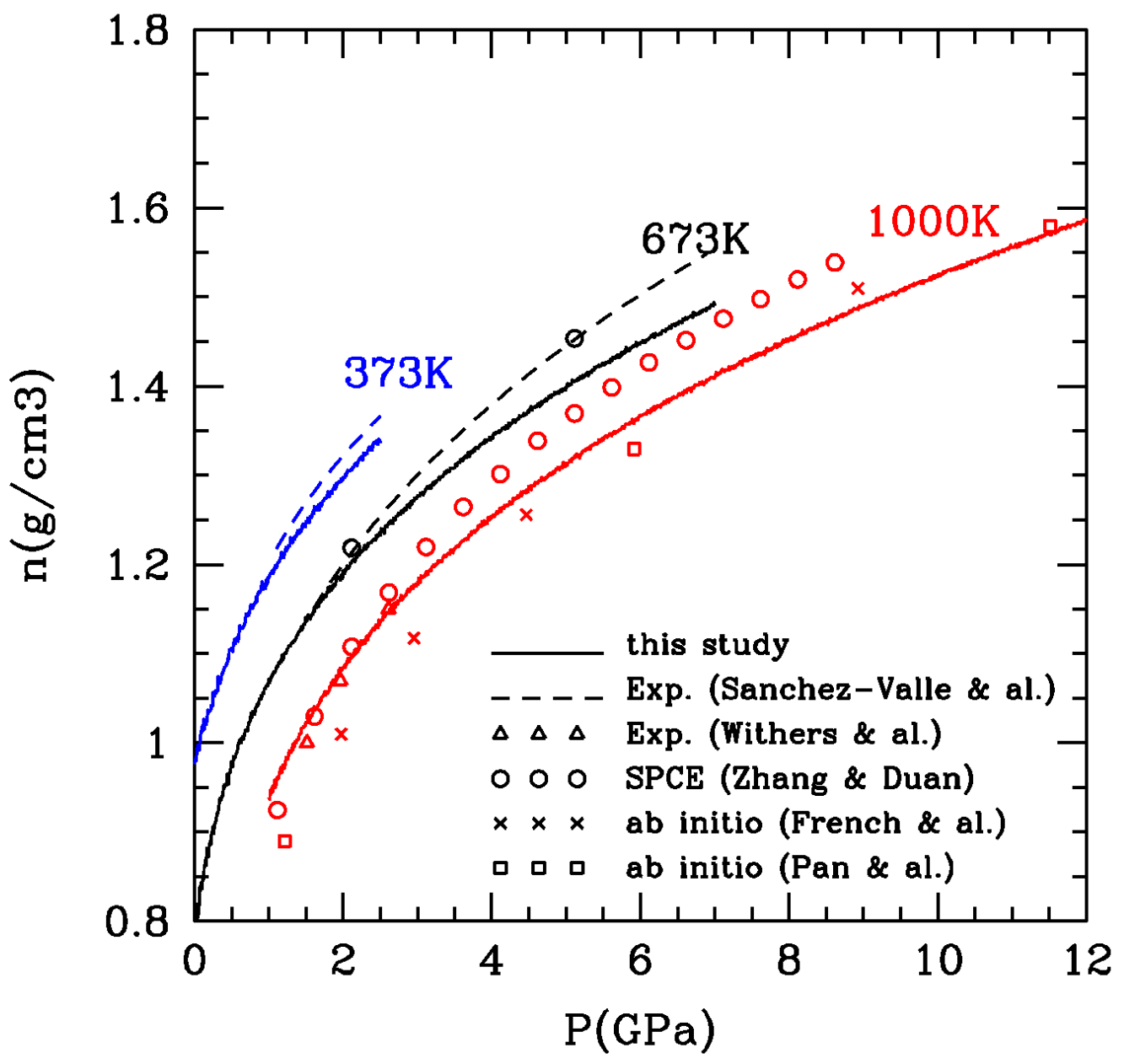

2073

2074

2075

2076

Fig.2

2077

2078

2079

2080

2081 
2082

2083

2084

2085

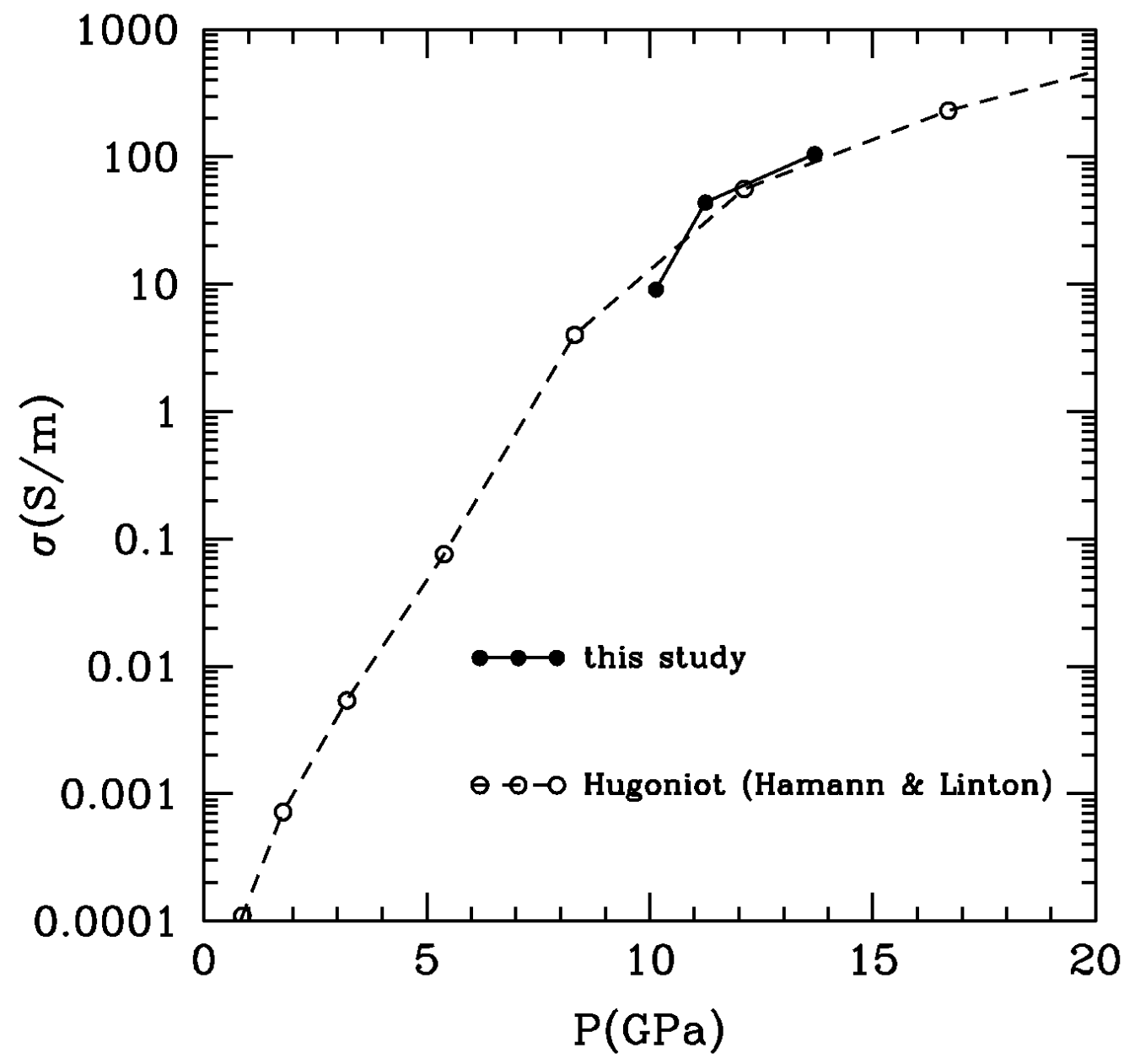

2086

2087

2088

Fig.3

2089

2090

2091

2092

2093

2094 
2095

2096

2097

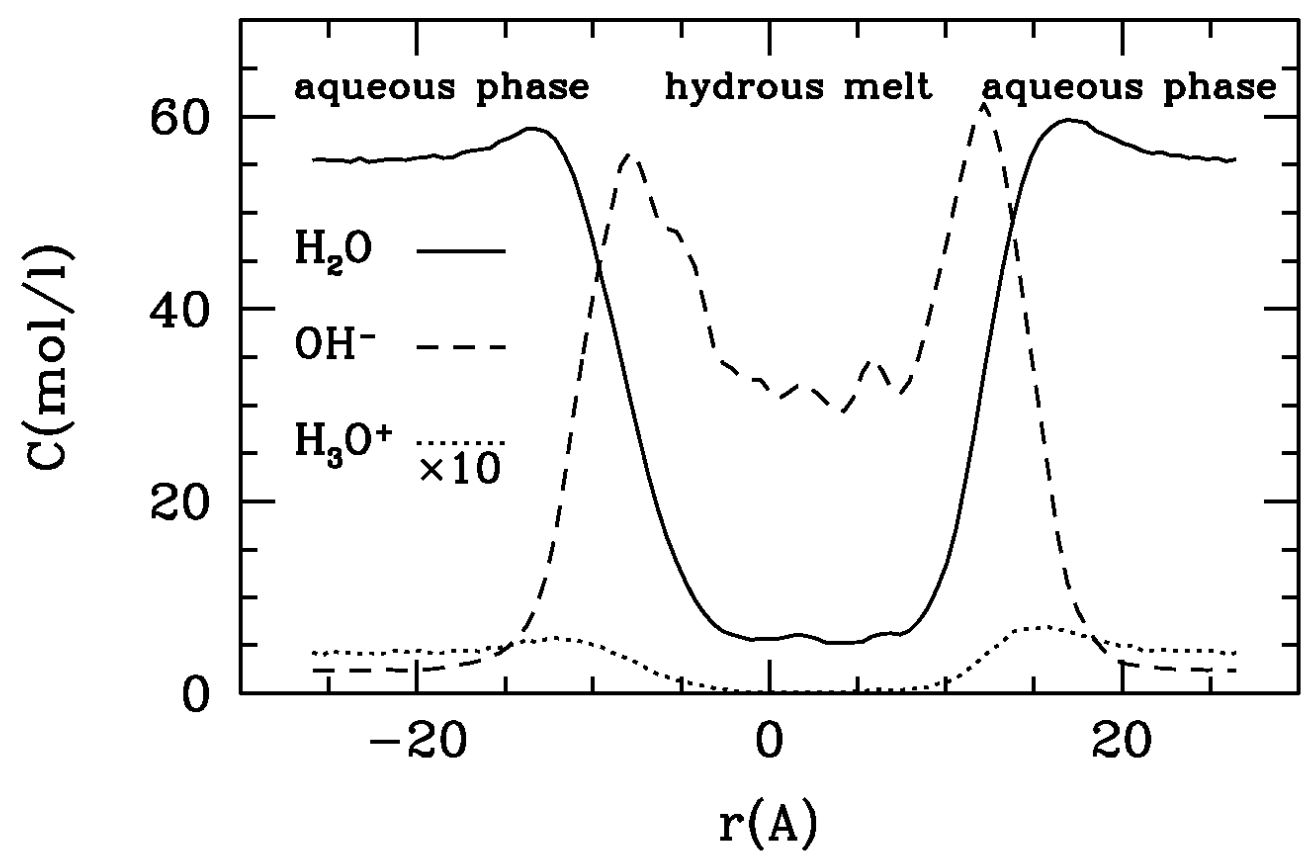

2098

2099

2100

Fig.4

2101

2102

2103

2104

2105

2106

2107 


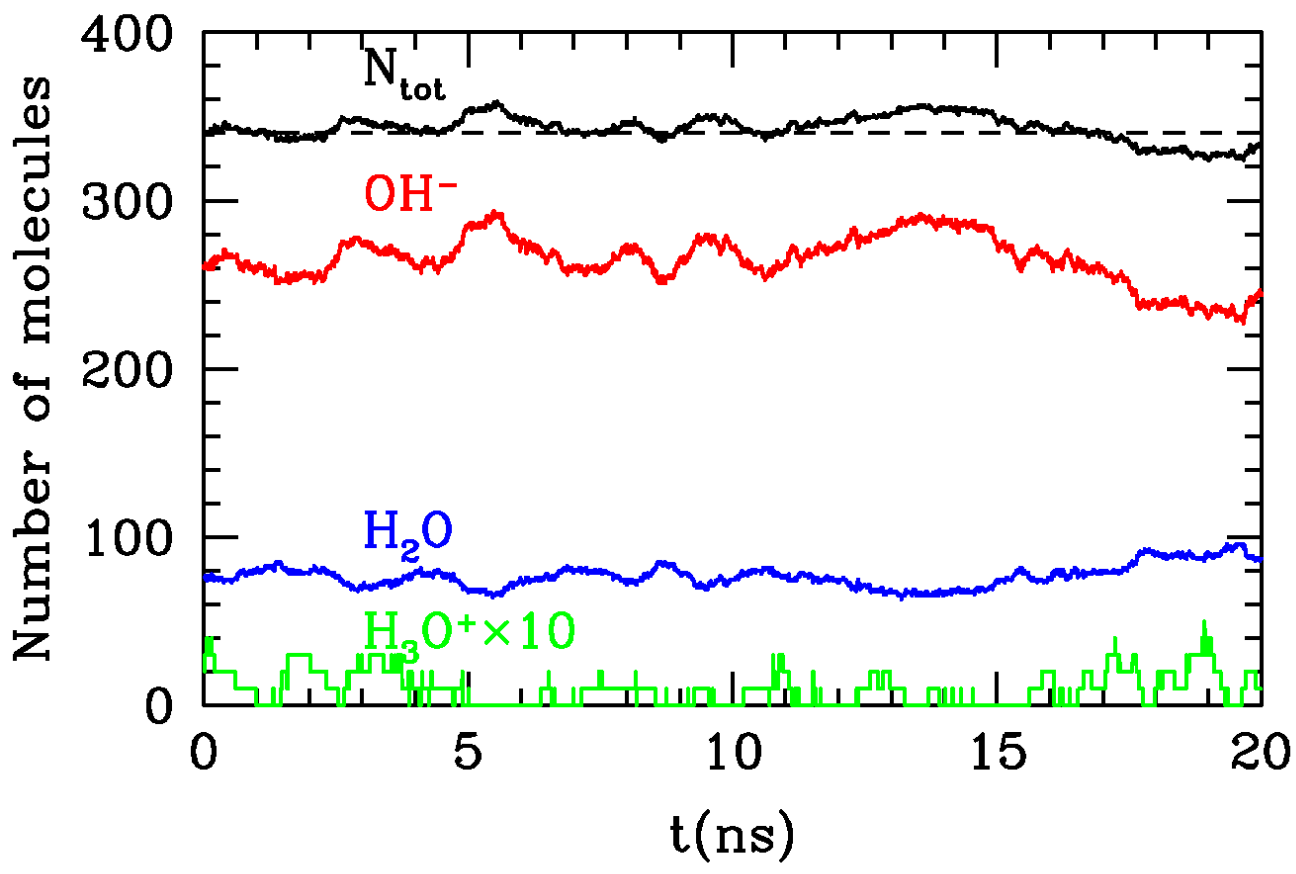

2110

2111

2112

2113

Fig.5

2114

2115

2116

2117

2118

2119

2120 
2121

2122

2123

2124

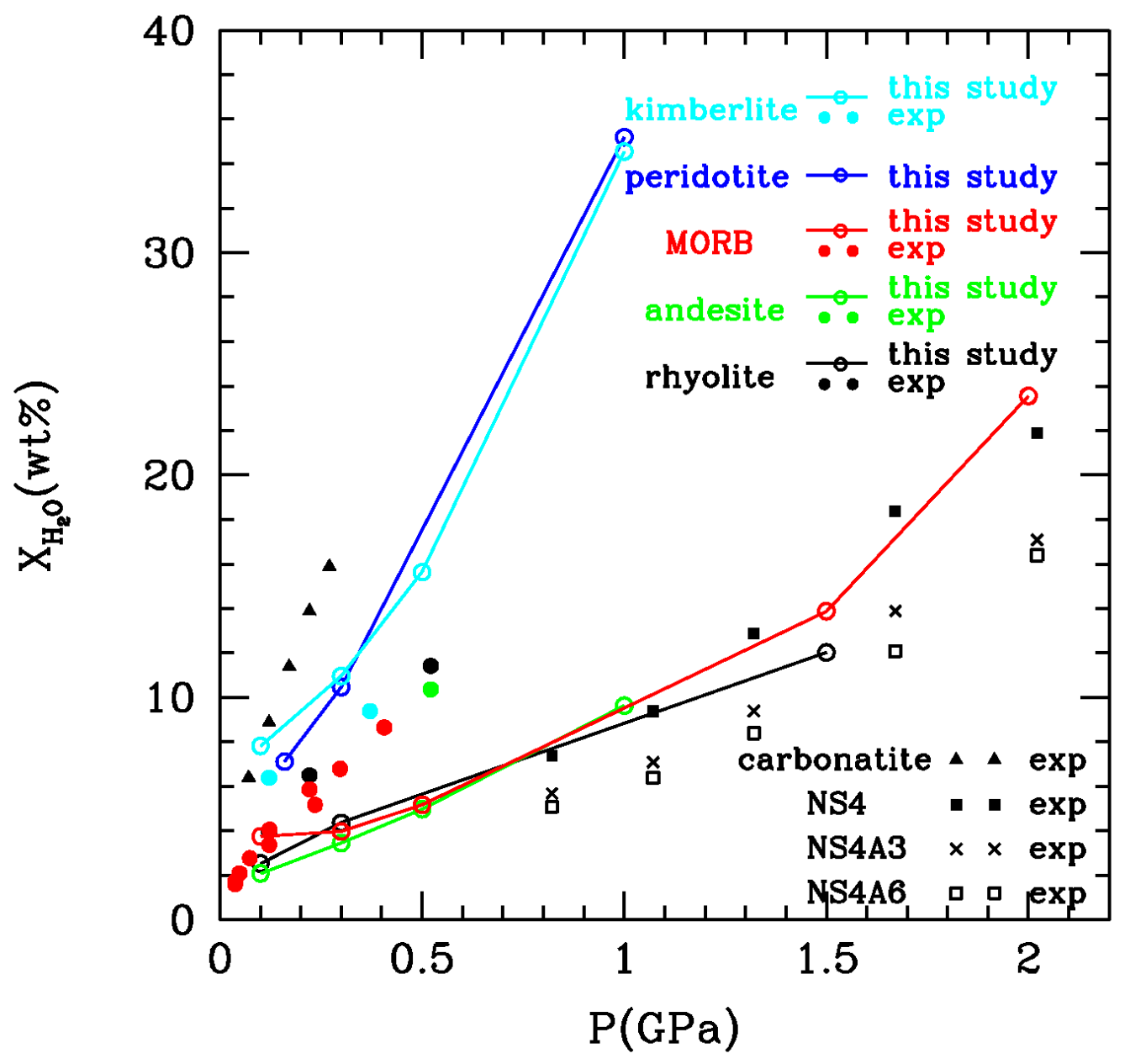

2125

2126

2127

Fig.6

2128

2129

2130

2131

2132

2133 
2134

2135

2136

2137

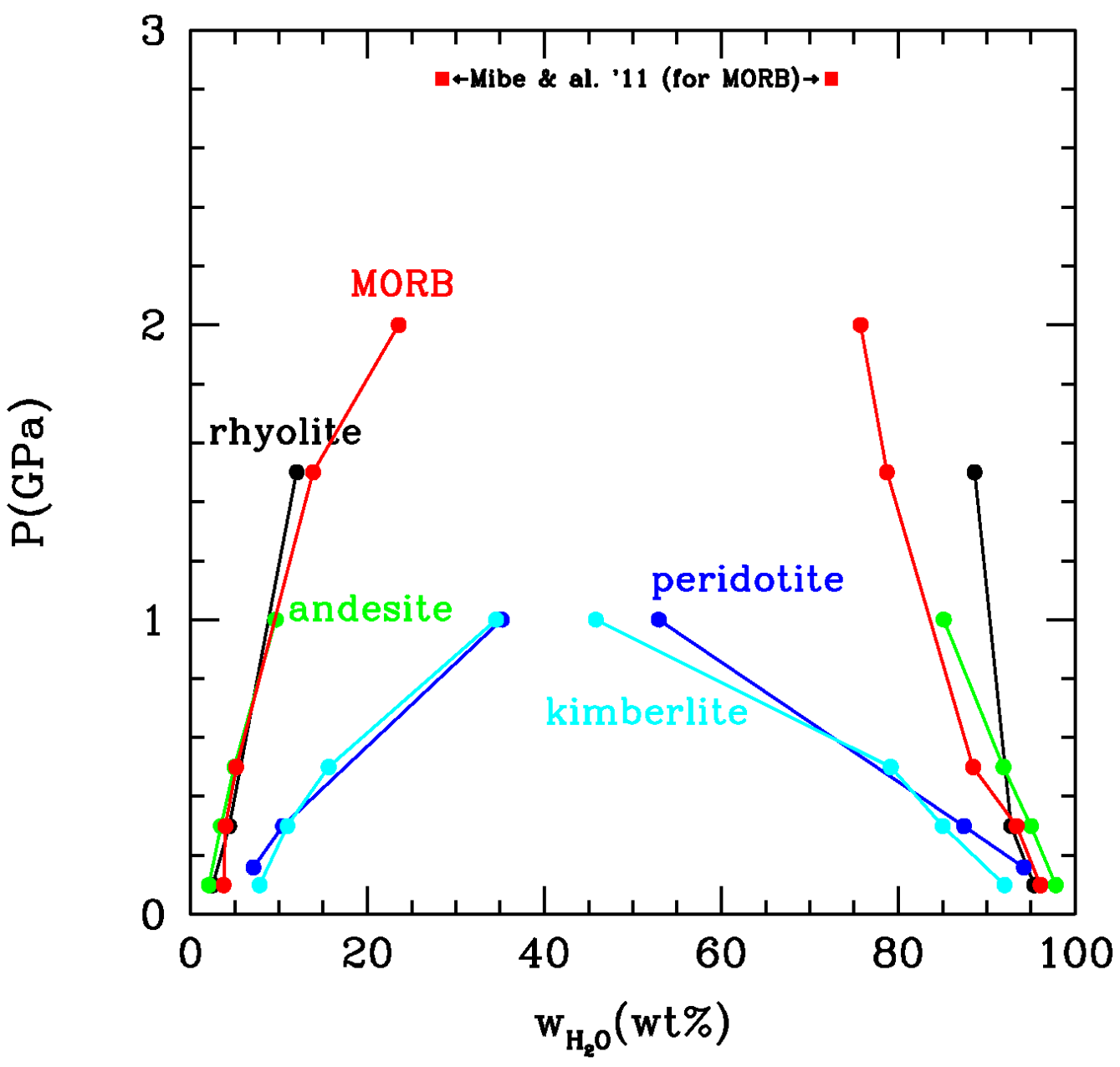

2138

2139

2140

2141

Fig.7

2142

2143

2144

2145

2146 
2147

2148

2149

2150

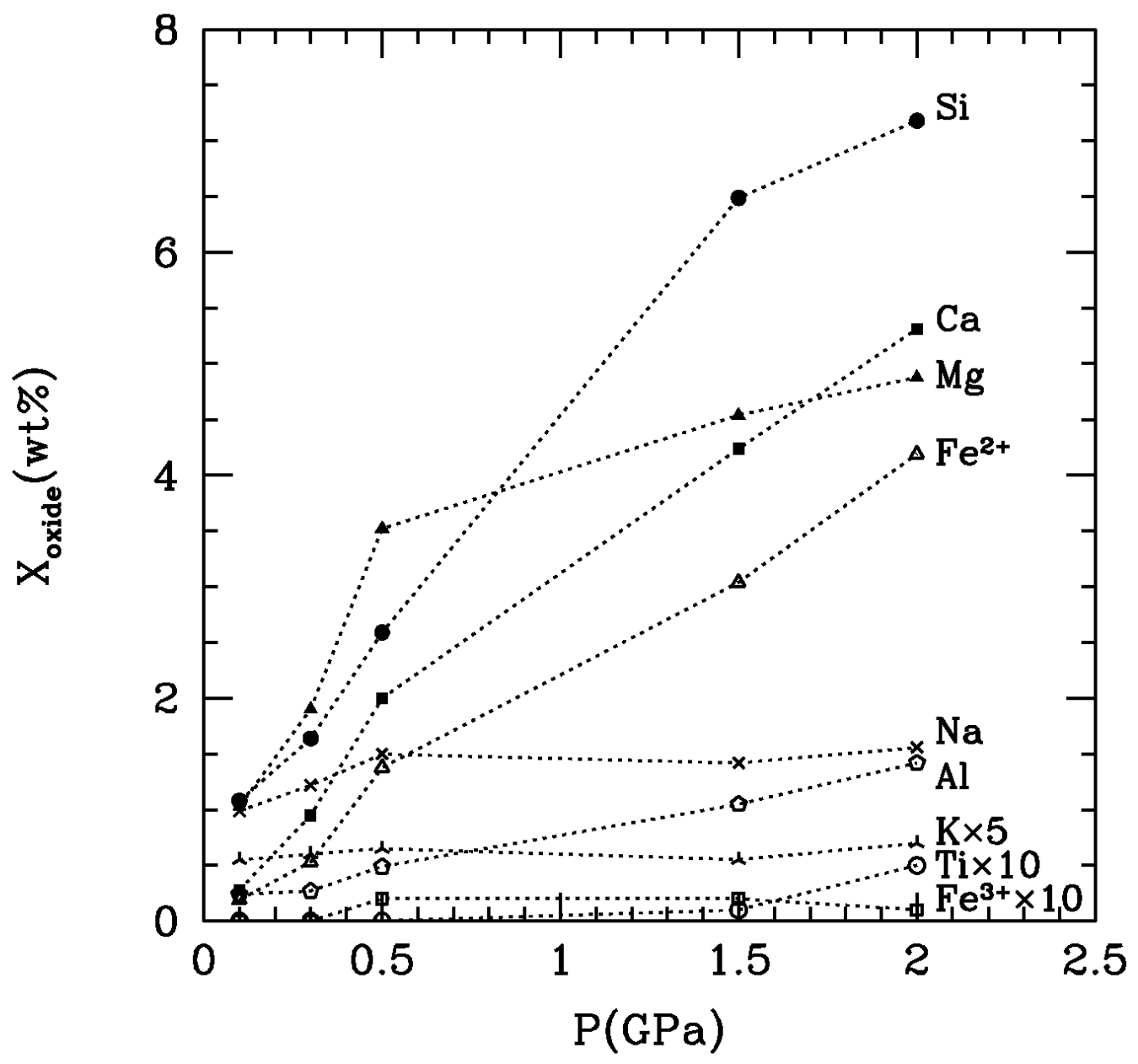

2151

2152

2153

2154

Fig.8

2155

2156

2157

2158

2159 
2160

2161

2162

2163

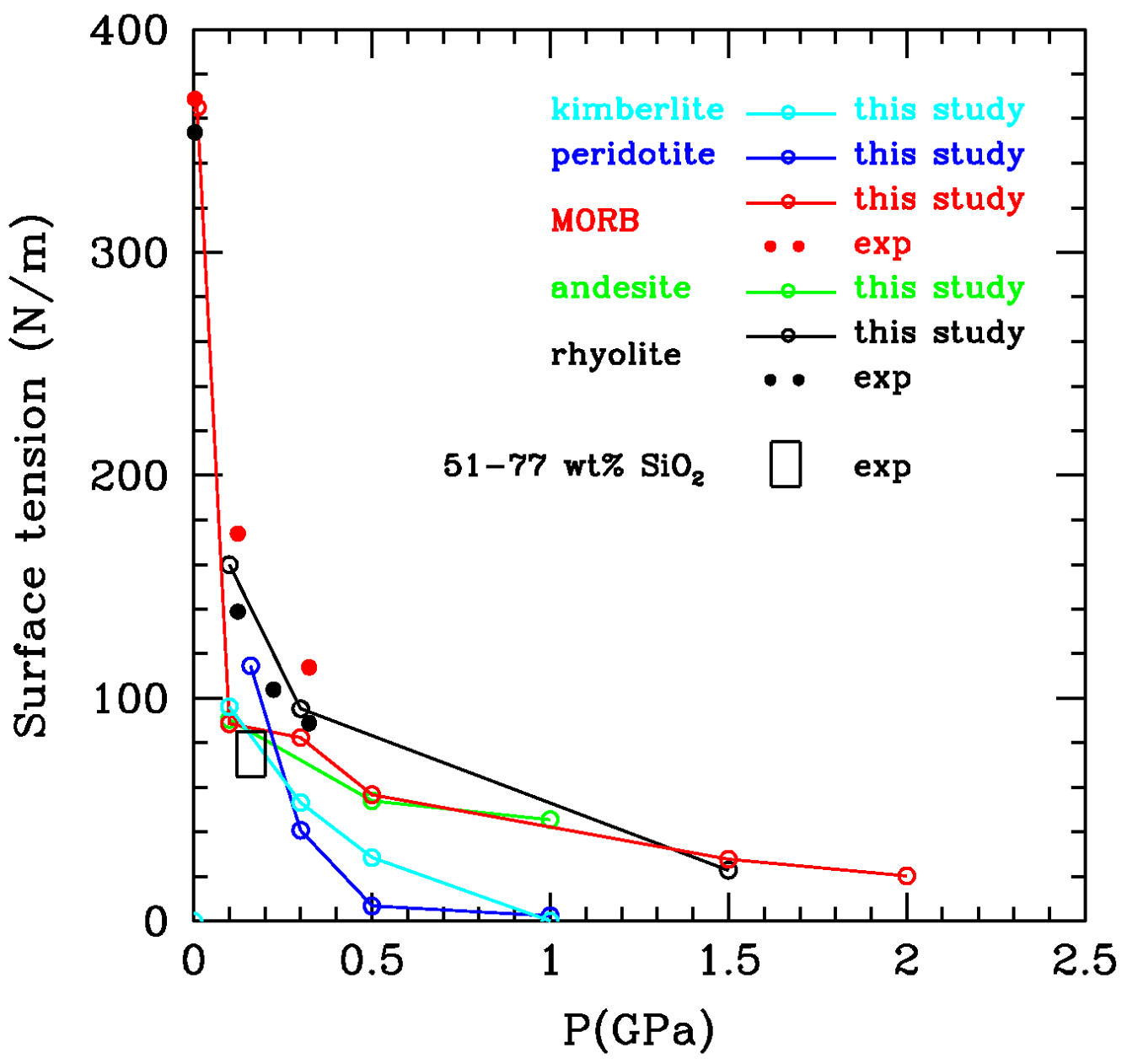

2164

2165

2166

Fig.9

2167

2168

2169

2170

2171

2172 
2173

2174

2175

2176

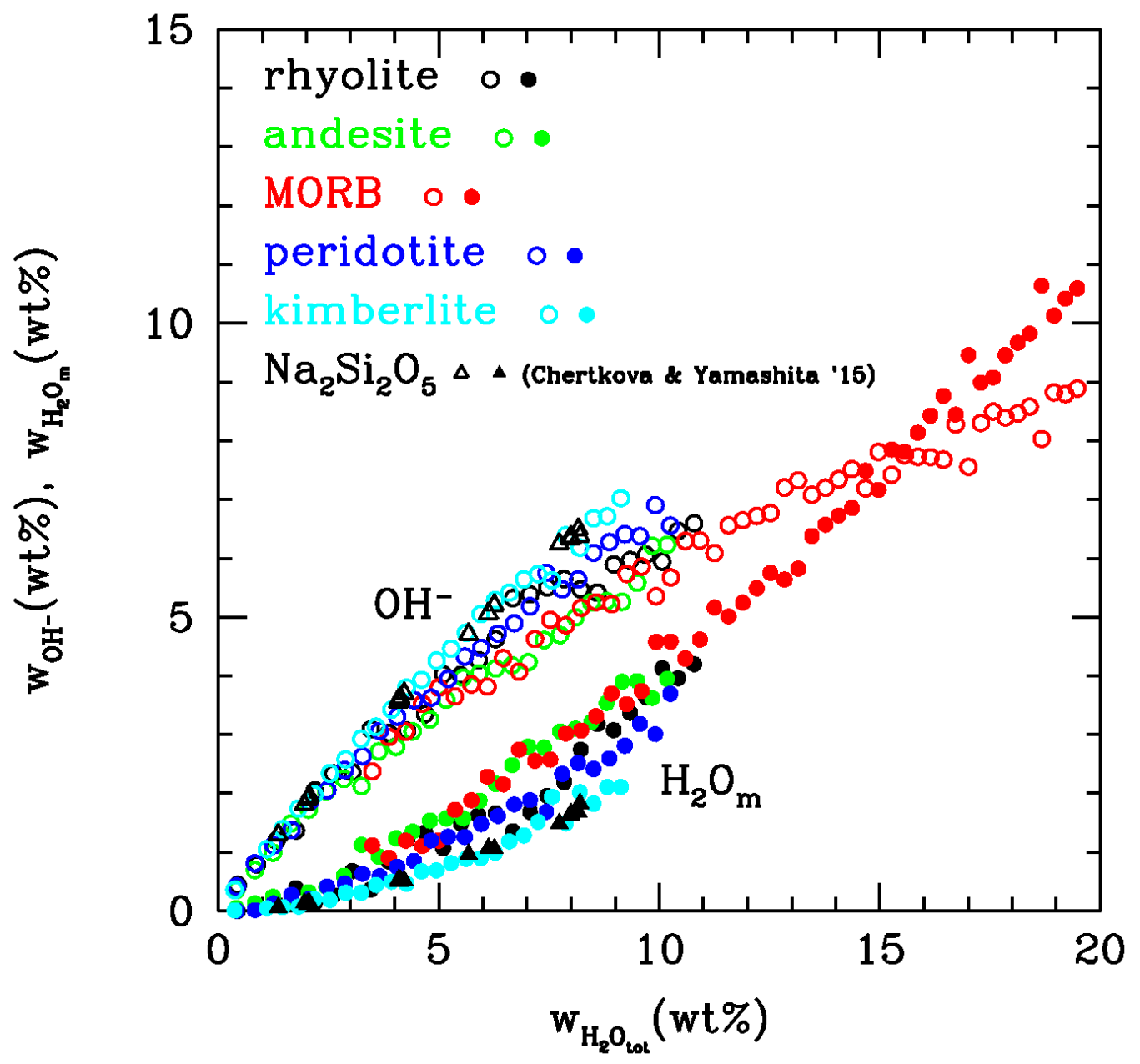

2177

2178

2179 Fig.10

2180

2181

2182

2183

2184

2185 
2186

2187

2188

2189

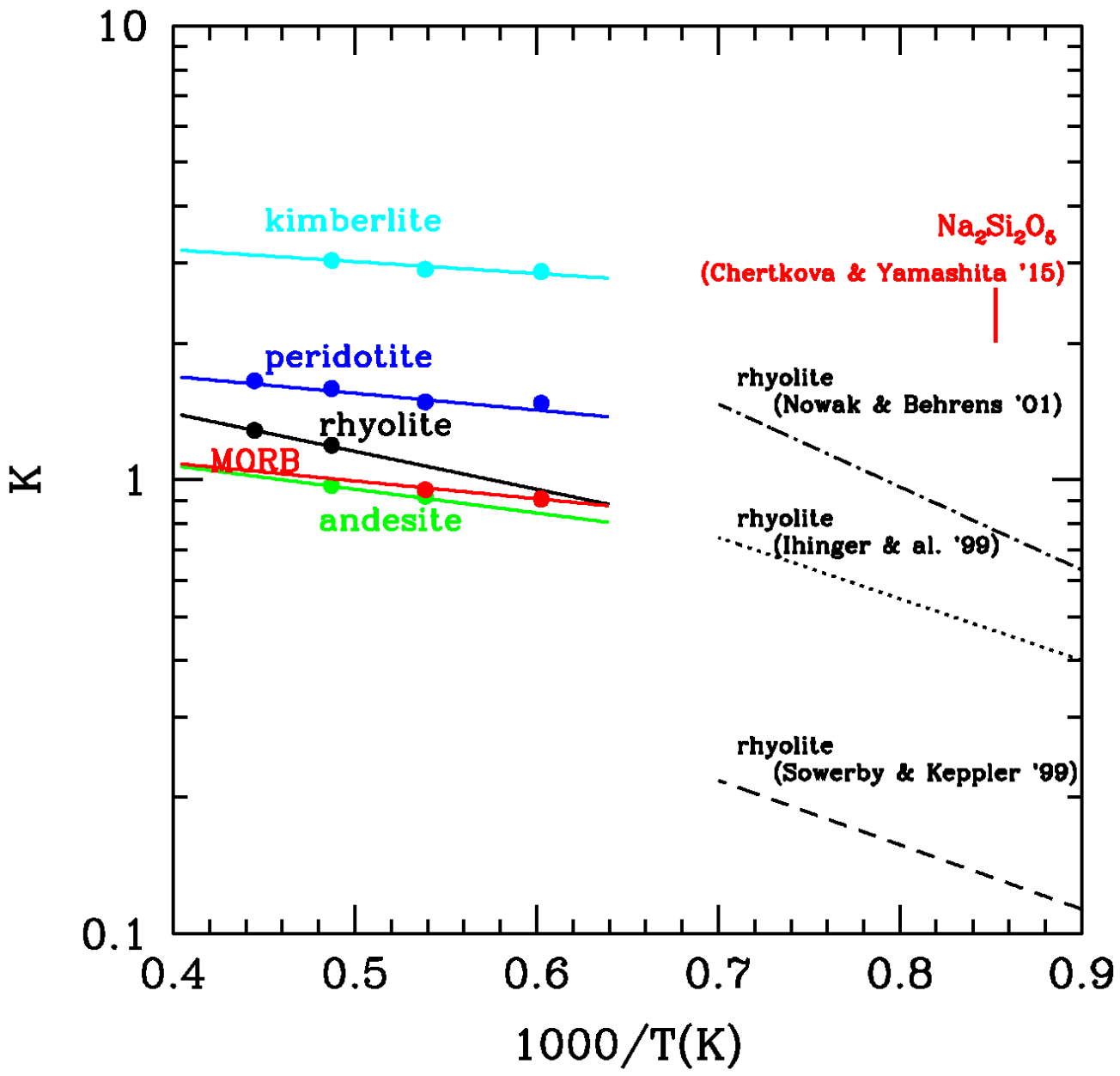

2190

2191

2192

Fig.11

2193

2194

2195

2196

2197

2198 
2199

2200

2201

2202

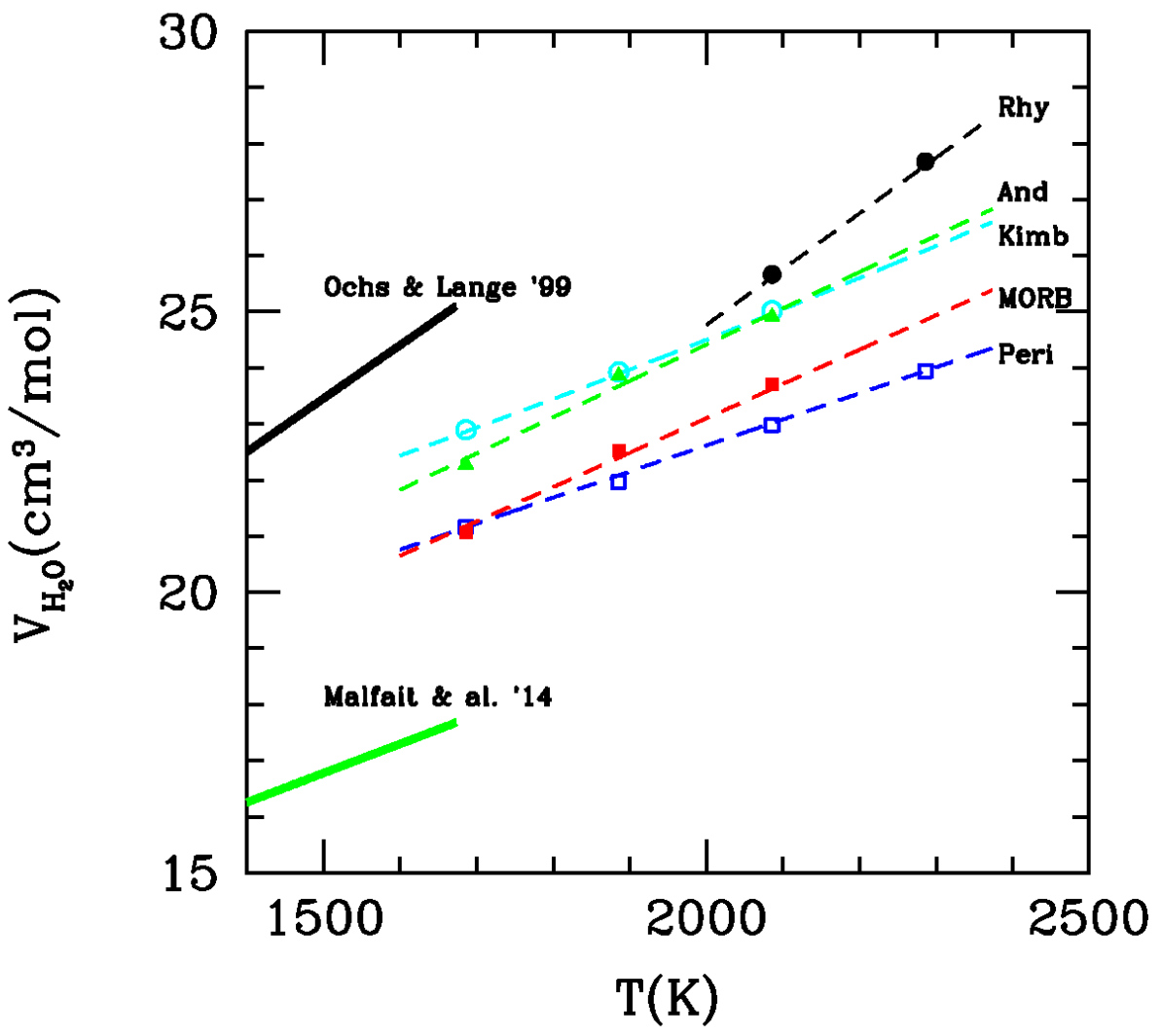


2212

2213

2214

2215

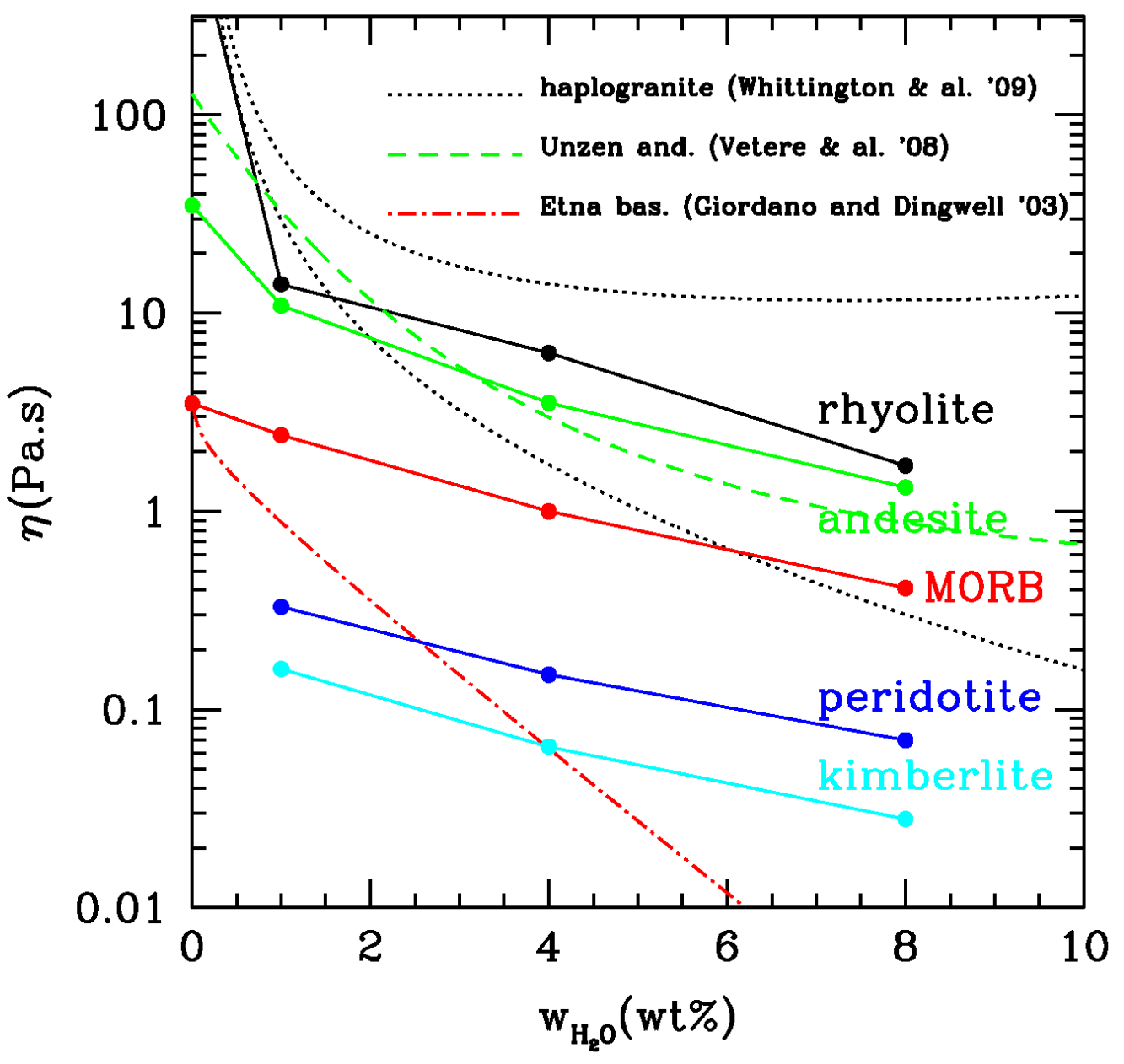

2216

2217

2218

Fig.13

2219

2220

2221

2222

2223

2224 
2225

2226

2227

2228

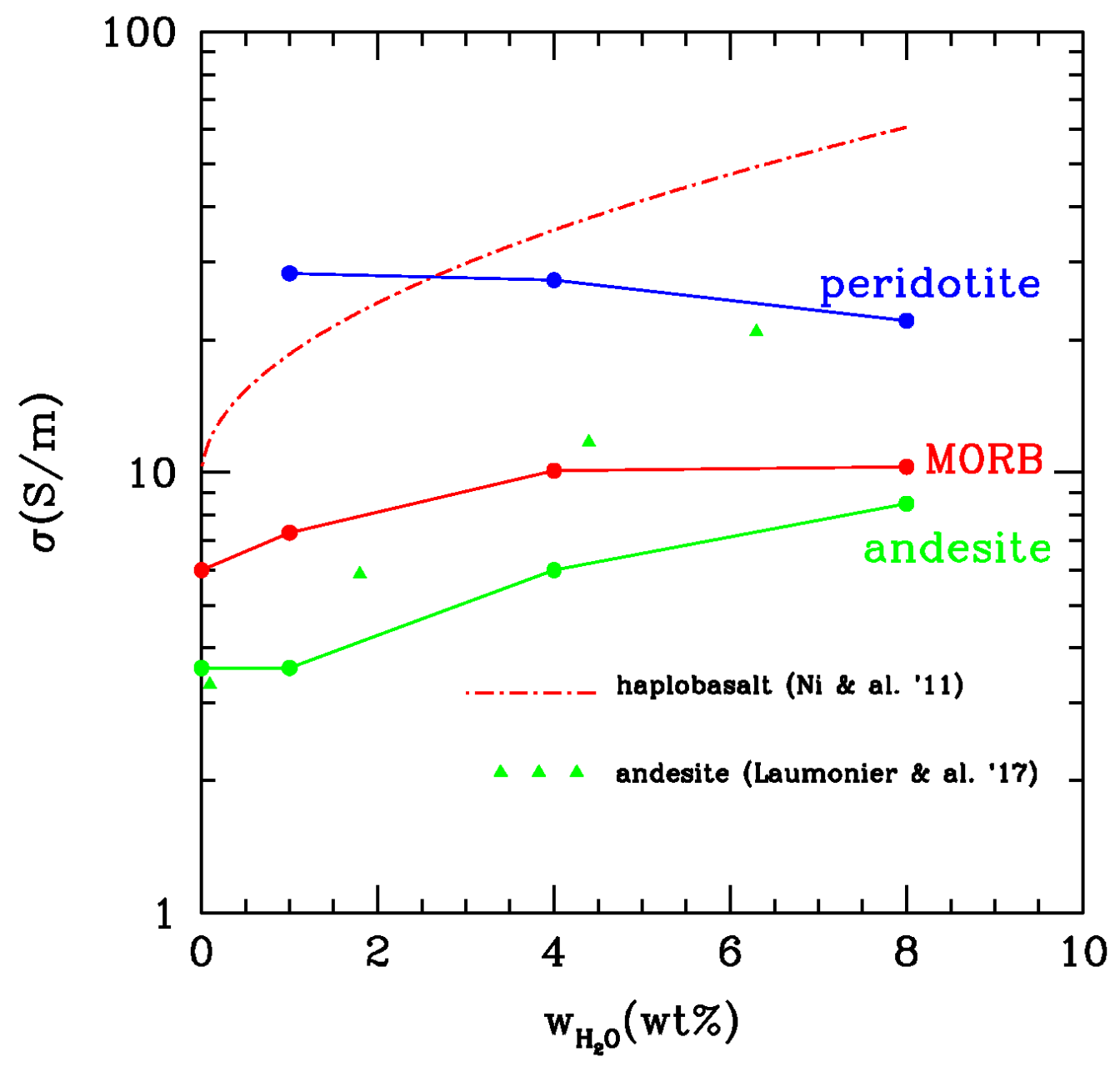

2229

2230

2231

Fig.14

2232

2233

2234

2235

2236

2237 

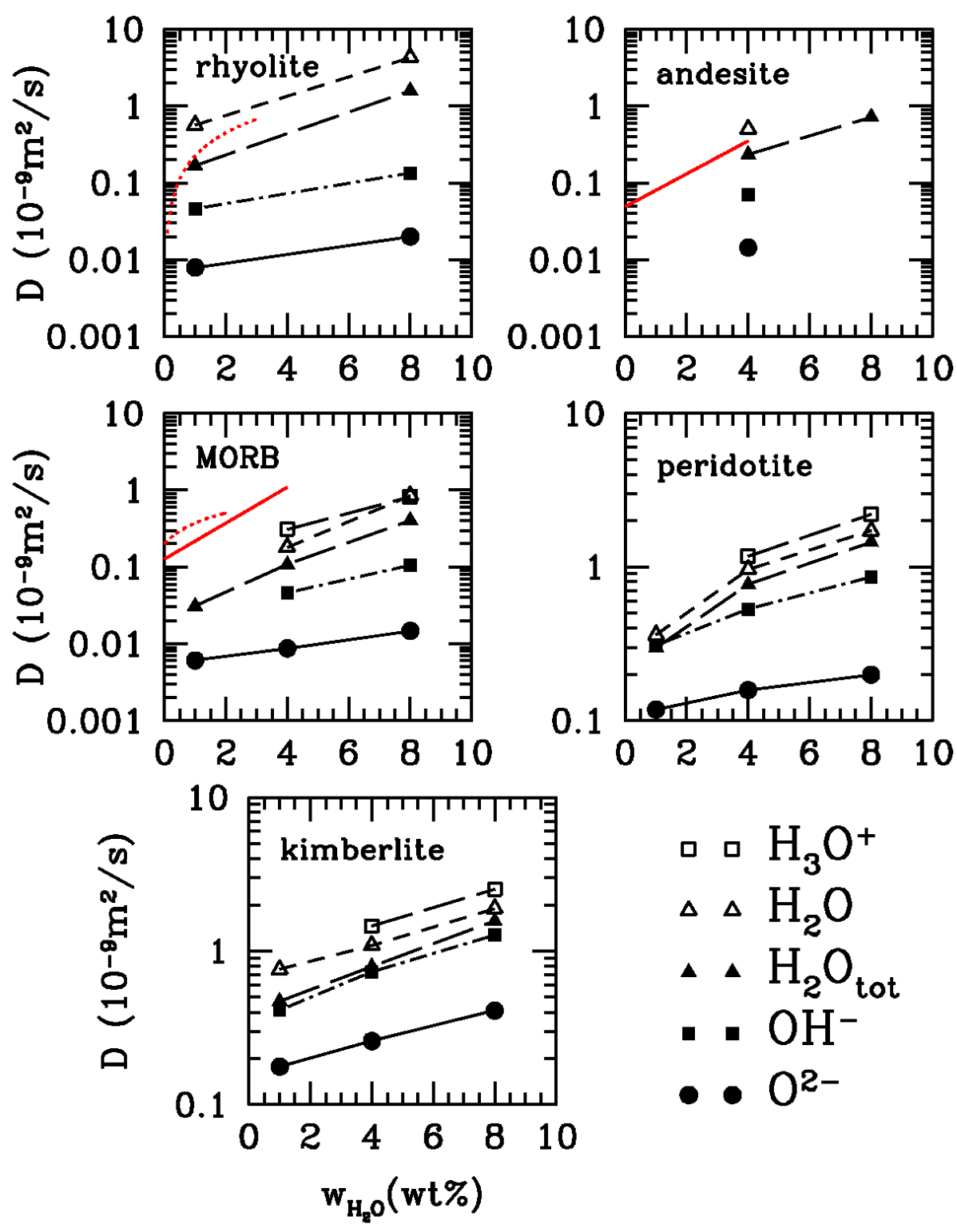

ㅁ $\mathrm{H}_{3} \mathrm{O}^{+}$

$\Delta \Delta \mathrm{H}_{2} \mathrm{O}$

- $\mathrm{H}_{2} \mathrm{O}_{\text {tot }}$

- $\mathrm{OH}^{-}$

- $\mathrm{O}^{2-}$ 

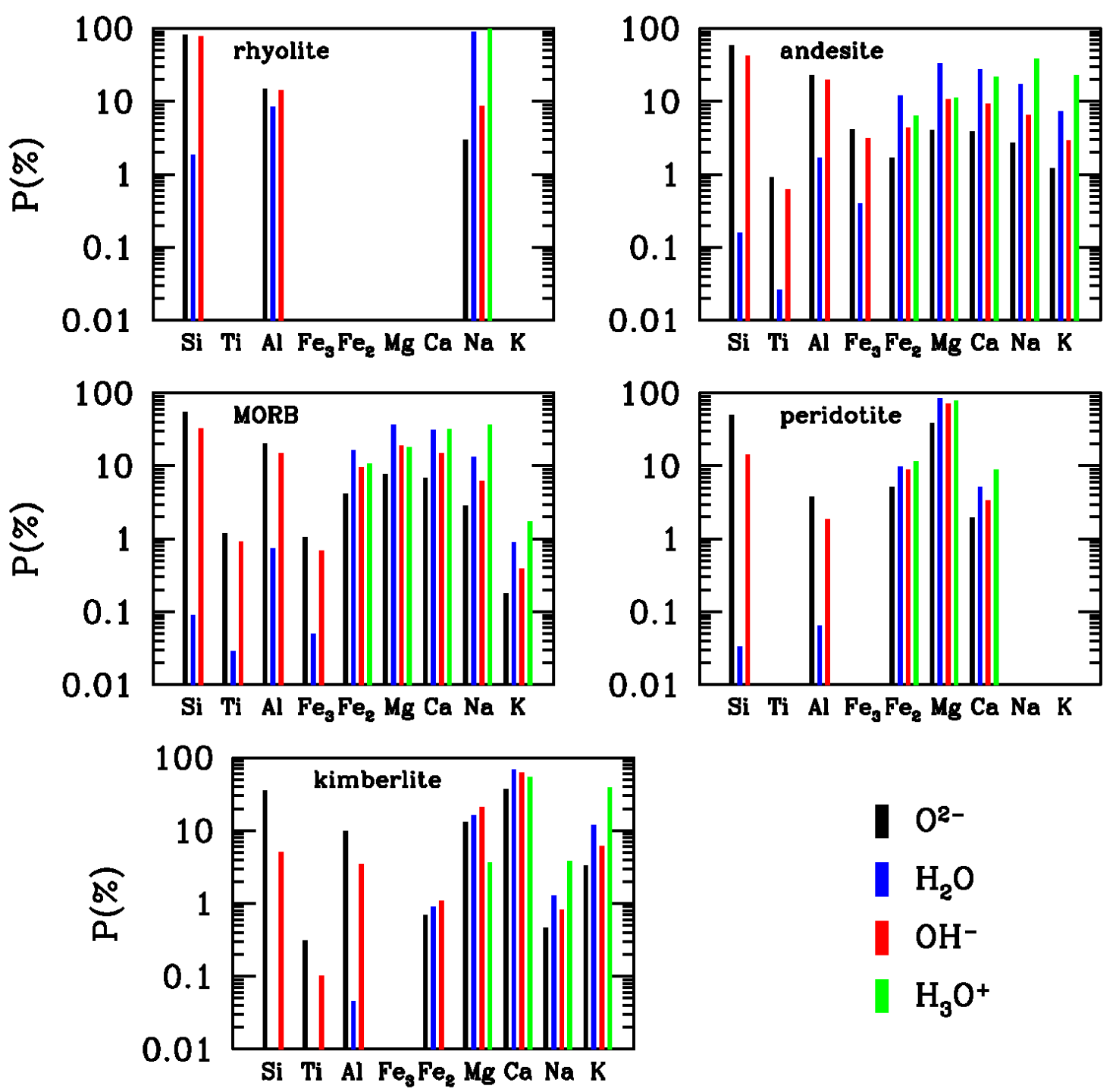
2264

2265

2266

2267
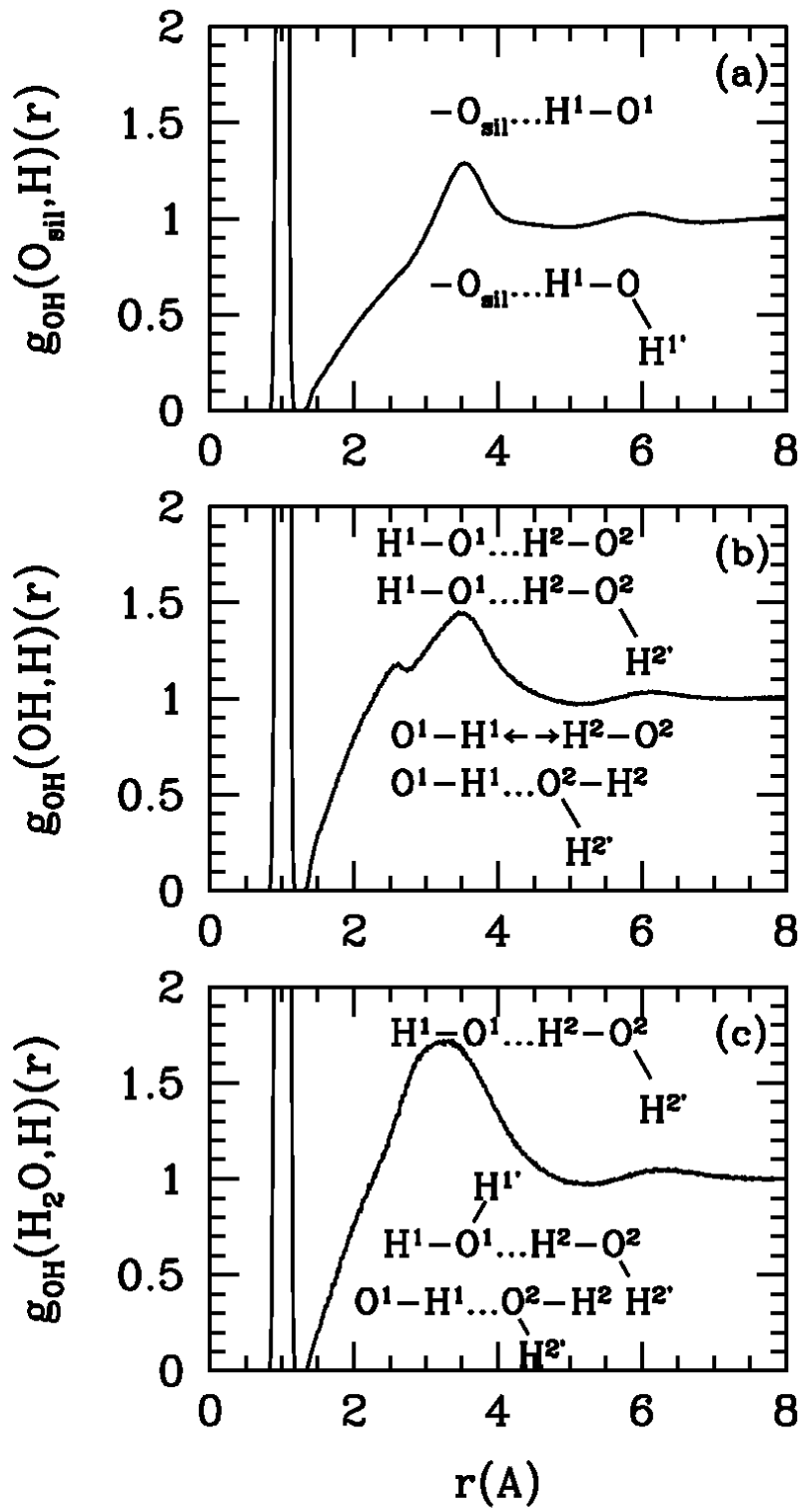